\title{
The biology of uveal melanoma
}

\author{
Adriana Amaro ${ }^{1} \cdot$ Rosaria Gangemi ${ }^{2} \cdot$ Francesca Piaggio $^{1} \cdot$ Giovanna Angelini $^{1}$. \\ Gaia Barisione $^{2} \cdot$ Silvano Ferrini ${ }^{2} \cdot$ Ulrich Pfeffer $^{1}$
}

Published online: 22 February 2017

(C) The Author(s) 2017. This article is published with open access at Springerlink.com

\begin{abstract}
Uveal melanoma (UM), a rare cancer of the eye, is distinct from cutaneous melanoma by its etiology, the mutation frequency and profile, and its clinical behavior including resistance to targeted therapy and immune checkpoint blockers. Primary disease is efficiently controlled by surgery or radiation therapy, but about half of UMs develop distant metastasis mostly to the liver. Survival of patients with metastasis is below 1 year and has not improved in decades. Recent years have brought a deep understanding of UM biology characterized by initiating mutations in the $\mathrm{G}$ proteins GNAQ and GNA11. Cytogenetic alterations, in particular monosomy of chromosome 3 and amplification of the long arm of chromosome 8 , and mutation of the BRCA1-associated protein 1, BAP1, a tumor suppressor gene, or the splicing factor SF3B1 determine UM metastasis. Cytogenetic and molecular profiling allow for a very precise prognostication that is still not matched by efficacious adjuvant therapies. G protein signaling has been shown to activate the YAP/TAZ pathway independent of HIPPO, and conventional signaling via the mitogen-activated kinase pathway probably also contributes to UM development and
\end{abstract}

Adriana Amaro and Rosaria Gangemi equally contributed to the work.

Ulrich Pfeffer

patologia.molecolare.integrata@gmail.com

1 Laboratory of Molecular Pathology, Department of Integrated Oncology Therapies, IRCCS AOU San Martino - IST Istituto Nazionale per la Ricerca sul Cancro, L.go Rosanna Benzi 10, 16132 Genoa, Italy

2 Laboratory of Biotherapies, Department of Integrated Oncology Therapies, IRCCS AOU San Martino - IST Istituto Nazionale per la Ricerca sul Cancro, Genoa, Italy progression. Several lines of evidence indicate that inflammation and macrophages play a pro-tumor role in $\mathrm{UM}$ and in its hepatic metastases. UM cells benefit from the immune privilege in the eye and may adopt several mechanisms involved in this privilege for tumor escape that act even after leaving the niche. Here, we review the current knowledge of the biology of UM and discuss recent approaches to UM treatment.

Keywords G-protein signaling · YAP/TAZ signaling · Immune checkpoint blockers $\cdot$ Targeted therapy $\cdot$ Molecular classification

\section{Introduction}

Uveal melanoma (UM) is a rare disease but the most frequent non-cutaneous melanoma and the most frequent primary cancer of the eye in the adult. In recent years, our understanding of this disease has made a leap forward through the identification of the molecular players likely responsible for tumor initiation and progression. The process of multistep carcinogenesis is now known in considerable detail, perhaps better than for any other neoplasia, and prognosis can be made with utmost precision. This is contrasted by the lack of adjuvant therapy and low efficacy of therapy for metastatic UM, leading to survival rates that have not significantly changed over decades.

This review gives a general overview of the current knowledge in the field of UM, incorporating the most relevant findings on the biology of this disease and their implications in clinical management. Reference to recent reviews that give more detailed descriptions is given wherever possible. 


\section{Clinical features of uveal melanoma}

\subsection{Epidemiology}

Approximately 5\% of all melanomas affect the eye, making it the most common site for melanoma development after the skin [1]. The vast majority (85\%) of ocular melanomas occur in the uveal tract, which is the vascular layer of the eye (comprising the choroid, the ciliary body, and the iris), and hence are known as UM. Conjunctival melanoma is a rare tumor that develops in the mucous membrane lining the inner surface of the eyelids and the forepart of the eyeball. The clinical and histopathological features of conjunctival and uveal melanomas are clearly different; hence, the two entities should not be confused. Uveal melanoma has molecular affinities with melanocytic tumors of the central nervous system [2] whereas conjunctival melanomas show mutation patterns similar to cutaneous melanoma $(\mathrm{CM})[3,4]$.

The incidence of UM in the USA is 4.3 per million (4.1$4.5 ; 95 \%$ confidence interval $[\mathrm{CI}])$ with a prevalence in males (males, 4.9 [4.6-5.2], 95\% CI; females, 3.7 [3.5-3.9], 95\% $\mathrm{CI})$. Of the cases registered, $97.8 \%$ occurred in the white population [5]. There is a strong difference in the incidence for different ethnic groups: the annual age-adjusted incidence is 0.31 for Afro-Americans, 0.38 for Asians, 1.67 for Hispanics, and 6.02 for non-Hispanic whites [6], yet prognosis does not differ for ethnic groups [7]. The European Cancer Registrybased study on survival and care of cancer patients (EUROCARE) for the years 1983-1994 reported similar incidence rates with a characteristic increase from south to north, from $<2$ per million in Spain and Southern Italy to $>8$ per million in Norway and Denmark [8]. This is consistent with increasing incidence observed with increasing latitude in the USA (4.91-fold from $20-22^{\circ}$ to $47-48^{\circ}$ ) [9].

UM has been reported in patients of all ages, but only $1 \%$ of cases occur in younger patients under the age of 18 . The incidence increases with age, peaking at the age of 70 . The ageadjusted incidence rate was stable between 1973 and 1997 in the USA [5]. More recently, an increase in the mean age at diagnosis for the interval between 1973 and 2009 was described based on the analysis of 7043 UM patients from the Surveillance, Epidemiology, and End Results Program (SEER) database [10]. This increase is most likely attributable to the growing life-span and more thorough screening for eye diseases.

Five-year relative survival of UM patients was $68.9 \%$ [11], $81.6 \%$ [12], and $81.4 \%$ [13] for cases diagnosed in Europe (1983-1994), the USA (1973-2008), and Western Australia (1981-2005), respectively. Death rates were slightly elevated in older patients and in males. The general trend in prolonged survival after cancer diagnosis $[14,15]$ does not apply to UM: no significant differences in overall survival or disease-specific survival were observed between 1973 and 2009 when the data were stratified by year of diagnosis [10-12]. UM thus belongs to the few cancers with stable or increasing death rates.

\subsection{Etiology}

The etiology of UM is still unclear. UV radiation has clearly been identified as the major risk factor for CM [16], but the role of UV radiation in the development of UM is still under debate [17]. Cornea, lens, and vitreous body absorb almost all wavelengths below $300 \mathrm{~nm}$ and much of the spectrum between 300 and $400 \mathrm{~nm}$ [18]. However, age-dependent alterations of the vitreous body [19] might alter the absorptive capacity of the latter. The associations between UM risk and blue iris or a generally weakly pigmented phenotype $[20,21]$ and sun exposure [22] suggest a role for UV radiation in the etiology of UM. A meta-analysis of 133 reports on UVassociated risk factors for UM showed a significant correlation for welding $(\mathrm{OR}=2.05$; CI 1.20-3.51) but not for outdoor leisure activities $(\mathrm{OR}=0.86$; CI $0.71-1.04)$, occupational sunlight exposure $(\mathrm{OR}=1.37$; CI $0.96-1.96)$, and latitude of birth $(\mathrm{OR}=1.08$, CI 0.67-1.74) [23]. If there is a role for UV light in UM etiology, it is certainly by far weaker than that for $\mathrm{CM}$. The etiologic effect of UV radiation for UM is likely too weak to overcome confounding factors such as co-distribution of weakly pigmented skin and iris and latitude, co-occurrence of UV radiation with light of longer wavelengths, and protective, vitamin D-mediated effects of sun exposure [24]. Violet/ blue light, the most energetic form next to UV light, has also been cited as a potential risk factor for UM [25]. Genetic variants on chromosome $15 \mathrm{q} 13.1$, close to the genes HERC2 and OCA2 on $15 \mathrm{q} 12$ that are involved in the determination of eye color, have been found associated with UM risk [26], and the G proteins GNAQ and GNA11 that are frequently mutated in UM $[27,28]$ are involved in the determination of skin color in mice [29].

In contrast to inconclusive epidemiological data, molecular data can clearly exclude a typical UV-associated mutational spectrum for UM; in fact, it shows a relatively low mutational load when analyzed by whole exome sequencing and no enrichment for UV-typical $\mathrm{C}>\mathrm{T}$ transitions at dipyrimidine sites [27, 28, 30-32]. UV-induced mutations in the promoter of the human Telomerase Reverse Transcriptase (TERT) gene occur in approximately $70 \%$ of CMs [33, 34] but are rare in UMs [35-37]. Hence, if light has a role in UM carcinogenesis, it certainly acts in a different manner than in CM.

\subsection{Diagnosis and treatment}

UM can develop without any symptom and is diagnosed by routine ophthalmic examination [38]. It often causes painless distortion of vision and other non-specific visual symptoms [39]. Diagnosis of UM relies primarily on clinical examination and ocular ultrasonography [40]. On the hand of an experienced ocular oncologist, elevated levels of accuracy [41] and first visit detection rates $[38,39]$ have been documented, minimizing the 
need for invasive diagnostic biopsy [42]. There might be an effect of the time of intervention especially for smaller tumors, and diagnostic delay in older patients might affect prognosis [43]. Treatment options include local radiotherapy $\left({ }^{106}\right.$ ruthenium or ${ }^{125}$ iodine brachytherapy, proton beam therapy, or stereotactic radiosurgery) or surgery (local resection, endoresection, or enucleation) [42]. Neoadjuvant phototherapy has been proposed with the scope of reducing side effects of brachytherapy [44].

Local control of disease reaches $96.4 \%$ after proton beam therapy $[45,46]$, but local recurrence can arise up to almost 10 years after primary therapy and determines an increased metastatic risk $[47,48]$.

\subsection{Metastatic disease}

Despite successful local treatment, 25 and $34 \%$ of UM patients develop metastases within 5 and 10 years, respectively [49]. The long-term cumulative melanoma-related mortality rate 25 years after primary treatment is over $50 \%$ for medium and large tumors [50]. High-risk cases (see below) should be integrated in a lifelong surveillance program including liver imaging for early detection of metastases [42] since it is the first site of metastasis of $\mathrm{UM}$ in most cases $[49,51,52]$. Based on self-reported outcome measures, quality of life reaches levels of the healthy population 6 months after treatment with some stress for younger and female patients and depression in patients with bad prognosis [53].

At present, there is no approved adjuvant therapy for UM, a fact that is in striking contrast with the elevated precision in prognostication (see below). Interferon- $\alpha 2 \mathrm{a}$ (IFN- $\alpha 2 \mathrm{a}$ [45] and methanol-extracted residue of Bacillus Calmette-Guerin [46] have been tested as an adjuvant therapy but did not affect survival. A trial with 22 patients to test adjuvant intra-arterial hepatic Fotemustine showed effects on survival together with considerable toxicity but did not reach statistical significance [47]. Several adjuvant trials are registered at the clinical trials service of the National Institute of Health (clinicaltrials.gov). The antivascular endothelial growth factor (VEGF) drug Avastin is being tested in a neoadjuvant setting for its capacity to reduce larger UM prior to therapy (NCT00596362 ${ }^{1}$ ). Dendritic cells and vaccine therapies are being tested (NCT00929019, NCT01983748, NCT00020475) as well as the anti-receptor tyrosine kinase drugs crizotinib (NCT02223819) and sunitinib alone (NCT02068586) or in combination with tamoxifen and cisplatin (NCT00489944), and the histone deacetylase inhibitor valproic acid (NCT02068586). Adjuvant chemotherapy is presently investigated in two trials (dacarbazine in combination with recombinant IFN- $\alpha 2 b$ [NCT01100528] and fotemustine [NCT02843386]) as well as prophylactic hepatic irradiation (NCT02336763). All

\footnotetext{
${ }^{1}$ ClinicalTrials.gov identifiers are indicated in parentheses for clinical trials throughout the text.
}

these trials rely on advanced prognostic testing (see below). $\mathrm{UM}$ is also contemplated in several trials for CM.

The mean survival after diagnosis of metastatic UM is approximately 1 year $[54,55]$, but a considerable proportion of patients survive more than 4 years [51]. Resection of liver metastases can be performed in relatively few patients where it shows some advantage in survival [56-59] and appears to work better for UM than for CM [60]. Hepatic intra-arterial chemotherapy improves progression-free survival but not overall survival [61]. A phase II trial reveals a 14-month gain in survival [62], indicating that isolated hepatic perfusion is active on established liver metastases [63, 64]. A phase III trial is presently recruiting [62].

At present, ClinicalTrials.gov lists 69 trials for metastatic UM (for recent reviews, see $[65,66]$ ). Targeted therapies based on the activation of the mitogen-activated protein (MAP) kinase pathway by mutated G protein GNAQ or GNA11 have been tested in several clinical trials. Selumetinib that inhibits the MAP kinase kinase enzymes MEK1 and MEK2 showed a slight improvement in progression-free survival [67] that, according to a preliminary report, was not confirmed in a phase III trial $[68,69]$. Selumetinib is also being tested in combination with temozolomide (NCT01143402), and the maximum tolerated dose of intermittent selumetinib is being investigated (NCT02768766) [69]. Bevacizumab was tested in combination with dacarbazine showing modest activity [70]. A pilot study with the kinase inhibitor sunitinib showed a potential clinical benefit that was independent of the expression level of the target kinase, c-Kit [71]. An institutional review from Mayo Clinic showed that local therapies were superior to kinase inhibitors [72].

For now, MAP kinase-targeted therapies for UM cannot equal the successes obtained for CM. Similarly, immune checkpoint blockade therapy using antibodies directed against immunomodulatory receptors and ligands induces long-term survival in a considerable portion of CM patients [73] but shows only limited activity in metastatic UM patients with extended responses in some patients [74-83]. A recent phase I trial with AM0010, a pegylated recombinant IL-10, showed responses of solid tumors with BRCA1-associated protein 1 (BAP1) mutations, among which is a UM [84].

Many preclinical studies have addressed UM therapy by analyzing the expression and function of pathways that are target for existing drugs [85-118]. These studies have not led to clinical trials, or the trials did not confirm the activity of the drug in UM patients, as for example for c-Kit-targeted treatment with Gleevec [87].

Table 1 summarizes these efforts.

The ADP ribosylation factor 6 (ARF6), not to be mistaken for the tumor suppressor gene (TSG) p16/INK4a-ARF, has recently been identified as a major hub for oncogenic signaling in UM [91]. ARF6 responds to the activation of several pathways that have been targeted in preclinical studies, among 


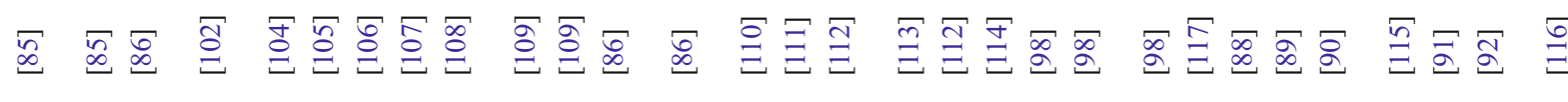

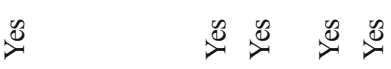

$\mathscr{8}$

$$
\frac{4}{8}
$$

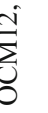

$\sum_{0}^{n} \sum^{n}$

हो

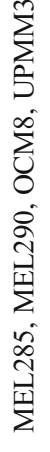

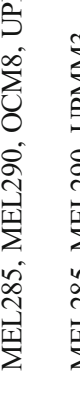

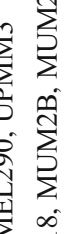

(

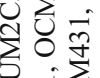

क्षे

तुํำ

$\Rightarrow 0$

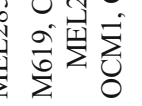

8 ठ

.

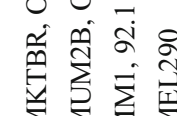

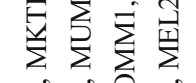

वैî̀

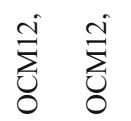

$\sum^{n} m \sum^{n} t-$

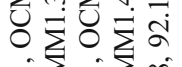

冓 $\sum^{-} \sum^{\infty}$

$0,0<04$

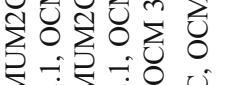

$\begin{array}{ll} & \\ 2 & \end{array}$

$\sum_{0}^{n} \sum_{0}^{n} \sum_{0}^{n} \sum_{0}^{n}$

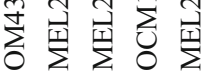

इ

on 0

के के $\sum_{0} \sum_{0} \sum_{0}$ के को

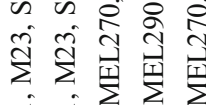

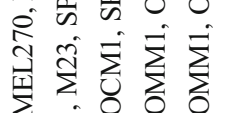

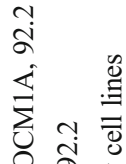

o.

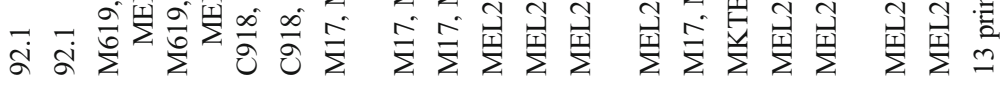
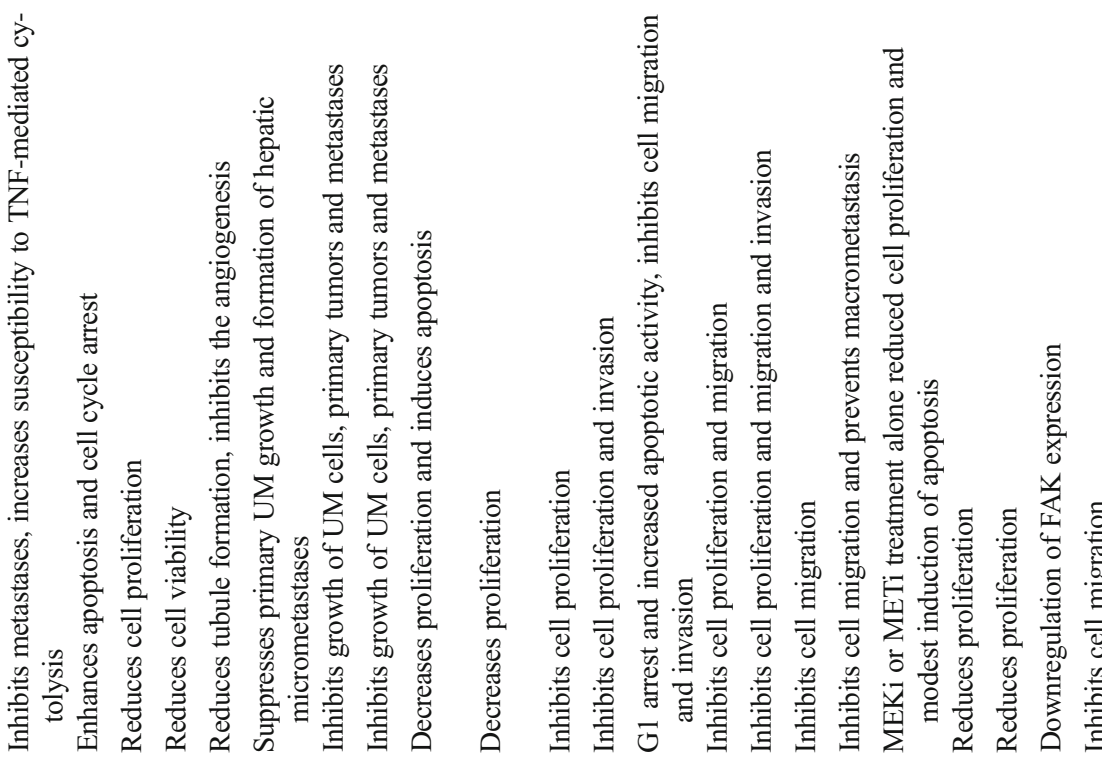

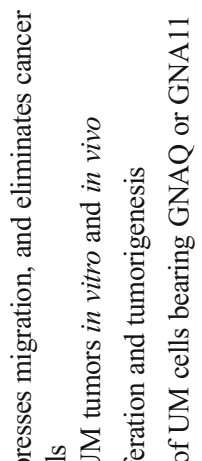

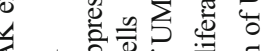
苛出

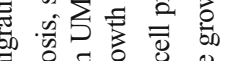

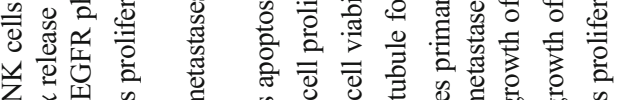

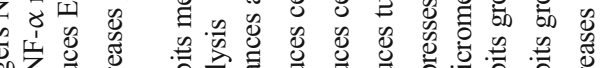

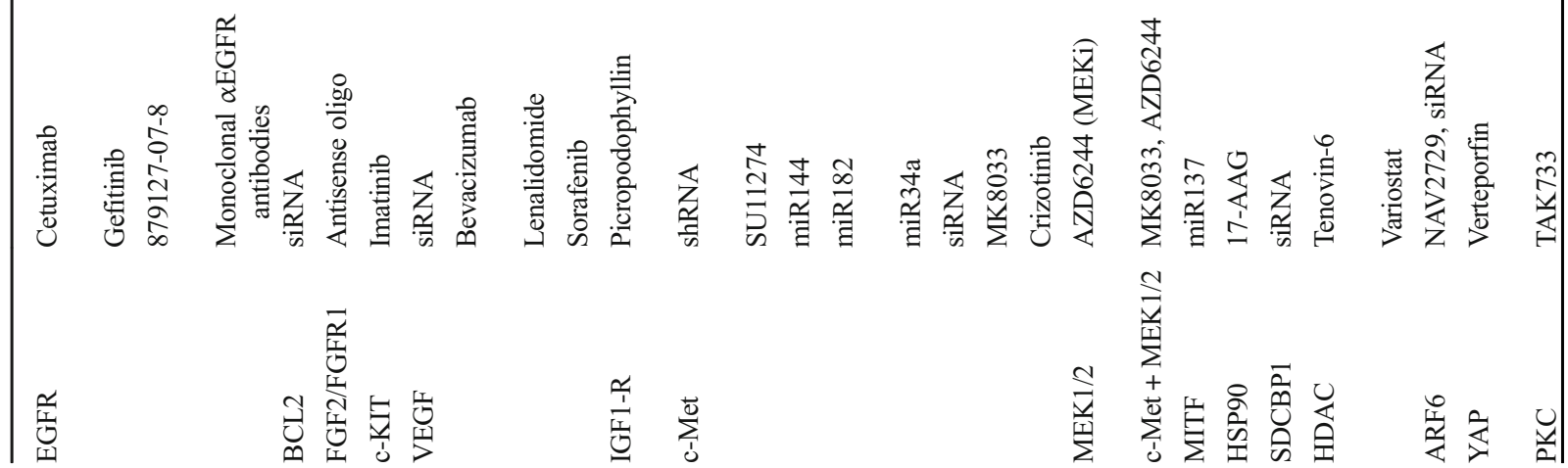

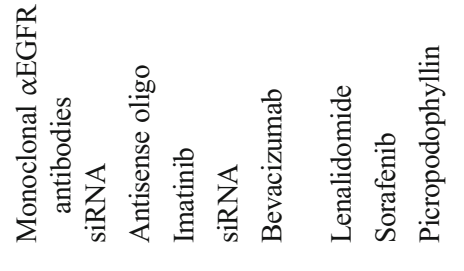

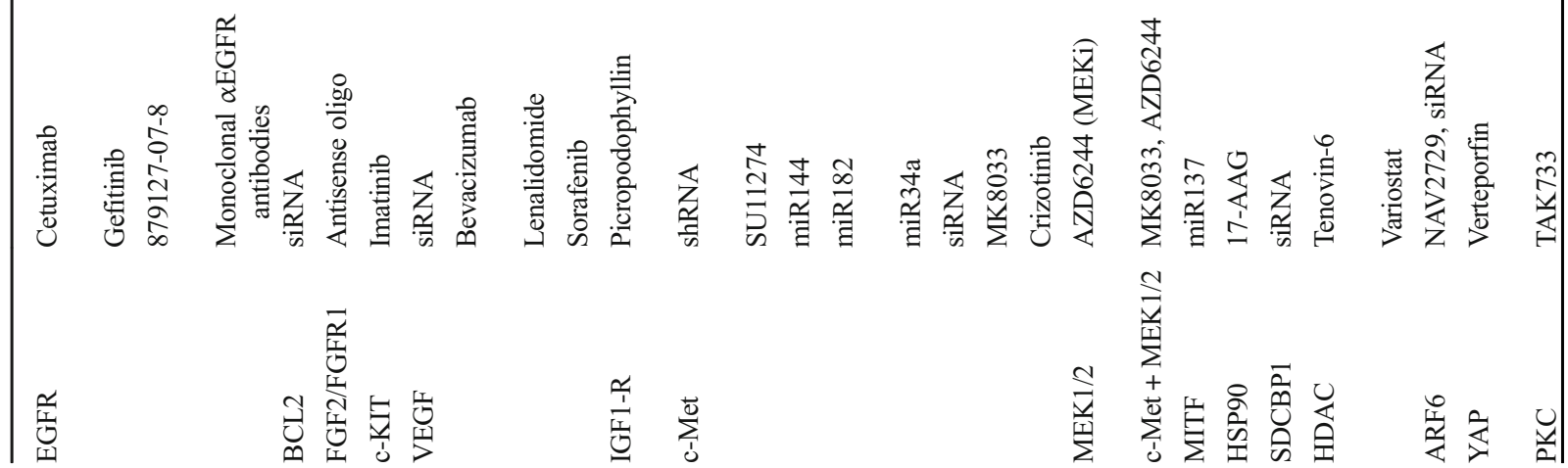

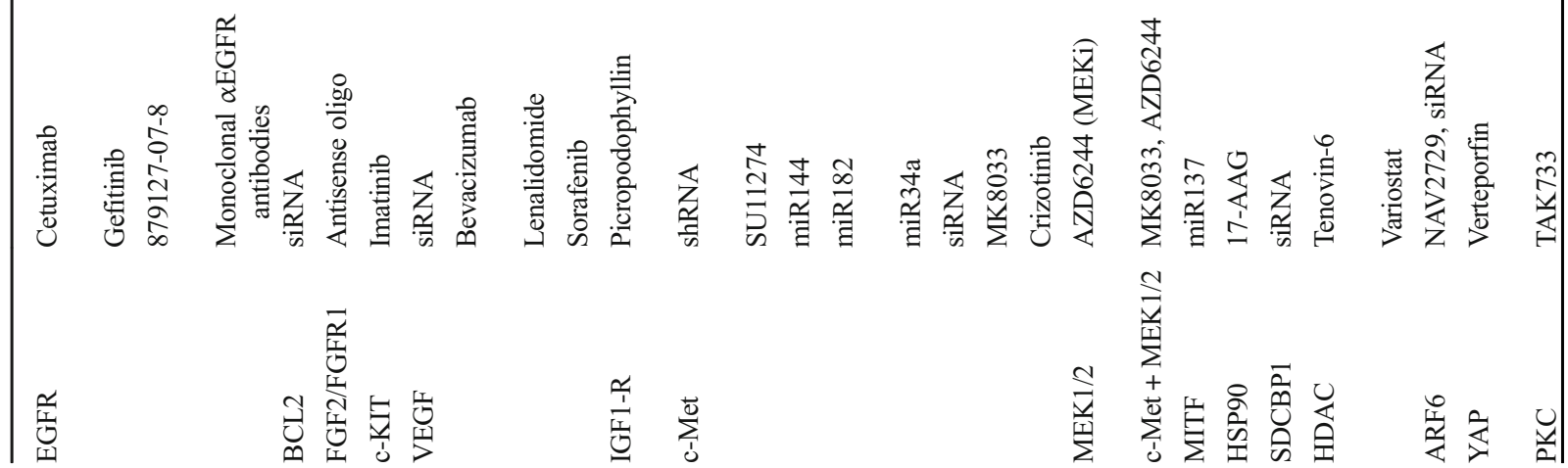

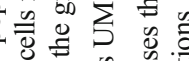

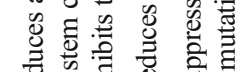


which are the epidermal growth factor receptor (EGFR) [119], the VEGF receptor [120], and the wingless-type MMTV integration site family of signaling protein (WNT) [121] pathways. In mice, ARF GTPase-activating proteins control c-kit endocytosis [122].

\subsection{Histopathology}

The diagnosis of UM is generally made by a trained ophthalmologic oncologist, and only few cases require cellular analyses in order to rule out an ocular metastasis of other solid tumors. Histopathology is primarily required for prognostication of UM [123]. Nuclear grade and cell type are linked to prognosis. Tumors dominated by epithelioid cells have a worse prognosis than those with prevalently spindle-like cells. Tumors with a mixed cell type have an intermediate risk [123-125]. The proportion of spindle cell histology is more frequent in younger patients and has decreased over time [10], probably as a consequence of increased age at diagnosis. Accordingly, metastatic UM shows prevalently epithelioid cells although a component of spindle-like cells is always present [126]. Other histopathological features commonly used for assessing the malignant potential of UM are the number of mitotic figures and the presence of extracellular matrix periodic acid-Schiff-positive closed loops.

More recently, immunohistochemistry has been proposed as a useful prognostic tool for the analysis of nuclear expression of the BAP1. The somatic mutation of this gene, resulting in a loss of protein expression, is associated with metastatic risk [127-130] (see below).

\section{Genetics of uveal melanoma}

\subsection{Cytogenetics}

The most frequent cytogenetic alterations encountered in UM are monosomy of chromosome 3 and amplification of 8q [131, $132]$, both associated with poor prognosis $[133,134]$. The amplifications are conserved in metastases [135]. Amplification of chromosome $6 p[132,136]$ and losses of $1 p$ are also frequent [137]. Table 2 summarizes the results of studies analyzing large cohorts by microsatellite analysis [140,141], fluorescence in situ hybridization (FISH) [142, 143], multiplex liganddependent PCR amplification (MLPA) [139], or single nucleotide polymorphism (SNP) microarrays [143]. These studies confirm the strong association of monosomy of chromosome 3 with death from metastasis as well as with other histopathological factors such as epithelioid cells, closed microvascular loops, ciliary body involvement, large basal tumor diameter, and tumor thickness. The latter two remain to be important histopathological prognostic factors [144, 145]. Also the highly prognostic chromosome 3 monosomy and 8q amplifications 
Table 2 Chromosomal deletions and amplifications in uveal melanoma (\%)

\begin{tabular}{|c|c|c|c|c|c|c|c|c|c|c|c|c|}
\hline \multirow{3}{*}{$\begin{array}{l}\text { No. of } \\
\text { cases }\end{array}$} & \multirow[t]{3}{*}{ Sample type } & \multirow[t]{3}{*}{ Method } & \multicolumn{9}{|l|}{ Chromosome } & \multirow[t]{3}{*}{ Reference } \\
\hline & & & \multicolumn{2}{|l|}{3} & \multirow{2}{*}{$\begin{array}{l}1 \mathrm{p} \\
\text { Losses }\end{array}$} & \multirow{2}{*}{$\begin{array}{l}6 \mathrm{p} \\
\text { Gains }\end{array}$} & \multicolumn{2}{|l|}{$6 \mathrm{q}$} & \multirow{2}{*}{$\begin{array}{l}8 \mathrm{q} \\
\text { Gains }\end{array}$} & \multicolumn{2}{|l|}{$8 p$} & \\
\hline & & & Monosomy & $\begin{array}{l}\text { Partial } \\
\text { monosomy }\end{array}$ & & & Losses & Gains & & Losses & Gains & \\
\hline 356 & Local resection or enucleation & FISH & 47 & & & & & & 37 & & & [138] \\
\hline 452 & Local resection or enucleation & MLPA & 61 & & & 54 & 22 & & 63 & 18 & & [139] \\
\hline 500 & Fine needle aspiration biopsy & MS & 25 & 27 & & & & & & & & {$[140]$} \\
\hline 374 & Enucleation & MS & 56 & & & & & & 54 & & & {$[141]$} \\
\hline 220 & Enucleation & FISH & 61 & & & 42 & 30 & & 61 & & & [142] \\
\hline 320 & $\begin{array}{l}\text { Fine needle aspiration biopsy } \\
\text { or enucleation }\end{array}$ & SNV arrays & 45 & 6 & 18 & 32 & 17 & 6 & 51 & 18 & 16 & [143] \\
\hline Total & & & 54 & & & 42 & 22 & & 53 & & & \\
\hline
\end{tabular}

occur independent of each other, and principal component analysis of karyotypes identifies four classes with prognostic relevance: (i) disomy 3/disomic 8q, (ii) monosomy 3/disomic 8q, (iii) disomy $3 / 8 \mathrm{q}$ gain, and (iv) monosomy $3 / 8 \mathrm{q}$ gain [146]. Three to seven copies of $8 \mathrm{q}$ could be detected [138]. Digital PCR which offers the possibility to detect rare events in heterogeneous tissue samples might further improve the prognostic power of molecular cytogenetics [147]. All chromosomal alterations except amplification of $6 p$ correlate with the largest basal tumor diameter, indicating that they do not occur at the onset of the disease but they are acquired later on [43].

It is clear that monosomy of chromosome 3 is the single strongest cytogenetic factor to predict UM metastasis. Almost all cancers show chromosomal aberrations. Often, tumors contain a mutated, non-functional allele of a TSG and the functional wild-type allele is lost by deletion. This has also been shown for UM where the tumor suppressor gene BAP1, located on 3 21.1, frequently shows somatic mutations in the only allele present in tumors with monosomy of chromosome 3 [148]. However, in contrast to other tumors, a loss of BAP1 function appears not to be sufficient. Most metastatic tumors show complete monosomy, but there are many cases with partial monosomy, indicating that it is not the result of mitotic nondisjunction of the entire chromosome. Interestingly, smaller tumors with a lower metastatic risk show a higher proportion of cases with partial monosomy 3 [140]. Hence, there must be a selective advantage for the loss of an entire chromosome 3. Principal component analysis of the results of an MLPAbased screening of chromosome 3 confirmed the association of metastasis risk with the loss of the entire chromosome rather than a single region therefrom [146]. The identification of the smallest overlapping regions (LOR) usually leads to the identification of TSGs. However, this approach has not worked out for UM where two LORs were identified but none of them contained BAP1 [149] that was later identified by exome sequencing. A similar, microsatellite-based analysis identified an adjacent lesion in 3p25.1-3p25.2 that also does not contain BAP1 [150]. Several cases with deletions spanning the BAP1 locus were identified in a bacterial artificial chromosome-based comparative genome hybridization study, yet the gene was not identified [151]. Isodisomy of chromosome 3 also occurs [152] and is apparently associated with a metastatic risk of UM [153]. The nature of the apparent selective advantage of monosomy or isodisomy over the simple deletion of the wild-type copy of BAP1 and the reason why BAP1 did not consistently show up in the cytogenetics-based tumor suppressor gene research is unknown. The p53 apoptosis effector (PERP) is expressed at low levels in UM with monosomy 3 [154], and the tumor protein p63, encoded by the TP63 gene, located on chromosome $3 q 27-29$, has been shown to be necessary to promote apoptosis in tumor protein p53 (TP53) wild-type UM cell lines. Yet, the role of monosomy remains unclear since the study used disomic cell lines and did not analyze UM tumors [155].

Copy number alteration analysis using SNP arrays has revealed several amplifications and deletions, among which are amplifications on chromosome 6q25.2 containing the membrane-associated guanylate kinase interacting proteinlike 1 (CNKSR3) that was amplified in a specific rare subset of UM with monosomy of chromosome 3 and extended metastasis-free survival [156].

\subsection{Somatic mutations}

Whole exome sequencing [30, 32, 157], including The Cancer Genome Atlas (TCGA) data (http://cancergenome.nih.gov/), shows that UM has relatively few recurring mutations, indicating a low genetic complexity and the absence of genomic instability. Many studies report mutation frequencies that are summarized in Table $3[27,28,30,32$, $35,83,126,128,130,147,148,157-172]$. Initially, BRAF mutations had also been described for UM [173, 174] but these reports have not been confirmed. 
Table 3 Frequent somatic mutations in primary uveal melanoma

\begin{tabular}{|c|c|c|c|c|c|c|c|c|}
\hline \multirow{2}{*}{$\begin{array}{l}\text { No. of } \\
\text { samples }\end{array}$} & \multicolumn{4}{|c|}{ Potential driver mutations } & \multicolumn{3}{|c|}{ Metastasis drivers } & \multirow[t]{2}{*}{ Reference } \\
\hline & GNAQ & GNA11 & CYSLTR2 & PLCB4 & BAP1 & SF3B1 & EIF1AX & \\
\hline 67 & $49 \%(33 / 67)$ & & & & & & & {$[158]$} \\
\hline 48 & $46 \%(22 / 48)$ & & & & & & & [27] \\
\hline 75 & $53 \%(40 / 75)$ & & & & & & & [159] \\
\hline 22 & $36 \%(8 / 22)$ & & & & & & & {$[2]$} \\
\hline 27 & $44 \%(12 / 27)$ & & & & & & & {$[2]$} \\
\hline 163 & $48 \%(55 / 115)$ & $34 \%(55 / 163)$ & & & & & & {$[28]$} \\
\hline 57 & $47 \%(7 / 15)$ & & & & $47 \%(27 / 57)$ & & & [148] \\
\hline 91 & $47 \%(43 / 91)$ & $44 \%(40 / 91)$ & & & & & & {$[160]$} \\
\hline 102 & $42 \%(36 / 86)$ & $52 \%(43 / 83)$ & & & $38 \%(32 / 85)$ & $19 \%(19 / 102)$ & & {$[32]$} \\
\hline 117 & $25 \%(3 / 12)$ & $58 \%(7 / 12)$ & & & $58 \%(7 / 12)$ & $15 \%(18 / 117)$ & $8 \%(1 / 12)$ & {$[161]$} \\
\hline $111^{\mathrm{a}}$ & $41 \%(9 / 22)$ & $41 \%(9 / 22)$ & & & $11 \%(5 / 45)$ & $20 \%(20 / 111)$ & $21 \%(23 / 111)$ & {$[30]$} \\
\hline 92 & $35 \%(6 / 17)$ & $43 \%(40 / 92)$ & & & & & & {$[162]$} \\
\hline 74 & & & & & $47 \%(35 / 74)$ & & & {$[128]$} \\
\hline 50 & $18 \%(9 / 50)$ & $20 \%(10 / 50)$ & & & & & & {$[156]$} \\
\hline 46 & $42 \%(19 / 45)$ & $33 \%(15 / 46)$ & & & $32 \%(12 / 38)$ & $10 \%(3 / 31)$ & $19 \%(7 / 37)$ & {$[35]$} \\
\hline 116 & $46 \%(52 / 113)$ & $35 \%(41 / 116)$ & & & $50 \%(56 / 111)$ & $10 \%(11 / 110)$ & $16 \%(18 / 111)$ & {$[163]$} \\
\hline 66 & $41 \%(27 / 66)$ & $50 \%(33 / 66)$ & & & & & & {$[147]$} \\
\hline 123 & $48 \%(59 / 123)$ & $46 \%(57 / 123)$ & & & & & & [164] \\
\hline 23 & $35 \%(8 / 23)$ & $39 \%(9 / 23)$ & & $9 \%(2 / 23)$ & $35 \%(8 / 23)$ & $9 \%(2 / 23)$ & $17 \%(4 / 23)$ & {$[157]$} \\
\hline 74 & & & & & & $22 \%(16 / 74)$ & & {$[165]$} \\
\hline 7 & $29 \%(2 / 7)$ & $57 \%(4 / 7)$ & & & $57 \%(4 / 7)$ & & & {$[130]$} \\
\hline 81 & $44 \%(36 / 81)$ & $44 \%(36 / 81)$ & & & $45 \%(29 / 64)$ & $23 \%(19 / 81)$ & $17 \%(14 / 81)$ & {$[166]$} \\
\hline 158 & $52 \%(67 / 130)$ & $44 \%(57 / 130)$ & & & $51 \%(81 / 158)$ & $22 \%(29 / 131)$ & $17 \%(23 / 133)$ & {$[167]$} \\
\hline 133 & $49 \%(67 / 132)$ & $38 \%(44 / 117)$ & & & $75 \%(9 / 12)$ & $24 \%(32 / 133)$ & $21 \%(28 / 133)$ & [168] \\
\hline $15^{\mathrm{a}}$ & $53 \%(8 / 15)$ & $40 \%(6 / 15)$ & & & & & & [83] \\
\hline 136 & $43 \%(58 / 136)$ & $49 \%(67 / 136)$ & $3 \%(4 / 136)$ & $4 \%(5 / 136)$ & $35 \%(48 / 136)$ & $18 \%(24 / 136)$ & $13 \%(18 / 136)$ & [169] \\
\hline 65 & & & & & $43 \%(28 / 65)$ & & & {$[130]$} \\
\hline 2013 & $45 \%(686 / 1518)$ & $42 \%(573 / 1373)$ & $3 \%(4 / 136)$ & $4 \%(7 / 159)$ & $43 \%(381 / 887)$ & $18 \%(193 / 1049)$ & $18 \%(136 / 777)$ & \\
\hline Range $(\%)^{\mathrm{b}}$ & $18-53$ & $20-58$ & 3 & $4-9$ & $32-75$ & $9-24$ & $8-21$ & \\
\hline
\end{tabular}

${ }^{\mathrm{a}}$ Selected patients

${ }^{\mathrm{b}}$ Studies with selected patients not considered

GNAQ [27] and GNA11 [28], two genes encoding G $\alpha$ subunits of $\mathrm{G}$ proteins, are considered the major drivers of UM carcinogenesis since they are found in a mutually exclusive manner in over $80 \%$ of UM (see Table 3) where they occur in most if not all of the cells forming the tumor [158]. A significantly lower frequency has been reported for patients from China [170]. Mutations in GNA11 but not GNAQ have been found more frequently in metastatic UM $[28,126]$. All mutations of GNAQ and GNA11 in UM involve the same two hotspots in both genes, Q209 and, less frequently, R183, in the Ras-like GTPase domain [175]. These mutations are also encountered in blue nevi and nevi of Ota [176] and melanocytic tumors of the central nervous system [177]. The somatic mosaic GNAQ R183Q mutation is associated with the neurocutaneous disorder Sturge-Weber syndrome and non- syndromic port wine stains [178]. The exclusively somatic nature of the mutation in the Sturge-Weber syndrome and the absence of GNAQ and GNA11 germline mutations in familiar cases of UM [179] suggest that the germline mutation, if present in all cells, is not compatible with life.

Consistent with their oncogenic function, GNAQ and GNA11 mutations in UM are activating mutations. GNAQ and GNA11 are activated by the serotonin $(5-\mathrm{HT})$ receptors 2A and 2B (HTR2A and HTR2B) [180]. The role of serotonin in uveal melanocytes is unknown, but the involvement of the neurotransmitter in the regulation of proliferation, cell shape, and migration of melanocytes has been described for frog skin [181]. Interestingly, HTR2B, the gene encoding the serotonin receptor 5-HT2B, is overexpressed in UM with high metastatic risk $[182,183]$ despite the fact that the activating mutations 
in GNAQ and GNA11 already activate the pathway. The endothelin receptor types A and B (EDNRA and EDNRB) also signal via GNAQ and GNA11 [184, 185]. Endothelin 2 is differentially expressed in UM [186], and its receptor EDNRB is downregulated in metastatic UM [187]. Evidence from mice indicates that endothelin signaling could be specific for Schwann cell precursor-derived melanocytes that also populate the uvea [188].

GNAQ and GNA11 activate the classical G protein signaling cascade via inositol-3-phosphate, diacylglycerol, and cyclic AMP, leading to the stimulation of MAP kinases, protein kinase $\mathrm{B}(\mathrm{Akt})$ and protein kinase $\mathrm{C}$ (PKC), phosphoinositide 3-kinase (PI3K), and mechanistic target of rapamycin (mTOR) [189]. More recently, GNAQ and GNA11 have been shown to activate the transcription factor complex YAP/TAZ in a HIPPO-independent manner [93, 190]. HIPPO has been identified as an important regulator of organ size, and its involvement in several cancer types has recently been appreciated [191]. At present, it is not clear which of the two pathways, YAP/TAZ or MAP kinase, is more important in UM. Interestingly, activation of YAP/TAZ has been shown to confer resistance to BRAF-targeted therapy in CM [192]. MAPKtargeted therapy has so far not been successful in UM (see above), and YAP/TAZ inhibition might become an alternative. The YAP/TAZ pathway can be interrupted by the photodynamic drug verteporfin [93] and through inhibition of the mevalonate pathway [193]. The stimulation of several signaling pathways including activation and nuclear translocation of $\beta$-catenin by mutated GNAQ and GNA11 proteins relies on the small GTPase ARF6 [91]. Its inhibition by the small molecule inhibitor NAV-2729 leads to the reduced growth of GNAQ mutant cells in vitro and in vivo [91].

Fifteen to twenty percent of UM show no mutations in GNAQ and GNA11 genes. The analysis of whole exome sequencing data in double wild-type UM has led to the identification of a L129G-activating mutation in the cysteinyl leukotriene receptor 2 (CYSLTR2) gene, coding for a G protein-coupled receptor. The mutation leads to constitutive activation of GNAQ signaling [169]. The D630Y mutation in the phospholipase $\mathrm{C} \beta 4$ (PLCB4) gene that has been observed in several GNAQ and GNA11 wild-type UM cases activates the same pathway acting downstream of GNAQ by catalyzing the formation of inositol 1,4,5-trisphosphate and diacylglycerol from phosphatidylinositol 4,5-bisphosphate [157]. In only a minor part of UM, no putative oncogenic mutation has been found so far. Mutations in the genes GNAQ, GNA11, CYSLTR2, and PCLB4 are likely the initiating driver mutations of UM.

The BAP1 gene encodes a nuclear ubiquitin carboxyterminal hydrolase with deubiquitinase activity [194] that behaves like a classical TSG in UM [148]. It is located on chromosome $3 \mathrm{p} 21.1$, and $84 \%$ of metastatic UM maintain only the mutated allele of BAP1 [148]. Germline mutations in BAP1 are associated with several familiar cancers, among which are lung adenocarcinoma, meningioma, mesothelioma, $\mathrm{CM}$, and UM [195-200]. The specific type of cancer that develops in BAP1 mutation carriers might depend on additional modifier genes [201]. Eight percent of patients with metastatic UM carried germline BAP1 mutations [198], and the penetrance in consideration of all types of malignancy approaches $70 \%$ and might increase with increasing age of the unaffected BAP1 carriers [200]. Germline BAP1 mutations could be more frequent in patients with early onset of UM [202]. Similar to what has been observed for other TSGs, loss of function mutations can occur over the whole coding region of the gene and mutation is associated with a loss of protein expression. For prognostication, immunohistochemistry has been established as a reliable method to predict BAP1 mutation [127-130].

BAP1 is associated with BRCA1 but does not lead to its deubiquitylation. Instead, it deubiquitylates BRCA1associated RING domain 1 (BARD1) and modulates the E3 ligase activity of the complex formed by BRCA1 and BARD1 that is needed for the regulation of the DNA damage response [203]. The tumor suppressor activity of BAP1 requires deubiquitylation activity and nuclear localization [204]. Among the substrates of BAP1, there is the repressive transcriptional regulator host cell factor 1 (HCF1) that acts on E2F-responsive promoters [205]. BAP1 also controls transcription and chromatin structure via histone $\mathrm{H} 2 \mathrm{~A}$ deubiquitylation [206] and through its interaction with HCF1 and the transcription factor Yin Yang 1 (YY1) affecting the transcription of many genes [207, 208]. Consistent with the profound effect on the transcription profile of the cells, depletion of BAP1 determines cell dedifferentiation and the acquisition of stem cell features [209]. The effect on H2A can be controlled by histone deacetylase inhibitors [115] that are presently tested in the clinics as a single agent (NCT00121225, NCT01587352) or in combination with immune checkpoint blockers (NCT02697630).

The Splicing Factor 3b Subunit 1 gene (SF3B1) is mutated in positions R625 [32, 161] and K666 [165] in a minority of UM cases, almost always in the absence of BAP1 mutations. These mutations only rarely occur in CM [210, 211]. SF3B1 is frequently mutated in hematopoietic malignancies with, however, another mutation hotspot in K700 [165] with likely the same or similar functional consequences. SF3B1 mutation alters its function in RNA splicing, leading to the selection of cryptic splice sites $[165,212,213]$ thus affecting many primary transcripts. It is therefore not possible to classify SF3B1 mutations in activating or inactivating mutations. SF3B1 mutations define a subclass of UM with chromosome 3 disomy and without BAP1 mutations that nevertheless develop metastases after extended latency $[167,214,215]$. This subclass is distinguished by overexpression of the preferentially expressed antigen in melanoma (PRAME) [215] which acts as a dominant repressor of retinoic acid receptor signaling 


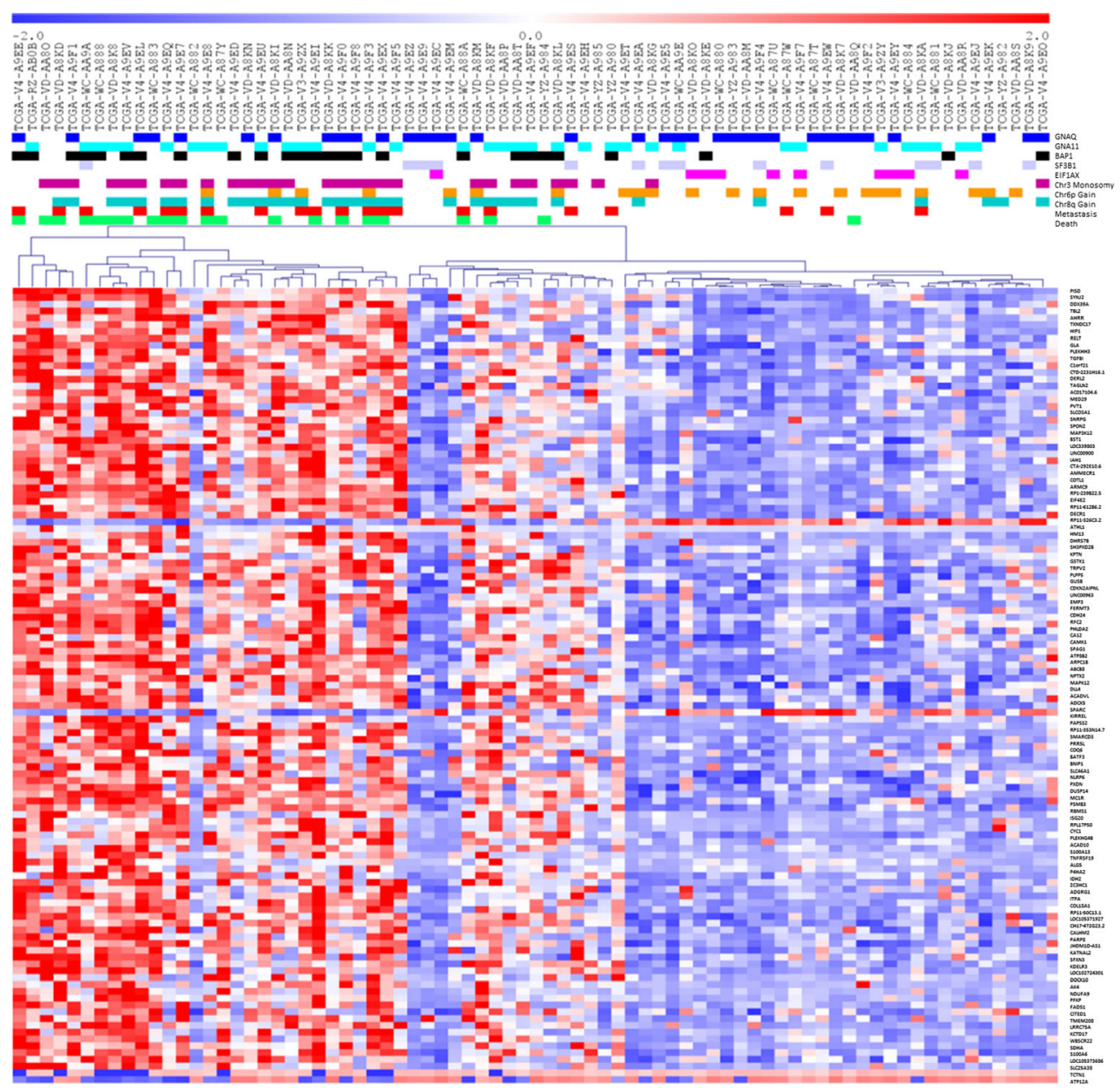

Fig. 1 Gene expression and mutational status in UM. Gene expression data from 79 cases of primary UM from the TCGA cohort were used for the identification of genes that are differentially expressed in cases that yielded distant metastases later on as compared to cases without progression to metastatic disease. Statistically significant gene expression differences were obtained by analysis using the bootstrapping algorithm significance analysis of microarrays as described [84]. Expression values over the mean value are indicated in red, values below the mean in blue, and values at the mean in white; the intensity of the color corresponds to the distances from the mean as indicated in the red-blue bar on top of the diagram. Differentially expressed genes were used for hierarchical clustering performed as described [84]. The dendrograms on top of the gene expression panel

[216], and its expression is controlled by promoter methylation and is associated with a metastatic risk in SF3B1 as well as in BAP1 mutated cases [217].

Missense mutations in the highly conserved aminoterminal portion of the Eukaryotic Translation Initiation Factor 1A X-Linked (EIF1AX) gene also occur prevalently in the absence of BAP1 mutations in disomic, low-risk UM [30]. The association of EIF1AX mutations with a low-risk profile has been confirmed in an independent study [163]. EIF1AX stimulates the transfer of methionyl initiator tRNA (Met-tRNAi) to the small ribosomal subunit during translation initiation. The functional consequences of these mutations are show the relationship of single samples and their agglomeration in clusters. The differences between the clusters are indicated by the length of the branches of the dendrograms. Above the dendrogram, the mutational status for GNAQ, GNA11, BAP1, SF3B1, and EIF1AX is indicated as well as chromosomal alterations (chromosome 3 monosomy, $6 \mathrm{p}$ and $8 \mathrm{q}$ gains) and the development of distant metastases and the status of the patients at the end of the follow-up. In all these cases, colored boxes indicate the presence and white boxes the absence of the alteration. Two main clusters are formed, one of which contains most of the cases that developed metastases. The mutation status of these cases evidences the correlation between chromosome 3 monosomy, BAP1 mutation, metastasis, and death. Note that this cohort contains an unusual case with mutations in both GNAQ and GNA11

unknown, and the involvement of alternative start codon recognition has been suggested [30]. BAP1, SF3B1, and EIF1AX mutations are almost mutually exclusive and associated with early (BAP1), late (SF3B1), or no (EIF1AX) metastasis (see Fig. 1). EIF1AX mutations are present in $18 \%$ of UM (Table 3), likely due to positive selection during carcinogenesis. UM with mutations in this gene have, however, a low risk of metastasis. Hence, EIF1AX is pro-tumorigenic with no or negative influence on metastasis or the link between its mutations and a specific pattern of metastasis is still unknown.

The Catalogue of Somatic Mutations in Cancer (COSMIC, http://cancer.sanger.ac.uk/cosmic) reports 58 mutations of 
EIF1AX in 33,058 cancers analyzed and occasional copy number changes, gains, and losses. EIF1AX mutations also occur in papillary [218] and anaplastic [219] thyroid carcinoma and serous ovarian tumors [220]. EIF1AX mutations are missense mutations mainly clustered in the amino-terminal portion of the encoded protein with some frameshift deletions in UM and a splice site mutation hotspot in thyroid cancer [220].

Figure 1 shows a combined view of frequent somatic mutations in UM and their associations with clinical features and gene expression in the TCGA dataset of 79 UM cases.

\subsection{Gene expression}

Several groups have assembled significant numbers of expression profiles of UM samples [182, 183, 221-223] which, in part, are publicly available. The TCGA dataset also contains gene expression profiles (GEPs) obtained by RNA sequencing. From the very first analysis, it was evident that the major hallmark of high-risk UM, chromosome 3 monosomy, is clearly associated with a specific expression profile [182]. This has been confirmed and extended by several other studies [153, 183, 224, 225] and has led to the development of a multigene prognostic classifier [225-229] (see also Fig. 1) with a prognostic power at least similar to cytogenetics-based procedures such as MLPA [139], eventually combined with histopathological criteria [144]. Public UM gene expression datasets build a domain knowledge that can be mined for many studies such as the expression analysis of targets for existing drugs [85, 222].

The gene expression-based classification of UM shows two very robust classes (Fig. 1) similar to what has been observed for breast cancer where the expression of the estrogen receptor $\alpha$ (ESR1) gene defines two classes with clearly distinguished GEPs [230]. The differences between these classes have been proposed to be determined by their origin, from either luminal or basal cells [231]. Cell lineage is in fact a major determinant of GEPs [232]. When applied to UM, this could indicate that tumors with monosomy 3 are derived from different precursor cells than disomic cases with a different intrinsic propensity to metastasize.

Several studies have performed microRNA (miRNA) expression screenings in UM (for a recent review, see [233]). miRNA expression is associated with chromosome 3 status, gene expression profiling classes and prognosis [234]. Functional studies have been performed for selected miRNAs identified in cell lines or very limited sample collections of UM [233]. There is no conclusive evidence for a functional role of miRNA dysregulation in UM due to the lack of large-scale analyses.

\section{Multistep carcinogenesis}

Our current understanding of how cancer develops is based on three concepts that, to some extent, present a conceptual evolution: (i) the two hits hypothesis postulating that transformation of a normal cell into a cancer cell needs at least two irreversible steps [235, 236], usually mutations in oncogenes and tumor suppressor genes; (ii) the multistep carcinogenesis model that predicts distinct morphological changes during tumor development based on specific molecular lesions [237]; and (iii) the hallmarks of cancer concept that establish distinct processes during cancer evolution: sustaining proliferative signaling, evading growth suppressors, avoiding immune destruction, enabling replicative immortality, genome instability and mutation, resisting cell death, deregulating cellular energetics, tumor-promoting inflammation, inducing angiogenesis, and activating invasion and metastasis [238, 239].

A growing body of data describes the accomplishment of the hallmarks by UM and has recently been reviewed in detail [240]. Our current knowledge of the steps of UM carcinogenesis is summarized in Fig. 2. Almost all UMs are characterized by mutations in either GNAQ, GNA11, PLCB4, or CYSLTR2 with few cases showing none of these mutations [27, 28, 157 , 169]. These mutations are most likely not sufficient for the establishment of the tumor. The second hit might be an additional mutation or specific systemic condition such as inflammation or angiogenesis. The progression to invasion and metastasis is driven in most cases by the loss of chromosome 3 and mutation of BAP1. Given the fact that partial deletion of chromosome 3 only occasionally yields a metastatic phenotype, additional factors on chromosome 3 are expected. Mutations in SF3B1 can also lead to metastasis in the absence of BAP1 mutations in disomic UM [32].

Amplifications of the long arm of chromosome 8 independently contribute to a metastatic phenotype. The V-Myc Avian Myelocytomatosis Viral Oncogene Homolog (MYC) oncogene is located on $8 \mathrm{q}$, but its expression does not follow the amplification status, instead the gene ArfGAP With SH3 Domain, Ankyrin Repeat and PH Domain 1 (ASAP1) also named DDEF1, AMAP1, or Centaurin- $\beta 4$, has been proposed to mediate the effects of $8 \mathrm{q}$ amplification [241]. This is particularly interesting, given the involvement of ARF6 in UM progression [91] since ASAP1 is a GTPase-activating protein for ARF1 [242] as well as ARF6 [243].

The molecular basis for the apparent protective effect of $6 p$ amplifications [244, 245] is unknown. Chromosome $6 \mathrm{p}$ contains genes that are involved in the development of the eye, and congenital deletions lead to eye malformation mainly involving the anterior chamber [246]. Chromosome $6 \mathrm{p}$ also harbors the HLA loci and a series of immunomodulatory genes belonging to the B7-CD28 superfamily [247]. HLA loci are not associated with UM risk [248] but might play a role in UM progression [249] through their ability to protect target cells from natural killer cell-mediated lysis [250].

We have recently reported expression of the B7 family member Butyrophilin-Like 2 (BTNL2) gene by UM cells 


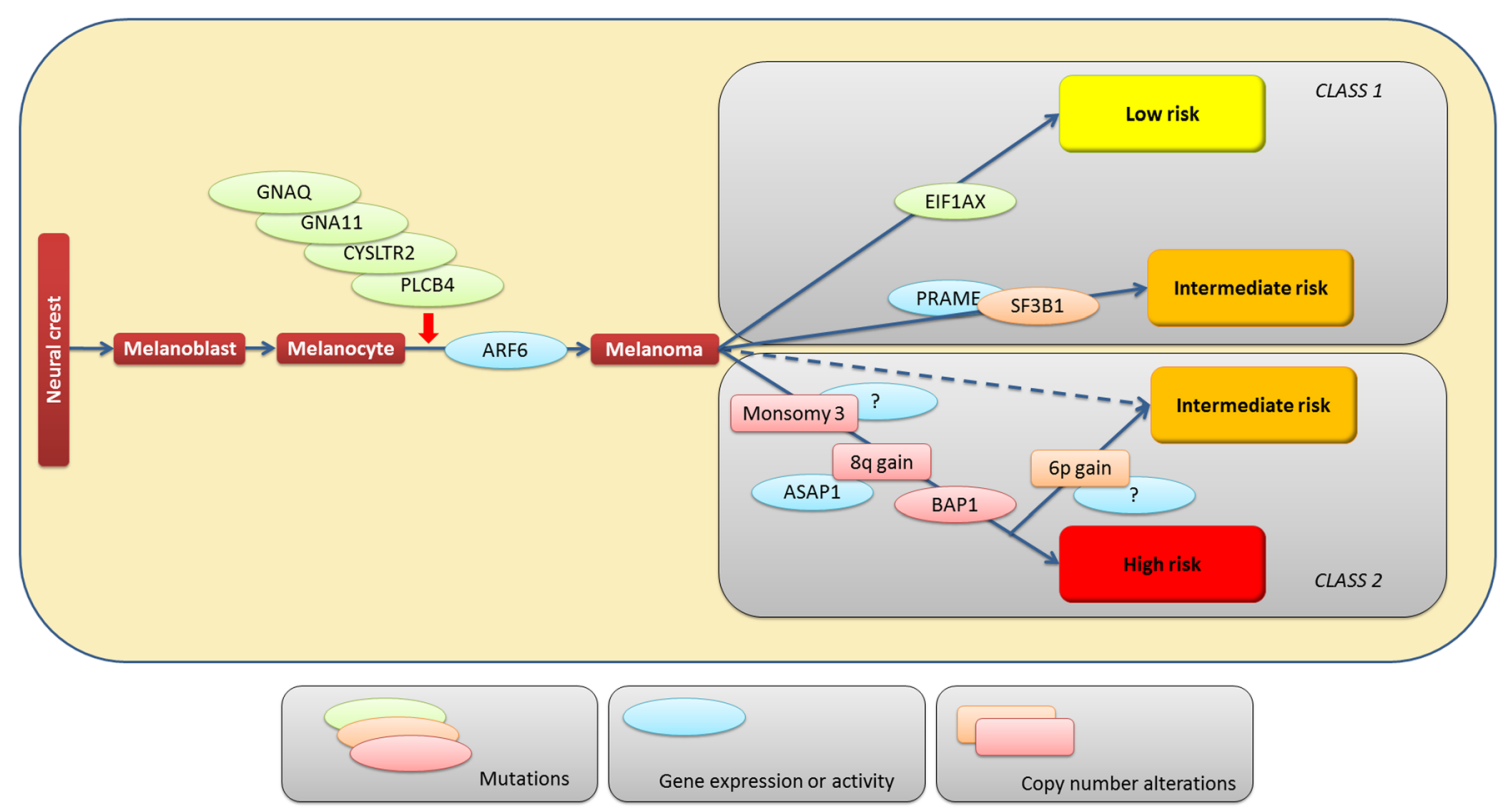

Fig. 2 Multistep carcinogenesis of UM. The diagram shows a hypothesis on UM carcinogenesis based on the current state of knowledge of molecular alterations. UM develops from normal melanoblasts or melanocytes and is initiated in most cases by mutations in the $\mathrm{G} \alpha$ proteins, GNAQ or GNA11, or in CYSLTR2 or PLCB4, two genes acting in the same pathway. An important functional mediator of these mutations is ARF6 that is activated. The resulting melanoma can undergo further molecular alterations that influence the risk of progression to metastasis. Loss of one copy of chromosome 3, mutation of the tumor suppressor BAP1, and amplification of chr8q yield a high metastatic risk that can be attenuated by concomitant amplification of chr6p. Intermediate risk is also observed for cases with chromosome 3 disomy in the presence of SF3B1 mutations. Mutations in EIF1AX and the lack of any of these mutations are associated with a low risk of metastasis and macrophages that might contribute to the definition of the specific immunologic niche [223].

\section{Inflammation}

In general, chronic inflammation may contribute to early steps of oncogenesis in different tumor types [251]. Indeed, inflammatory cells such as tumor-associated macrophages (TAMs) and several soluble factors are fundamental components of the tumor microenvironment and mediate tumor-promoting effects $[252,253]$. The recruitment of monocytes from peripheral circulation and their subsequent differentiation to TAMs is an essential step in establishing the tumor microenvironment, which has several features of a chronic inflammatory state. Several chemokines, cytokines, and protein products of the complement cascade contribute to monocyte recruitment at the tumor site and their differentiation in TAMs [254]. In the microenvironment, TAMs establish multiple cross-talks with cancer cells, endothelial cells, fibroblasts and other mesenchymal cells, and lymphoid cells. These interactions result in tumor progression through the promotion of tumor cell proliferation and survival, angiogenesis, and suppression of antitumor immune responses.

Monocytes and macrophages have a highly functional plasticity and may undergo divergent functional polarization in response to activation signals such as cytokines, microbial components, or products deriving from tissue damage or metabolism [255, 256]. In particular, classical activation with LPS or IFN- $\gamma$ induces M1 polarization of macrophages that results in their ability to produce CXCL9 and CXCL10 antiangiogenic chemokines and pro-inflammatory (e.g., TNF- $\alpha$ ) and Th1-polarizing (e.g., IL-12) cytokines. In addition, M1 macrophages acquire cytotoxic properties towards intracellular pathogens and tumor cells. On the other hand, alternative activation with IL-4 or IL-13 induces M2 polarization resulting in the production of CCL17, CCL22, IL-10, proangiogenic factors, and matrix metalloproteinases involved in tissue remodeling. However, M1- and M2-type macrophages represent only the two extremes of a broad spectrum of functional states which macrophages can acquire in response to different stimuli. Within the tumor environment stimuli such as hypoxia, cytokines produced by cancer cells (e.g., CCL2, transforming growth factor (TGF)- $\beta$, and CSF-1) or by Treg cells (e.g., IL-10), metabolic products, and immune complexes may drive TAM functional polarization mainly towards an M2 status [252].

Several lines of evidence indicate that inflammation and macrophages play a pro-tumor role also in UM [257]. In UM, a high density of macrophages was significantly associated with the presence of epithelioid cells, heavy pigmentation, and elevated density of microvessels. More importantly, the presence of high numbers of TAMs in primary tumors correlated with an increased UM-specific mortality rate at 10 years 
[258]. Other studies showed that UM TAMs were predominantly CD68+CD163+ M2-type macrophages and that their high density correlated with monosomy 3 , ciliary body involvement, increased microvascular density, and worse survival $[259,260]$. Monosomy 3 is a well-known predictive marker of a poor prognosis in $\mathrm{UM}$, in relationship to the presence on this chromosome of the tumor suppressor gene BAP1 [148]. It has been proposed that the loss of BAP1 function may favor the generation of an inflammatory tumor environment [261]. Indeed, in a BAP1(+/-) mouse model, intraperitoneal exposure to low-dose asbestos fibers showed higher levels of protumorigenic M2 macrophages and incidence of mesothelioma than in wild-type littermates [262].

TAMs may also contribute to hepatic metastases, where CD68+ TAMs showed more intermediate and dendritic cells associated with a higher microvascular density than the primary UMs. In addition, the survival of metastatic UM patients tended to be shorter if hepatic metastases had a high microvessel density [263]. Altogether, the data from primary or metastatic UM support the hypothesis that TAMs have proangiogenic and tumor-promoting activities in human UM. Accordingly, intraocular models of melanoma in syngeneic mice showed a tumor-promoting role of M2 type macrophages, particularly in aged mice $[264,265]$. Indeed, depletion of macrophages strikingly inhibited intraocular melanoma growth in a syngeneic model [264] and, more recently, in a transgenic model of UM [266]. Expression of M1/M2 polarization genes is strongly associated with metastatic risk [223].

Regarding the mechanisms stimulating macrophage recruitment, expression of endothelial monocyte-activating polypeptide (EMAP)-II, detected by immunohistochemistry, correlated with the accumulation of macrophages in primary UM. In areas with high EMAP-II, intercellular adhesion molecule (ICAM)-1 was strongly expressed on endothelial cells. These results suggested that macrophage recruitment is facilitated by the chemotactic activity of EMAP-II and by the expression of ICAM-1 on vascular endothelial cells [267]. The vitreal concentration of many pro-inflammatory cytokines and chemokines, such as IL-6, CXCL-8, CXCL-10, CCL-2, CCL-3, CCL-4, CCL-5, and TNF- $\alpha$, increased in the eyes of UM patients relative to controls. On the opposite, the levels of the anti-inflammatory IL-1R antagonist were lower in UM vitreous. Notably, IL-6 levels positively correlated with high macrophage infiltration [268]. It should be considered that several of these cytokines may exert immune-suppressive and M2-polarizing effects. In addition, co-culture of UM cells with activated T cells upregulated the expression of chemokines and cytokines such as CXCL8, CXCL9, CXCL10, CXCL11, CCL2, CCL5, VEGF, and granulocyte-macrophage colony-stimulating factor (GM-CSF), which coincided with an enhanced ability to stimulate monocyte chemotaxis [269]. These data suggested that the crosstalk between tumor cells and T cells may result in the recruitment of pro-tumoral macrophages. CXCL-8 may be relevant not only as a pro-inflammatory but also as a proangiogenic factor. In vitro studies suggested that UM may activate IL-8 signaling as an alternative pro-angiogenic pathway [270].

Following local treatment of UM by brachytherapy with ruthenium plaques $[271,272]$, proton beam irradiation [273], or trans-pupillary thermotherapy [274], intratumoral macrophages are always present or even increased in the treated UM area. These TAMs are frequently engulfed with pigment released by dying tumor cells, thus having the appearance of melanophages. Also, macrophages are present in extratumoral tissues since brachytherapy may alter their migration and increase their numbers in the sclera and episclera [272]. TAMs infiltrating tumors treated by trans-pupillary thermotherapy predominantly showed a CD $68+C D 163+$ M2 phenotype [274]. However, eyes enucleated after brachytherapy showed a lower density of microvessels than those from untreated UM [263]. In addition, different from untreated UM, no correlation between the amounts of TAMs and microvascular density was observed in the treated eyes. Altogether, these data suggest that M2-type macrophages are present in UM eyes after local treatments, which leads to tumor cell destruction. Under these circumstances, TAMs may mainly mediate a clearance of damaged UM cells and tissue repair but do not exert pro-angiogenic activity.

A small group of patients showed rapid UM regression associated with inflammation and uveitis following I-125 brachytherapy. Interestingly, these patients had a class 1 tumor, based on gene expression analysis. Class 1 tumors show higher expression of melanocyte differentiation antigens, which are recognized by the immune system, relative to class 2 tumors. Therefore, class 1 tumors may be more immunogenic than class 2 tumors upon antigen release induced by I125 brachytherapy [275].

\section{Role of immunity in UM biology and therapy}

A growing body of evidence supports an important role of the immune system in the surveillance of cancers. Indeed, in recent years, immunotherapy by immune checkpoint blockers has shown unprecedented long-lasting responses in different metastatic cancers [276]. Cytotoxic T lymphocytes (CTLs), which recognize tumor-associated antigen (TAA) epitopes in an HLA class I-restricted manner, play a major role in tumor cell elimination. Indeed, in different tumors, the presence of an abundant $\mathrm{T}$ cell lymphoid infiltrate rich in CD8+ T cells frequently correlates with a good prognosis [277-279].

However, it became clear that tumors evade from immune surveillance through several mechanisms. The immune editing or "three e" theory proposes that the immune system efficiently controls tumor growth in a first phase of tumor cell 
elimination [280]. In a second phase of equilibrium, the immune system still eliminates immunogenic tumor cells but may also select less immunogenic cell variants. This immune selection process sculpts the features of clinically evident tumors that are characterized by uncontrolled growth due to immune escape mechanisms, which are particularly active in the tumor microenvironment.

Among these mechanisms, the adaptive immune resistance is due to the induction of programmed death ligand 1 (PDL-1) expression on tumor cells through IFN- $\gamma$ released by tumorinfiltrating CTLs [276]. In turn, PDL-1 switches off the response of CD8+ CTLs by engaging the PD-1 inhibitory receptor at the $\mathrm{T}$ cell surface [281]. Antibodies blocking the PDL-1/PD-1 immune checkpoint restore the silenced immune response at the tumor site, leading to CTL-mediated tumor cell lysis. As a matter of fact, anti-PD-1 or anti-PDL-1 blocking monoclonal antibodies (mAbs) mediate potent and longlasting anti-tumor responses in metastatic cutaneous melanoma $[282,283]$ and other metastatic cancers.

The efficacy of immune checkpoint blockers is related to a high load of tumor non-synonymous mutations, which potentially lead to the generation of immunogenic neo-antigens, recognized by the $T$ cells [284]. In cutaneous melanoma, the response to anti-PD-1 therapy has been correlated with the expression of PL-1 on tumor cells, which is geographically associated with infiltrating immune cells [285]. More recent observations related the responsiveness to anti-PD1 mAb with the abundance of tumor-infiltrating PD-1high/CTLA-4high CD8+ T cells, which may correspond to exhausted antimelanoma-specific CTL [286]. Another clinically relevant immune checkpoint in cutaneous melanoma is CTLA-4, a highaffinity receptor for the B7.1 and B7.2 co-stimulatory ligands. Engagement of CTLA-4 with these ligands prevents their interaction with the co-stimulatory receptor CD28 and switches off T cell activation [287]. The anti-CTLA-4 mAb ipilimumab has been the first immune checkpoint blocker approved for immunotherapy of metastatic melanoma [288].

In spite of their common origin from the neural crests and the shared expression of differentiation antigens (e.g., MART-1, gp100, and tyrosinase), cutaneous melanoma is highly immunogenic, whereas UM is considered as a poorly immunogenic tumor [289-291]. The low immunogenicity of UM may reflect its peculiar site of origin and also its biological characteristics.

It is well known that the eye is an immune-privileged organ and has the ability to prevent the potential damage caused by the immune response through several mechanisms (reviewed in [292]). Indeed, skin allografts implanted in the ocular anterior chamber of rabbits showed prolonged survival, leading to the concept of the eye immune privilege. Also, the injection of foreign antigen into the anterior chamber activates suppressor T cells, which inhibit the systemic immune response against the same antigen, a phenomenon defined as anterior chamber- associated immune deviation (ACAID) [293]. In the mouse, this phenomenon is related to F480+ macrophages, which develop tolerogenic functions in the eye environment. Upon migration in lymphoid organs, these macrophages act as antigenpresenting cells and initiate a response of suppressor $\mathrm{T}$ cells [294]. The aqueous humor contains several immunesuppressive factors including, for example, the neuropeptides $\alpha$-melanocyte-stimulating hormone (MSH) and vasointestinal polypeptide (VIP), the cytokines macrophage migrationinhibitory factor (MIF) and TGF- $\beta 2$. TGF- $\beta$ inhibits the proinflammatory activity of macrophages and mediates their conversion to tolerogenic APC-mediating ACAID [295]. In addition, TGF- $\beta$ suppresses $T$ cell responses and mediates the conversion of $\mathrm{T}$ cells to immune-suppressive regulatory $\mathrm{T}$ cells [291]. Also, the enzyme indoleamine 2,3-dioxygenase (IDO) is expressed in the cells lining the anterior chamber cells and may contribute to inhibiting $\mathrm{T}$ and $\mathrm{NK}$ cell responses through tryptophan depletion and generation of kynurenines [296, 297].

It has been proposed that UM cells benefit from the immune privilege in the eye and may adopt several mechanisms involved in this privilege for tumor escape, also during the metastatic process [289]. Indeed, UM cells express several immune-suppressive cytokines found in the eye, including, for example, TGF- $\beta$ and MIF, which are inhibitors of NK cell functions and may therefore contribute to UM metastasis development [298]. In addition, UM cells may also express HLA-E, an MHC class Ib molecule, which binds to the inhibitory receptor NKG2A and blocks NK cell functions [299]. Also, classical HLA class I molecules (A, B, and C) protect target cells from NK-mediated lysis, through the engagement of inhibitory receptors termed KIRs [300]. Interestingly, the loss of classical HLA class I molecules is associated with a better prognosis in UM, opposite to what found in most other tumors. This finding suggested that NK cells are involved in immune surveillance of UM, possibly by reducing the chance of the hematogenous dissemination [250]. Therefore, mechanisms impairing NK cell responses may be relevant in tumor escape during the metastatic progression of UM. Indeed, MIC-A/B class I-like molecules, which are ligands of the NK-activating receptor NKG2D, were found on $50 \%$ of primary UM, but not on metastatic lesions [301].

Notably, opposite to findings reported in other tumors, a high density of infiltrating lymphocytes in primary UM has been associated with a worse prognosis [302, 303]. An immunohistochemistry analysis of tumor-infiltrating lymphocytes (TILs) showed that CD8+ CTLs and, to a lesser extent, CD4+ T lymphocytes and Treg cells were present in UM inflammatory infiltrates. In this study, the presence of elevated numbers of TILs correlated with infiltrating macrophages and with chromosome 3 monosomy, which is associated with a worse prognosis [290]. Another study showed that the numbers of CD3+ T cells and CD11+ macrophages were correlated with HLA class I and class II expression, suggesting that 
low levels of HLA expression may lead to a lower inflammatory infiltrate [304]. Overall, these data indicate that the presence of an inflammatory microenvironment, rich in M2-type macrophages, $\mathrm{T}$ cells, and pro-inflammatory cytokines, may favor angiogenesis and UM progression [305].

$\mathrm{CD} 4+\mathrm{CD} 25+\mathrm{FoxP} 3+$ Treg cells are capable of suppressing Th1/CTL responses and represent a major mechanism of tumor escape in several cancers. Treg cells are present in a fraction of UM accounting for 12 or $24 \%$ of primary UM, in two different studies [306, 307]. In another study, UMinfiltrating Treg cells were associated with COX-2 expression and with worse survival. Indeed, prostaglandin E(2) (PGE(2) produced by COX-2 is an inducer of Treg cell differentiation from precursors [307].

Besides M2-type macrophages and Treg cells, it has been proposed that also PDL-1 expression by UM cells may contribute to immune suppression. UM cell lines treated with IFN- $\gamma$ express PDL-1 $[308,309]$. In addition, metastatic and primary UM cell lines upregulating PDL-1 expression upon IFN- $\gamma$ stimulation suppressed IL-2 production by Jurkat $\mathrm{T}$ cells in vitro. Either anti-PDL-1 or anti-PD-1 antibodies restored IL-2 production. Although these data indicate that expression of PDL-1 by UM cells inhibits T function in vitro, immunohistochemistry showed no PDL-1 expression in primary UM in vivo [310]. Similarly, IDO is not expressed in primary or metastatic UM, but it is inducible in UM cell lines by in vitro stimulation with IFN- $\gamma$ [311]. These findings suggest that suppressive mechanisms other than PDL-1 and IDO may dominate in the microenvironment of primary UM.

The weak immunogenic potential of UM may relate to the lower incidence of somatic mutations than those found in sunexposed skin melanomas [312]. Therefore, sun-shielded UMs may have fewer immunogenic neoepitopes encoded by mutated genes than those found in cutaneous melanoma.

Perhaps the low mutational load may explain the low response rates observed in UM patients treated with immune checkpoint-blocking mAbs. For example, a recent study on 58 patients treated in different academic institutions with antiPD-1 (pembrolizumab or nivolumab) or anti-PDL-1 mAb (atezolizumab) reported a $3.6 \%$ overall response rate, $9 \%$ of disease stabilizations, and a progression-free survival of 2.5 months [83]. Also, a phase II study of the anti-CTLA-4 $\mathrm{mAb}$ ipilimumab at $3 \mathrm{mg} / \mathrm{kg}$ dose has shown limited clinical activity in pretreated metastatic UM [75]. Another phase II study of ipilimumab at $10 \mathrm{mg} / \mathrm{kg}$ in treatment-naïve metastatic UM reported better results (10\% response rate and overall survival of 10 months) [261].

A further phase II study of the anti-PD-1 mAb pembrolizumab is ongoing (NCT02359851), and particular interest may deserve two clinical studies of the combination of the anti-PD-1 mAb nivolumab with the anti-CTLA-4 mAb ipilimumab (NCT01585194 and NCT02626962). This combination has previously shown improved effects, relative to each $\mathrm{mAb}$ alone, in metastatic cutaneous melanoma [313]. Interestingly, also patients with scarce lymphoid infiltrates and low PDL-1 expression in their tumors, a situation commonly found in UM, showed clinical benefit from this combination therapy.

Therefore, although most biological and clinical data suggest that UM is a poorly immunogenic tumor, some piece of evidence suggests that this may not always be the case. For example, a pilot study of a gp100 and tyrosinase-based dendritic cell (DC) vaccination in 14 metastatic UM patients showed a median overall survival of 19.2 months, longer than that reported in the literature [314]. In addition, recent data support the existence of an immunogenic UM subset, accounting for $46 \%$ of metastasizing UM, characterized by the absence of melanin pigmentation in the metastases, as detected by clinical MRI. These tumors showed the presence of tumor-infiltrating lymphocytes capable of mounting an efficient anti-melanoma response in vitro, suggesting that this subtype of metastatic UM may represent an optimal target for immunotherapy [315].

\section{Biomarkers}

Although less than $1 \%$ of UM patients have clinical evidence of metastasis at the time of diagnosis, about half of them bear a lifetime risk of fatal progression. Prediction of metastatic risk in UM patients may be assessed by tumor genotyping to improve the accuracy of clinical and pathological staging [166, 227]. It remains questionable if surveillance strategies for metastases development should differentially apply to patients in accordance with their risk classification after treatment of the primary tumor.

Also, it should be considered that primary UM tissue is not always available for risk assessment and no effective adjuvant therapies have been established so far. Therefore, the detection of subclinical micrometastases before they progress may allow the early recruitment of patients in clinical trials. Indeed, local therapy of a limited number of liver lesions was shown to improve survival $[57,316]$. In this respect, the identification of sensitive blood biomarkers would be particularly useful both for the early detection of metastases and to monitor the response to new therapies. Since UM metastatic spread is preponderant to the liver, liver function tests (LFTs), which are quite inexpensive and commonly used in the clinic setting, are mostly used for surveillance. A Finnish study showed a low sensitivity but high specificity of individual LFTs, with lactate dehydrogenase (LDH) being the most sensitive parameter. Notably, the authors showed that the association of LFTs with abdominal ultrasonography (USG) every 6 months would identify over $95 \%$ of asymptomatic patients [317]. However, a more recent study showed that the sensitivity and metastasis prediction value of LFTs is very poor, although normal LFTs have a negative predictive value of $90 \%$ and 
identify patients with low chance of having metastases [318]. Also, a retrospective study on a cohort of $263 \mathrm{UM}$ patients showed that only $13 \%$ of patients with USG-detectable metastasis had simultaneous abnormal LFTs [319].

In the search for better serum biomarkers, $S 100-\beta$, a reliable biomarker for monitoring $\mathrm{CM}$, was tested in UM patients but showed limited utility. Indeed, S100- $\beta$ serum levels showed no correlations with other prognostic parameters or development of metastases [320]. Another protein biomarker considered has been melanoma inhibitory activity (MIA). However, serum levels of MIA increased only after clinical detection of metastases [321, 322]. In another study, the combination of S100- $\beta$ and LDH performed better in identifying UM metastases than $\gamma$ glutamyl transpeptidase and MIA alone [323]. Elevated serum levels of MIA, S100- $\beta$, and osteopontin (OPN) correlated with liver UM metastases, and the combination of these three biomarkers enhanced the sensitivity and specificity in detecting hepatic metastases [324]. Serum levels of cytokeratin 18 (TPS) [325], insulin-like growth factor 1 (IGF1) [326], growth differentiation factor 15 (GDF15) [327], and Parkinson protein N7 (PARK7 or DJ-1) [328] are significantly more elevated in metastatic than in metastasis-free patients. An increase in VEGF on serial measurements might indicate the presence of metastases, but its value was limited by the large variability among patients [329]. We recently showed that patients with metastatic UM display significantly higher serum levels of a soluble form of the hepatocyte growth factor receptor c-Met (sc-Met) than metastasis-free patients and healthy donors. Analyses of receiver operating characteristic (ROC) curves showed that sc-Met performs better than S100- $\beta$ and LDH in the identification of UM liver metastases. Serial measurement in patients with metastatic disease showed a progressive rise of sc-Met levels whereas in disease-free patients, sc-Met levels were stable [330]. None of these biomarkers have entered into clinical practice so far. Indeed, prospective studies with a large cohort of patients are still necessary to identify biomarkers or a combination of them with a predictive value of the early development of metastases.

\subsection{Circulating tumor cells, DNA, miRNA, and exosomes}

Circulating tumor cells (CTCs) in the blood have been proposed as a prognostic biomarker, potentially useful to monitor the response to therapy in patients with metastatic carcinoma [331]. Since UM metastasizes through hematogenous dissemination, it is conceivable that detection of circulating UM cells into the blood may be useful for monitoring disease progression or response to treatment.

Different technical approaches have been used to detect or isolate UM CTCs, including immunomagnetic sorting [332], enrichment by size of tumor cells [333], or RT-PCR detection of tyrosinase and MelanA/MART1 mRNA [334]. Variable results have been reported on the prognostic value of CTC detection in UM, and comparisons among studies are difficult due to the different methodologies applied.

CTCs expressing the melanoma-associated chondroitin sulfate proteoglycan (MCSP) were isolated by immunomagnetic cell sorting in 10 of 52 patients with primary UM. The presence of CTCs showed correlation with clinical parameters of progression but not with the outcome due to the short follow-up [335]. However, a subsequent study involving 81 primary UM patients did not confirm these results. Indeed, the presence and number of CTCs isolated by the same technique showed no significant association with prognostic parameters or with metastatic progression and no therapy-related changes [336]. A recent study reported the isolation of $\mathrm{CTCs}$ by immunomagnetic sorting of CD146 (MUC18)-positive cells, which were further characterized for high molecular weight melanoma-associated antigen (MEL) expression in four of eight patients with primary, not metastatic UM whereas no CTCs were found in four choroidal nevus patient [337]. The small patient sample did not allow a correlation of CTC number and prognosis. Also, the combination of two monoclonal antibodies against a melanoma-associated glycoprotein was used for CTC immunomagnetic sorting from the blood of $31 \mathrm{UM}$ patients without metastatic disease. The presence or number of CTCs did not show a significant association with clinical prognostic factors [332]. One recent study combined the isolation of CTCs with the same technology with immuno-FISH detection of monosomy of chromosome 3 in 44 primary UM patients. Monosomy 3 was detected in intact CTCs of $58 \%$ of patients and was confirmed in the primary tumor of 10 out of 11 tested patients [338]. These results suggest that the FISH-cytogenetics of CTCs might provide useful prognostic information, particularly in UM patients not undergoing surgery or biopsy.

A different approach for identifying CTCs is based on RTPCR analysis of melanoma-associated transcripts. The presence of CTCs detected by RT-PCR of tyrosinase or MelanA/ MART1 transcripts represented an independent prognostic factor for metastases and survival, in patients with high-risk primary UM [339]. Also, in metastatic UM patients, the RT-PCR detection of CTCs resulted to be a poor prognostic factor [340].

Therefore, the prognostic value of the presence or number of CTCs in the blood of UM patients differs depending on the methods of detection and further studies are needed to better define the significance of CTCs as a biomarker in UM.

Circulating tumor DNA (ctDNA) has also been detected in different tumors and correlated with disease burden, prognosis, and response to therapy [341]. Most of the circulating free DNA (cfDNA) present in healthy individuals derives from physiologic apoptosis of hematopoietic cells. The contribution of tumor cells on the blood DNA is limited and depends on tumor burden or cell turnover [342]. Therefore, quantification of ctDNA needs to be associated with detection of a tumorspecific mutation that identifies cfDNA of tumor origin. The development of powerful sequencing techniques has 
improved the limit of detection of ctDNA copies in the total normal DNA from $10 \%$ by Sanger sequencing up to $1-2 \%$ by ultradeep sequencing [343] and $0.01 \%$ by droplet digital PCR (ddPCR) [344]. The comparative analysis of CTC detection and that of the quantification of ctDNA bearing UM-specific GNAQ/GNA11 mutations showed that both CTC and ctDNA levels were associated with the presence of miliary hepatic metastasis and with poor disease-free and overall survival. However, in multivariate analyses, ctDNA was a better prognostic marker than CTCs [345]. A clinical trial (NCT02849145) is recruiting participants to evaluate the ctDNA in the blood, before and after resection of hepatic metastasis of UM and during post-surgery follow-up.

Serum microRNA (miRNA) are also attractive biomarkers of tumor progression and response to therapy and are mostly encapsulated within vesicles of endosomal origin from 30 to $150 \mathrm{~nm}$ known as exosomes [346, 347] MicroRNA are small non-coding RNA involved in different biological processes through the regulation of gene expression at the posttranscriptional level. Two studies [348, 349] reported higher levels of miR146a in the serum of patients with primary UM than those of healthy controls, and levels were even higher in patients undergoing metastatic progression. MicroR146a is involved in NK cell function and inflammation and is upregulated by the MAPK cascade, which is activated by GNAQ/ GNA11 mutations in UM. A study investigated the presence of exosomes and their miRNA content in the liver perfusate of 12 patients with UM liver metastases. MelanA-positive exosomes were present in the liver circulation in metastatic UM, with similar miRNA profiles among patients. Also, the peripheral blood contained higher levels of exosomes compared to healthy controls [350]. Further studies with the larger number of patients are required to evaluate the role of circulating miRNA and exosomes as biomarkers for the early detection of distant metastases.

\section{Animal models}

A spontaneous UM might be the ideal animal model, provided that it would reproduce the human disease. Although rare cases of spontaneous intraocular melanomas have been reported in different animal species, including dogs [351, 352], cats [353, 354], horses [355], and cattle [356], no spontaneous UMs were reported in mice, which would represent the most convenient species. Syngeneic transplantable and transgenic models of UM allow investigating the interaction between the host immune system and the tumor. On the other hand, in vivo xenotransplantation models of human UM require immunedeficient hosts. The subcutaneous implant of patient-derived $\mathrm{UM}$ fragments (patient-derived xenografts, PDXs) is of special interest since PDXs reproduce the genetic, histopathological, and biological properties of the original human tumor.
Considering the implant of UM cell suspensions, the injection site is of crucial importance. UM cells may be orthotopically injected in the posterior or anterior chamber of the eye to better mimic primary tumor growth. Different routes of injection may be used to mimic metastatic dissemination, such as injection into the spleen, liver, tail vein, or heart. In addition, the genetic features of human UM cell lines, such as GNAQ or GNA11 mutations, chromosome 3 monosomy, BAP1 mutation, and liver tropism, should be considered.

Hence, the development of UM in vivo models of spontaneous liver metastases should be an important issue and may be helpful in the preclinical testing of new therapeutic strategies.

\subsection{Syngeneic models}

Most syngeneic models were based on the mouse cutaneous melanoma cell line $\mathrm{B} 16$ or its metastatic variant $\mathrm{B} 16 \mathrm{~F} 10$ [357, 358], mostly injected into the eye of C57BL6 mice. In addition, the subline B16LS9 has been derived by repeated in vivo passages to select for melanoma cells with metastatic tropism to the liver, to better reproduce the human metastatic disease. Intraocular injection of B16LS9 cells has been utilized as an orthotopic syngeneic model producing liver metastases [359]. The syngeneic orthotopic models have been used to study immunologic aspects of UM development such as the inhibitory effect of NK T cell-derived IL-10 on the anti-metastatic activity of NK cells [360]. A recent study showed that activation of NK cells by administration of the Toll-like receptor- 5 agonist entolimod suppressed the development of spontaneous hepatic metastases in the orthotopic B16LS9 model [361]. The growth of primary ocular tumor derived by the orthotopic implant of B16LS9 cells with the p53 activator Nutlin-3 and the topoisomerase inhibitor topotecan delayed tumor growth [362]. Although relevant information on UM derives from syngeneic models, it should be taken into account that the results obtained using B16 melanoma cells or their derivatives may not reflect the biology of the human UM. B16 cells carry a BRAF mutation that is very rare in UM.

\subsection{Xenotransplantation models}

Historically, the first xenotransplantation animal models mimicking UM were developed by implantation of hamster melanoma tissue in the anterior chamber of rabbits (Greene HS PMID: 5934903). Human xenograft models of UM have been established in immune-deficient mice [363] and rats [364], rabbits [365], and zebrafish [366]. Established primary uveal melanoma cell lines have been injected into the anterior or posterior chamber and into the ciliary body or choroid. For example, OCM1, OCM3, OCM8, EOM3, 92.1, OM431, and MEL202 were injected intracamerally into $\mathrm{nu} / \mathrm{nu} \mathrm{BALB} / \mathrm{c}$ (H-2d) mice [367]. In this study, OCM1 and 92.1 cells gave 
rise to liver metastasis at day 50 with an incidence of $80 \%$. However, the OCM1 cell line harbors the BRAF V600E mutation typical of CM, while it is wild type for GNAQ, GNA11, and BAP1. Differently, 92.1 cell bears the GNAQ Q209L driver mutation, but is wild type for the BAP1 gene. In addition, both cell lines are disomic for chromosome 3 and therefore lack the main features of UM at high metastatic risk.

Patients with ciliary body or choroid melanomas have metastasis with higher frequency and have a worse prognosis. To mimic this situation, MEL290 UM cells, transduced by lentiviral EGFP encoding for a fluorescent protein, were injected into the posterior chamber of the eye of nu/nu mice. This approach led to micrometastasis development into the liver at 4-6 weeks after transplantation with an incidence of $100 \%$ [368]. Moreover, more liver micrometastases developed in the intraocular model than in the tail injection model.

Orthotopic xenograft models have been used for the preclinical assessment of new treatments [369-371]. For example, the UM cell line OMM1.3, bearing a GNAQ Q209P mutation, retro-orbitally injected into $\mathrm{nu} / \mathrm{nu}$ mice developed liver metastases 9 weeks post injection. In this model, treatment with the c-Met/ALK tyrosine kinase inhibitor crizotinib prevented liver metastasis development without blocking ocular tumor growth [98]. These data point out to an important role of the HGF/c-Met axis in metastatic spreading of UM to the liver.

The majority of human metastatic UM has chromosome 3 loss and BAP1 mutation; however, xenograft models using monosomic human UM cells have not been developed so far. Surprisingly, OCM1A, 92.1, and Mel290 cell lines, silenced for the expression of BAP1, gave rise to smaller tumors or developed fewer metastases than BAP1 WT cells when injected subcutaneously or intravenously, respectively [209].

Pseudo-metastatic xenotransplantation models of UM have also been obtained by intracardiac or tail vein injection [368, $372]$ or by implant into the liver $[325,373]$ or spleen $[89,374$, 375]. Spleen transplantation allows UM cells to reach and colonize the liver through the portal circulation. It has been used as a pseudo-metastatic model to evaluate treatment, mechanisms of metastasis, or UM biomarkers [89, 330, 376-378]. For example, preliminary detection of human-soluble sc-Met in the serum of UM xenograft led to the identification of this molecule as a potential biomarker of metastases in UM patients [330]. The human GNAQ-mutated UM cell line TJU-UM001, transplanted under the spleen capsule of NSG mice, developed multiple hepatic metastases whereas lung metastases were not observed. Interestingly, a laminin-rich vasculogenic mimicry pattern was seen in the hepatic lesions similar to that observed in primary and metastatic human UMs [379].

PDXs were generated from primary or metastatic UM tissues to propagate tumors in vivo, for pathogenesis and preclinical therapy studies. Transplantation of UM fragments into the subcutis or the interscapular fat pad of nu/nu [380] or SCID [381] mice yielded a low take rate. Tumor takes were significantly higher when implanted fragments were derived from metastases as compared to those derived from primary tumors (52.9\%). Interestingly, engraftment of metastatic tumors was predictive of a short overall survival of metastatic patients. In addition, xenograft growth of primary tumors inversely correlated with 5-year metastasis-free survival [381]. The comparison of serial UM xenografts to the original tumor showed that xenografts are genetically stable over in vivo passages and maintain the genetics features of the original human UM [382]. Despite the limits of a low rate of engraftment and growth delay after initial transplantation, panels of UM PDXs have been employed to test combinations of targeted therapies [383, 384].

Human UM cell line xenografts have also been developed in rabbits which bear larger eyes than mice and are therefore more suitable for examination and surgical procedures, upon immunosuppression with cyclosporine-A. However, in these models, most of the metastases were found in the lungs and rarely in the liver [385-387].

Injection of human UM cell lines into the chick embryo, which lacks an immune system till days 10-15, has also been used as an easily accessible and economical xenograft model [388, 222]. Preliminary data of the chick embryo metastasis model show that OMM1 and 92.1 cells injected into the circulation of 7-day embryos mostly colonize tissues of neural crest derivation [389].

Recently, human UM xenotransplantation models were established in zebrafish using cell lines derived from primary UM or metastatic UM expressing a red fluorescent protein. This model was suitable to test the efficacy of different experimental anticancer drugs (e.g., quisinostat and the neddylation [ubiquitin-like protein NEDD8 conjugation to target proteins] pathway inhibitor MLN-4924) which repressed the migration and proliferation of UM cells. As the drugs were dissolved in the water, the rate of drug absorbance into zebrafish embryos needs a better characterization [390].

\subsection{Transgenic mouse models}

Transgenic animals, which constitutively express an oncogene, represent a useful tool for the study of tumorigenesis in vivo and to explore tumor-host interactions in the tumor microenvironment [391]. Several transgenic mouse models of $\mathrm{CM}$, which resemble the biological features of the human disease, also develop a choroidal melanoma, although they do not bear mutations typical of human UM [265]. Very recent studies exploited the activated GNAQ oncogene, which is found in a significant fraction of human UM, to develop transgenic UM models.

One of the earliest CM models has been the MT-ret transgenic mice, which express the human RET oncogene 
controlled by the mouse metallothionein I promoter-enhancer. These mice develop hyperplastic and tumoral lesions in different melanocyte-containing tissues [392]. Although Ret kinase mutations have not been found in human melanomas, the RET oncogene stimulates the downstream MAP kinase pathways, which are typical of melanoma [393] and may explain melanoma formation, in the transgenic mice. These mice also develop UM as an early event, revealed by exophthalmos [392]. MT-ret transgenic mice were also crossed with ADD transgenic mice, which express the chimeric MHC molecule AAD (HLA-A2/H2-Dd). These MT-ret/AAD mice are suitable for analyzing CD8+ $T$ cell responses directed against immunogenic antigens found in HLA-A2+ melanoma patients [394]. This model allowed establishing the pro-metastatic effects of macrophages, which could be abrogated by treatment with the CSF-1R-specific kinase inhibitor Ki20227 [266]. In another study, the effect of the pro-inflammatory and autoimmune background of the non-obese diabetic (NOD) strain was assessed by back-crossing MT-ret with NOD mice, which resulted in rapid UM development. Dectin-1 expression was reduced in granulocytic myeloid cells in relationship with an increase of regulatory $\mathrm{T}$ cells and that of IFN- $\gamma$-producing $\mathrm{CD} 8+\mathrm{T}$ cells in tumors. IFN- $\gamma$-inducible nitric oxide synthase (Nos2) was involved in inflammation and accelerated tumorigenesis. These data point to a role of inflammation in UM development and to dectin- 1 and Nos 2 as potential therapeutic targets [395].

Mice bearing targeted deletions of oncosuppressor genes can be generated to mimic a cancer-prone condition. These mice can be eventually crossed with transgenic mice bearing active oncogenes to enhance the oncogenic effect of the transgene. This is the case of spontaneous malignant melanomas occurring in male Tyr-RAS+ Ink4a/Arf-/- transgenic mice. In these mice, a human tyrosinase enhancer/promoter element drives melanocyte-specific expression of a human activated $\mathrm{H}$-ras gene integrated into the $\mathrm{Y}$ chromosome. Such transgenic mice crossed in an Ink4a/Arf-deficient background (TyrRAS+ Ink4a/Arf-/-) develop CM and UM, in males [396]. These UMs showed epithelioid- and spindle-shaped features and local invasiveness resembling the human counterpart but no metastatic progression [397].

In $\operatorname{Tg}(\mathrm{Grm} 1) \mathrm{EPv}$ transgenic mice, the metabotropic glutamate receptor 1 ( $\mathrm{Grm} 1)$ gene is under the control of the dopachrome tautomerase (Dct, Trp2) promoter, specifically expressed in melanocytes [398]. These mice develop melanomas, in the hairless skin of ear, tail, and anus, and also develop choroidal hyperplastic lesions and UM-like tumors. Furthermore, GRM1 is expressed in human uveal and skin melanoma, suggesting that the glutamate signaling pathway is a possible target for UM therapy [399].

Recently, the first transgenic mouse model, reproducing genetic defects of human UM, has been developed. A transgenic mouse strain, expressing oncogenic GNAQ(Q209L) under control of the Rosa26 promoter, showed not only UM but also dermal nevi and other melanocytic tumors of the central nervous system [400]. In this model, the Yap protein was activated in the eyes, and uveal blood vessels showed melanocytic invasion. However, most of these mice developed metastases only in the lungs. This model is the first transgenic mouse model using a relevant oncogene of human UM and may represent a tool for testing new targeted therapies in vivo.

A transgenic model of spontaneous UM was also established in zebrafish, engineered to express oncogenic GNAQ(Q209P) in the melanocyte lineage. These zebrafishes display hyperplasia of uveal melanocytes, but no evidence of tumor progression. However, the combined expression of GNAQ(Q209P) with p53 oncosuppressor inactivation mediated an earlier onset of hyperplastic lesions that evolved in UM. A weak phosphorylation of ERK1/2 was observed in transgenic UM, while staining for nuclear YAP was evident. Therefore, enhanced ERK1/2 signaling seems not a major feature of GNAQ(Q209P)-driven transgenic UM [401].

Recently, cells from a genetically modified mouse strain were used to identify new potential targets for UM. Ric-8A is a molecular chaperone that folds GNAQ and GNA11 subunits and may therefore serve as a target to reduce the abundance of these oncoproteins in UM. Melanocytes obtained from a conditional Ric-8AFlox/Flox; Rosa-CreER+/- mouse strain transduced with the human GNAQQ209L showed autonomous cell proliferation in vitro and, upon grafting in mice, developed melanoma tumors. Deletion of Ric-8A in GNAQ Q209L-transduced cells by tamoxifen reduced G $\alpha$ q-Q209L levels and prevented tumorigenesis in vivo. Also, phorbol ester (TPA) treatment inhibited GNAQ Q209L cell proliferation in vitro and in vivo. The authors propose Ric-8A inhibition or phorbol esters as novel potential treatments of UM [402].

\section{Conclusions}

The last years have brought a dramatic progress of our understanding of UM. The evolution of this rare cancer is now described in considerable detail in terms of cytogenetic, genetic, and transcriptional alterations as well as the signaling pathways involved in the formation of UM and its progression to metastasis. We still have a limited understanding of several central aspects of the disease:

- The etiology of UM

- The ontogenetic cellular origin of UM and its precursor cells

- The role in metastasis of chromosome 3 monosomy as opposed to losses of single regions of the same chromosome

- The molecular basis of the effects of minor cytogenetic alterations $(6 p, 1 p)$ 
- The precise way of action of BAP1

- Metastatic players in BAP1/SF3B1 wild-type metastatic UM

- The role of epigenetic alterations

- The determinants of the liver tropism of UM metastases.

Most importantly, our understanding has so far not led to a sensible improvement in survival of patients with metastatic UM. Research should therefore be focused on the translation of the mechanistic understanding of the disease into proposals for clinical trials using drugs that are targeted at UM-specific molecular alterations. This should hopefully lead to an increase in survival of metastatic patients similar to what has recently been observed for $\mathrm{CM}$ patients.

Acknowledgements Our work is generously supported by the Associazione Italiana per la Ricerca sul Cancro (AIRC, IG 17103) to UP.

Open Access This article is distributed under the terms of the Creative Commons Attribution 4.0 International License (http:// creativecommons.org/licenses/by/4.0/), which permits unrestricted use, distribution, and reproduction in any medium, provided you give appropriate credit to the original author(s) and the source, provide a link to the Creative Commons license, and indicate if changes were made.

\section{References}

1. Chang, A. E., Karnell, L. H., \& Menck, H. R. (1998). The National Cancer Data Base report on cutaneous and noncutaneous melanoma: a summary of 84,836 cases from the past decade. The American College of Surgeons Commission on Cancer and the American Cancer Society. Cancer, 83(8), 1664-1678.

2. Kusters-Vandevelde, H. V., Kusters, B., van Engen-van Grunsven, A. C., Groenen, P. J., Wesseling, P., \& Blokx, W. A. (2015). Primary melanocytic tumors of the central nervous system: a review with focus on molecular aspects. Brain Pathology, 25(2), 209-226. doi:10.1111/bpa.12241.

3. Griewank, K. G., Westekemper, H., Murali, R., Mach, M., Schilling, B., Wiesner, T., et al. (2013). Conjunctival melanomas harbor BRAF and NRAS mutations and copy number changes similar to cutaneous and mucosal melanomas. Clinical Cancer Research, 19, 3143-3152. doi:10.1158/1078-0432.CCR-13-0163.

4. Gear, H., Williams, H., Kemp, E. G., \& Roberts, F. (2004). BRAF mutations in conjunctival melanoma. Investigative Ophthalmology \& Visual Science, 45(8), 2484-2488. doi:10. 1167/iovs.04-0093.

5. Singh, A. D., \& Topham, A. (2003). Incidence of uveal melanoma in the United States: 1973-1997. Ophthalmology, 110(5), 956961. doi:10.1016/S0161-6420(03)00078-2.

6. Hu, D. N., Yu, G. P., McCormick, S. A., Schneider, S., \& Finger, P. T. (2005). Population-based incidence of uveal melanoma in various races and ethnic groups. American Journal of Ophthalmology, 140(4), 612-617. doi:10.1016/j.ajo.2005.05.034.

7. Shields, C. L., Kaliki, S., Cohen, M. N., Shields, P. W., Furuta, M., \& Shields, J. A. (2015). Prognosis of uveal melanoma based on race in 8100 patients: the 2015 Doyne lecture. Eye (London, England), 29(8), 1027-1035. doi:10.1038/eye.2015.51.
8. Virgili, G., Gatta, G., Ciccolallo, L., Capocaccia, R., Biggeri, A., Crocetti, E., et al. (2007). Incidence of uveal melanoma in Europe. Ophthalmology, 114(12), 2309-2315. doi:10.1016/j. ophtha.2007.01.032.

9. Yu, G. P., Hu, D. N., \& McCormick, S. A. (2006). Latitude and incidence of ocular melanoma. Photochemistry and Photobiology, 82(6), 1621-1626. doi:10.1562/2006-07-17-RA-970.

10. Andreoli, M. T., Mieler, W. F., \& Leiderman, Y. I. (2015). Epidemiological trends in uveal melanoma. The British Journal of Ophthalmology, 99(11), 1550-1553. doi:10.1136/ bjophthalmol-2015-306810.

11. Virgili, G., Gatta, G., Ciccolallo, L., Capocaccia, R., Biggeri, A., Crocetti, E., et al. (2008). Survival in patients with uveal melanoma in Europe. Archives of Ophthalmology, 126(10), 1413-1418. doi:10.1001/archopht.126.10.1413.

12. Singh, A. D., Turell, M. E., \& Topham, A. K. (2011). Uveal melanoma: trends in incidence, treatment, and survival. Ophthalmology, 118(9), 1881-1885. doi:10.1016/j.ophtha.2011.01.040.

13. Chew, A. L., Spilsbury, K., \& Isaacs, T. W. (2015). Survival from uveal melanoma in Western Australia 1981-2005. Clinical \& Experimental Ophthalmology, 43(5), 422-428. doi:10.1111/ceo.12490.

14. De Angelis, R., Sant, M., Coleman, M. P., Francisci, S., Baili, P., Pierannunzio, D., et al. (2014). Cancer survival in Europe 19992007 by country and age: results of EUROCARE-5-a population-based study. The Lancet Oncology, 15(1), 23-34. doi:10.1016/S1470-2045(13)70546-1.

15. Siegel, R. L., Miller, K. D., \& Jemal, A. (2016). Cancer statistics, 2016. CA: a Cancer Journal for Clinicians, 66(1), 7-30. doi:10. 3322/caac. 21332.

16. Gandini, S., Sera, F., Cattaruzza, M. S., Pasquini, P., Picconi, O., Boyle, P., et al. (2005). Meta-analysis of risk factors for cutaneous melanoma: II. Sun exposure. Eur J Cancer, 41(1), 45-60. doi:10. 1016/j.ejca.2004.10.016.

17. Mallet, J. D., Gendron, S. P., Drigeard Desgarnier, M. C., \& Rochette, P. J. (2013). Implication of ultraviolet light in the etiology of uveal melanoma: a review. Photochemistry and Photobiology, 90(1), 15-21. doi:10.1111/php.12161.

18. Balazs, E. A. (1954). Studies on the structure of the vitreous body. I. The absorption of ultraviolet light. American Journal of Ophthalmology, 38(1:2), 21-28.

19. Los, L. I., van der Worp, R. J., van Luyn, M. J., \& Hooymans, J. M. (2003). Age-related liquefaction of the human vitreous body: LM and TEM evaluation of the role of proteoglycans and collagen. Investigative Ophthalmology \& Visual Science, 44(7), 2828-2833.

20. Gallagher, R. P., Elwood, J. M., Rootman, J., Spinelli, J. J., Hill, G. B., Threlfall, W. J., et al. (1985). Risk factors for ocular melanoma: Western Canada Melanoma Study. [Research support, non-U.S. Gov't]. Journal of the National Cancer Institute, 74(4), 775-778.

21. Holly, E. A., Aston, D. A., Char, D. H., Kristiansen, J. J., \& Ahn, D. K. (1990). Uveal melanoma in relation to ultraviolet light exposure and host factors. Cancer Research, 50(18), 5773-5777.

22. Vajdic, C. M., Kricker, A., Giblin, M., McKenzie, J., Aitken, J., Giles, G. G., et al. (2002). Sun exposure predicts risk of ocular melanoma in Australia. International Journal of Cancer, 101(2), 175-182. doi:10.1002/ijc.10579.

23. Shah, C. P., Weis, E., Lajous, M., Shields, J. A., \& Shields, C. L. (2005). Intermittent and chronic ultraviolet light exposure and uveal melanoma: a meta-analysis. Ophthalmology, 112(9), 1599 1607. doi:10.1016/j.ophtha.2005.04.020.

24. Gandini, S., Boniol, M., Haukka, J., Byrnes, G., Cox, B., Sneyd, M. J., et al. (2011). Meta-analysis of observational studies of serum 25-hydroxyvitamin D levels and colorectal, breast and prostate cancer and colorectal adenoma. International Journal of Cancer, 128(6), 1414-1424. doi:10.1002/ijc.25439. 
25. Logan, P., Bernabeu, M., Ferreira, A., \& Burnier Jr., M. N. (2015). Evidence for the role of blue light in the development of uveal melanoma. Journal of Ophthalmology, 2015, 386986. doi:10. 1155/2015/386986.

26. Ferguson, R., Vogelsang, M., Ucisik-Akkaya, E., Rai, K., Pilarski, R., Martinez, C. N., et al. (2016). Genetic markers of pigmentation are novel risk loci for uveal melanoma. Scientific Reports, 6 , 31191. doi:10.1038/srep31191.

27. Van Raamsdonk, C. D., Bezrookove, V., Green, G., Bauer, J., Gaugler, L., O’Brien, J. M., et al. (2009). Frequent somatic mutations of GNAQ in uveal melanoma and blue naevi. Nature, 457(7229), 599-602. doi:10.1038/nature07586.

28. Van Raamsdonk, C. D., Griewank, K. G., Crosby, M. B., Garrido, M. C., Vemula, S., Wiesner, T., et al. (2010). Mutations in GNA11 in uveal melanoma. The New England Journal of Medicine, 363(23), 2191-2199. doi:10.1056/NEJMoa1000584.

29. Van Raamsdonk, C. D., Fitch, K. R., Fuchs, H., de Angelis, M. H., \& Barsh, G. S. (2004). Effects of G-protein mutations on skin color. Nature Genetics, 36(9), 961-968. doi:10.1038/ng1412.

30. Martin, M., Masshofer, L., Temming, P., Rahmann, S., Metz, C., Bornfeld, N., et al. (2013). Exome sequencing identifies recurrent somatic mutations in EIF1AX and SF3B1 in uveal melanoma with disomy 3. Nature Genetics, 45(8), 933-936. doi:10.1038/ng.2674.

31. Luscan, A., Just, P. A., Briand, A., Burin des Roziers, C., Goussard, P., Nitschke, P., et al. (2015). Uveal melanoma hepatic metastases mutation spectrum analysis using targeted nextgeneration sequencing of 400 cancer genes. The British Journal of Ophthalmology, 99(4), 437-439. doi:10.1136/bjophthalmol2014-305371.

32. Harbour, J. W., Roberson, E. D., Anbunathan, H., Onken, M. D., Worley, L. A., \& Bowcock, A. M. (2013). Recurrent mutations at codon 625 of the splicing factor SF3B1 in uveal melanoma. [Research support, N.I.H., extramural research support, non-U.S. Gov't]. Nature Genetics, 45(2), 133-135. doi:10.1038/ng.2523.

33. Horn, S., Figl, A., Rachakonda, P. S., Fischer, C., Sucker, A., Gast, A., et al. (2013). TERT promoter mutations in familial and sporadic melanoma. [Research support, non-U.S. Gov't]. Science, 339(6122), 959-961. doi:10.1126/science.1230062.

34. Huang, F. W., Hodis, E., Xu, M. J., Kryukov, G. V., Chin, L., \& Garraway, L. A. (2013). Highly recurrent TERT promoter mutations in human melanoma. [Research support, N.I.H., extramural research support, non-U.S. Gov't]. Science, 339(6122), 957-959. doi:10.1126/science.1229259.

35. Dono, M., Angelini, G., Cecconi, M., Amaro, A., Esposito, A. I., Mirisola, V., et al. (2014). Mutation frequencies of GNAQ, GNA11, BAP1, SF3B1, EIF1AX and TERT in uveal melanoma: detection of an activating mutation in the TERT gene promoter in a single case of uveal melanoma. British Journal of Cancer, 110(4), 1058-1065. doi:10.1038/bjc.2013.804.

36. Griewank, K. G., Murali, R., Schilling, B., Scholz, S., Sucker, A., Song, M., et al. (2013). TERT promoter mutations in ocular melanoma distinguish between conjunctival and uveal tumours. British Journal of Cancer, 109(2), 497-501. doi:10.1038/bjc. 2013.312.

37. Koopmans, A. E., Ober, K., Dubbink, H. J., Paridaens, D., Naus, N. C., Belunek, S., et al. (2014). Prevalence and implications of TERT promoter mutation in uveal and conjunctival melanoma and in benign and premalignant conjunctival melanocytic lesions. Investigative Ophthalmology \& Visual Science, 55(9), 60246030. doi:10.1167/iovs.14-14901.

38. Damato, B. (2001). Detection of uveal melanoma by optometrists in the United Kingdom. Ophthalmic \& Physiological Optics, 21(4), 268-271.

39. Eskelin, S., \& Kivela, T. (2002). Mode of presentation and time to treatment of uveal melanoma in Finland. The British Journal of Ophthalmology, 86(3), 333-338.
40. Bedi, D. G., Gombos, D. S., Ng, C. S., \& Singh, S. (2006). Sonography of the eye. AJR. American Journal of Roentgenology, 187(4), 1061-1072. doi:10.2214/AJR.04.1842.

41. Accuracy of diagnosis of choroidal melanomas in the collaborative ocular melanoma study: Coms report no. 1 (1990). Archives of Ophthalmology, 108(9), 1268-1273, doi:10.1001/archopht.1990. 01070110084030.

42. Nathan, P., Cohen, V., Coupland, S., Curtis, K., Damato, B., Evans, J., et al. (2015). Uveal melanoma UK national guidelines. European Journal of Cancer, 51(16), 2404-2412. doi:10.1016/j. ejca.2015.07.013.

43. Damato, B. E., Heimann, H., Kalirai, H., \& Coupland, S. E. (2014). Age, survival predictors, and metastatic death in patients with choroidal melanoma: tentative evidence of a therapeutic effect on survival. JAMA Ophthalmol, 132(5), 605-613. doi:10. 1001/jamaophthalmol.2014.77.

44. Blasi, M. A., Laguardia, M., Tagliaferri, L., Scupola, A., Villano, A., Caputo, C. G., et al. (2016). Brachytherapy alone or with neoadjuvant photodynamic therapy for amelanotic choroidal melanoma: functional outcomes and local tumor control. Retina. doi: 10.1097/IAE.0000000000001048.

45. Seibel, I., Cordini, D., Rehak, M., Hager, A., Riechardt, A. I., Boker, A., et al. (2015). Local recurrence after primary proton beam therapy in uveal melanoma: risk factors, retreatment approaches, and outcome. American Journal of Ophthalmology, 160(4), 628-636. doi:10.1016/j.ajo.2015.06.017.

46. Munzenrider, J. E., Verhey, L. J., Gragoudas, E. S., Seddon, J. M., Urie, M., Gentry, R., et al. (1989). Conservative treatment of uveal melanoma: local recurrence after proton beam therapy. International Journal of Radiation Oncology, Biology, Physics, 17(3), 493-498. doi:10.1016/0360-3016(89)90099-0.

47. Force, O. O. T. (2015). Local recurrence significantly increases the risk of metastatic uveal melanoma. Ophthalmology, 123(1), 8691. doi:10.1016/j.ophtha.2015.09.014.

48. Harbour, J. W., Char, D. H., Kroll, S., Quivey, J. M., \& Castro, J. (1997). Metastatic risk for distinct patterns of postirradiation local recurrence of posterior uveal melanoma. Ophthalmology, 104(11), 1785-1792 discussion 1792-1783. doi:10.1016/S0161-6420(97)30025-6.

49. Diener-West, M., Reynolds, S. M., Agugliaro, D. J., Caldwell, R., Cumming, K., Earle, J. D., et al. (2005). Development of metastatic disease after enrollment in the COMS trials for treatment of choroidal melanoma: collaborative ocular melanoma study group report no. 26. Archives of Ophthalmology, 123(12), 1639-1643. doi:10.1001/archopht.123.12.1639.

50. Kujala, E., Makitie, T., \& Kivela, T. (2003). Very long-term prognosis of patients with malignant uveal melanoma. Investigative Ophthalmology \& Visual Science, 44(11), 4651-4659.

51. Rietschel, P., Panageas, K. S., Hanlon, C., Patel, A., Abramson, D. H., \& Chapman, P. B. (2005). Variates of survival in metastatic uveal melanoma. Journal of Clinical Oncology, 23(31), 80768080. doi:10.1200/JCO.2005.02.6534.

52. Damato, B. (2010). Does ocular treatment of uveal melanoma influence survival? British Journal of Cancer, 103(3), 285-290. doi:10.1038/sj.bjc.6605765.

53. Hope-Stone, L., Brown, S. L., Heimann, H., Damato, B., \& Salmon, P. (2016). Two-year patient-reported outcomes following treatment of uveal melanoma. Eye (London, England). doi:10. 1038/eye.2016.188.

54. Gragoudas, E. S., Egan, K. M., Seddon, J. M., Glynn, R. J., Walsh, S. M., Finn, S. M., et al. (1991). Survival of patients with metastases from uveal melanoma. Ophthalmology, 98(3), 383-389 discussion 390 .

55. Singh, A. D., \& Borden, E. C. (2005). Metastatic uveal melanoma. Ophthalmology Clinics of North America, 18(1), 143-150 ix. doi: 10.1016/j.ohc.2004.07.003. 
56. Mariani, P., Piperno-Neumann, S., Servois, V., Berry, M. G., Dorval, T., Plancher, C., et al. (2009). Surgical management of liver metastases from uveal melanoma: 16 years' experience at the Institut Curie. European Journal of Surgical Oncology, 35(11), 1192-1197. doi:10.1016/j.ejso.2009.02.016.

57. Frenkel, S., Nir, I., Hendler, K., Lotem, M., Eid, A., Jurim, O., et al. (2009). Long-term survival of uveal melanoma patients after surgery for liver metastases. The British Journal of Ophthalmology, 93(8), 1042-1046. doi:10.1136/bjo.2008. 153684.

58. Rivoire, M., Kodjikian, L., Baldo, S., Kaemmerlen, P., Negrier, S., \& Grange, J. D. (2005). Treatment of liver metastases from uveal melanoma. Annals of Surgical Oncology, 12(6), 422-428. doi:10. 1245/ASO.2005.06.032.

59. Aoyama, T., Mastrangelo, M. J., Berd, D., Nathan, F. E., Shields, C. L., Shields, J. A., et al. (2000). Protracted survival after resection of metastatic uveal melanoma. Cancer, 89(7), 1561-1568. doi:10.1002/1097-0142(20001001)89:7<1561::AIDCNCR21>3.0.CO;2-R.

60. Pawlik, T. M., Zorzi, D., Abdalla, E. K., Clary, B. M., Gershenwald, J. E., Ross, M. I., et al. (2006). Hepatic resection for metastatic melanoma: distinct patterns of recurrence and prognosis for ocular versus cutaneous disease. Annals of Surgical Oncology, 13(5), 712-720. doi:10.1245/ASO.2006.01.016.

61. Leyvraz, S., Piperno-Neumann, S., Suciu, S., Baurain, J. F., Zdzienicki, M., Testori, A., et al. (2014). Hepatic intra-arterial versus intravenous fotemustine in patients with liver metastases from uveal melanoma (EORTC 18021): a multicentric randomized trial. Annals of Oncology, 25(3), 742-746. doi:10.1093/ annonc/mdt585.

62. Olofsson, R., Ny, L., Eilard, M. S., Rizell, M., Cahlin, C., Stierner, U., et al. (2014). Isolated hepatic perfusion as a treatment for uveal melanoma liver metastases (the SCANDIUM trial): study protocol for a randomized controlled trial. Trials, 15(1), 317. doi:10.1186/ 1745-6215-15-317.

63. Leyvraz, S., Spataro, V., Bauer, J., Pampallona, S., Salmon, R., Dorval, T., et al. (1997). Treatment of ocular melanoma metastatic to the liver by hepatic arterial chemotherapy. Journal of Clinical Oncology, 15(7), 2589-2595.

64. Alexander Jr., H. R., Libutti, S. K., Pingpank, J. F., Steinberg, S. M., Bartlett, D. L., Helsabeck, C., et al. (2003). Hyperthermic isolated hepatic perfusion using melphalan for patients with ocular melanoma metastatic to liver. Clinical Cancer Research, 9(17), 6343-6349.

65. Goh, A. Y., \& Layton, C. J. (2016). Evolving systemic targeted therapy strategies in uveal melanoma and implications for ophthalmic management: a review. Clinical \& Experimental Ophthalmology, 44(6), 509-519. doi:10.1111/ceo.12688.

66. Carvajal, R. D., Schwartz, G. K., Tezel, T., Marr, B., Francis, J. H., \& Nathan, P. D. (2016). Metastatic disease from uveal melanoma: treatment options and future prospects. British Journal of Ophthalmology. doi:10.1136/bjophthalmol-2016-309034.

67. Carvajal, R. D., Sosman, J. A., Quevedo, J. F., Milhem, M. M., Joshua, A. M., Kudchadkar, R. R., et al. (2014). Effect of selumetinib vs chemotherapy on progression-free survival in uveal melanoma: a randomized clinical trial. JAMA: The Journal of the American Medical Association, 311(23), 2397-2405. doi:10. 1001/jama.2014.6096.

68. https://www.astrazeneca.com/media-centre/press-releases/2015/ astrazeneca-selumetinib-uveal-melanoma-oncology-22072015. html. (Accessed on 16 August 2016).

69. Carvajal, R. D., Schwartz, G. K., Mann, H., Smith, I., \& Nathan, P. D. (2015). Study design and rationale for a randomised, placebocontrolled, double-blind study to assess the efficacy of selumetinib (AZD6244; ARRY-142886) in combination with dacarbazine in patients with metastatic uveal melanoma (SUMIT). BMC Cancer, 15, 467. doi:10.1186/s12885-015-1470-z.

70. Piperno-Neumann, S., Diallo, A., Etienne-Grimaldi, M. C., Bidard, F. C., Rodrigues, M., Plancher, C., et al. (2016). Phase II trial of bevacizumab in combination with temozolomide as first-line treatment in patients with metastatic uveal melanoma. The Oncologist, 21(3), 281-282. doi:10.1634/theoncologist.2015-0501.

71. Mahipal, A., Tijani, L., Chan, K., Laudadio, M., Mastrangelo, M. J., \& Sato, T. (2012). A pilot study of sunitinib malate in patients with metastatic uveal melanoma. Melanoma Research, 22(6), 440-446. doi:10.1097/CMR.0b013e328358b373.

72. Moser, J. C., Pulido, J. S., Dronca, R. S., McWilliams, R. R., Markovic, S. N., \& Mansfield, A. S. (2015). The Mayo Clinic experience with the use of kinase inhibitors, ipilimumab, bevacizumab, and local therapies in the treatment of metastatic uveal melanoma. Melanoma Research, 25(1), 59-63. doi:10. 1097/cmr.0000000000000125.

73. Topalian, S. L., Taube, J. M., Anders, R. A., \& Pardoll, D. M. (2016). Mechanism-driven biomarkers to guide immune checkpoint blockade in cancer therapy. Nature Reviews. Cancer, 16(5), 275-287. doi:10.1038/nrc.2016.36.

74. Karydis, I., Chan, P. Y., Wheater, M., Arriola, E., Szlosarek, P. W., \& Ottensmeier, C. H. (2016). Clinical activity and safety of pembrolizumab in ipilimumab pre-treated patients with uveal melanoma. Oncoimmunology, 5(5), e1143997. doi:10.1080/ 2162402X.2016.1143997.

75. Zimmer, L., Vaubel, J., Mohr, P., Hauschild, A., Utikal, J., Simon, J., et al. (2015). Phase II DeCOG-study of ipilimumab in pretreated and treatment-naive patients with metastatic uveal melanoma. PloS One, 10(3), e0118564. doi:10.1371/journal.pone.0118564.

76. Moser, J. C., Pulido, J. S., Dronca, R. S., McWilliams, R. R., Markovic, S. N., \& Mansfield, A. S. (2015). The Mayo Clinic experience with the use of kinase inhibitors, ipilimumab, bevacizumab, and local therapies in the treatment of metastatic uveal melanoma. Melanoma Research, 25(1), 59-63. doi:10. 1097/CMR.0000000000000125.

77. Alexander, M., Mellor, J. D., McArthur, G., \& Kee, D. (2014). Ipilimumab in pretreated patients with unresectable or metastatic cutaneous, uveal and mucosal melanoma. The Medical Journal of Australia, 201(1), 49-53. doi:10.5694/mja13.10448.

78. Maio, M., Danielli, R., Chiarion-Sileni, V., Pigozzo, J., Parmiani, G., Ridolfi, R., et al. (2013). Efficacy and safety of ipilimumab in patients with pre-treated, uveal melanoma. Annals of Oncology, 24(11), 2911-2915. doi:10.1093/annonc/mdt376.

79. Luke, J. J., Callahan, M. K., Postow, M. A., Romano, E., Ramaiya, N., Bluth, M., et al. (2013). Clinical activity of ipilimumab for metastatic uveal melanoma: a retrospective review of the Dana-Farber Cancer Institute, Massachusetts General Hospital, Memorial Sloan-Kettering Cancer Center, and University Hospital of Lausanne experience. Cancer, 119(20), 3687-3695. doi:10.1002/cncr.28282.

80. Khattak, M. A., Fisher, R., Hughes, P., Gore, M., \& Larkin, J. (2013). Ipilimumab activity in advanced uveal melanoma. Melanoma Research, 23(1), 79-81. doi:10.1097/CMR. 0b013e32835b554f.

81. Kelderman, S., van der Kooij, M. K., van den Eertwegh, A. J., Soetekouw, P. M., Jansen, R. L., van den Brom, R. R., et al. (2013). Ipilimumab in pretreated metastastic uveal melanoma patients. results of the Dutch working group on immunotherapy of oncology (WIN-O). Acta Oncologica, 52(8), 1786-1788. doi:10. 3109/0284186X.2013.786839.

82. Danielli, R., Ridolfi, R., Chiarion-Sileni, V., Queirolo, P., Testori, A., Plummer, R., et al. (2012). Ipilimumab in pretreated patients with metastatic uveal melanoma: safety and clinical efficacy. [Research 
support, non-U.S. Gov't]. Cancer Immunology, Immunotherapy: CII, 61(1), 41-48. doi:10.1007/s00262-011-1089-0.

83. Algazi, A. P., Tsai, K. K., Shoushtari, A. N., Munhoz, R. R., Eroglu, Z., Piulats, J. M., et al. (2016). Clinical outcomes in metastatic uveal melanoma treated with PD-1 and PD-L1 antibodies. Cancer. doi:10.1002/cncr.30258.

84. Naing, A., Papadopoulos, K. P., Autio, K. A., Ott, P. A., Patel, M. R., Wong, D. J., et al. (2016). Safety, antitumor activity, and immune activation of pegylated recombinant human interleukin-10 (AM0010) in patients with advanced solid tumors. Journal of Clinical Oncology. doi:10.1200/jco.2016.68.1106.

85. Amaro, A., Mirisola, V., Angelini, G., Musso, A., Tosetti, F., Esposito, A. I., et al. (2013). Evidence of epidermal growth factor receptor expression in uveal melanoma: inhibition of epidermal growth factor-mediated signalling by gefitinib and cetuximab triggered antibody-dependent cellular cytotoxicity. European Journal of Cancer, 49(15), 3353-3365. doi:10.1016/j.ejca.2013.06.011.

86. Wu, X., Zhou, J., Rogers, A. M., Janne, P. A., Benedettini, E., Loda, M., et al. (2012). c-Met, epidermal growth factor receptor, and insulin-like growth factor-1 receptor are important for growth in uveal melanoma and independently contribute to migration and metastatic potential. [Research support, non-U.S. Gov't]. Melanoma Research, 22(2), 123-132. doi:10.1097/CMR. 0b013e3283507ffd.

87. Hofmann, U. B., Kauczok-Vetter, C. S., Houben, R., \& Becker, J. C. (2009). Overexpression of the KIT/SCF in uveal melanoma does not translate into clinical efficacy of imatinib mesylate. Clinical Cancer Research, 15(1), 324-329. doi:10.1158/10780432.CCR-08-2243.

88. Faingold, D., Filho, V. B., Fernandes, B., Jagan, L., de Barros Jr., A. M., Orellana, M. E., et al. (2014). Expression of focal adhesion kinase in uveal melanoma and the effects of Hsp90 inhibition by 17-AAG. Pathology, Research and Practice, 210(11), 739-745. doi:10.1016/j.prp.2014.06.023.

89. Gangemi, R., Mirisola, V., Barisione, G., Fabbi, M., Brizzolara, A., Lanza, F., et al. (2012). Mda-9/syntenin is expressed in uveal melanoma and correlates with metastatic progression. PloS One, 7(1), e29989. doi:10.1371/journal.pone.0029989.

90. Dai, W., Zhou, J., Jin, B., \& Pan, J. (2016). Class III-specific HDAC inhibitor tenovin-6 induces apoptosis, suppresses migration and eliminates cancer stem cells in uveal melanoma. Scientific Reports, 6, 22622. doi:10.1038/srep22622.

91. Yoo, J. H., Shi, D. S., Grossmann, A. H., Sorensen, L. K., Tong, Z., Mleynek, T. M., et al. (2016). ARF6 is an actionable node that orchestrates oncogenic GNAQ signaling in uveal melanoma. Cancer Cell, 29(6), 889-904. doi:10. 1016/j.ccell.2016.04.015.

92. Lyubasyuk, V., Ouyang, H., Yu, F. X., Guan, K. L., \& Zhang, K. (2015). YAP inhibition blocks uveal melanogenesis driven by GNAQ or GNA11 mutations. Mol Cell Oncol, 2(1), e970957. doi: $10.4161 / 23723548.2014 .970957$.

93. Yu, F. X., Luo, J., Mo, J. S., Liu, G., Kim, Y. C., Meng, Z., et al. (2014). Mutant $\mathrm{Gq} / 11$ promote uveal melanoma tumorigenesis by activating YAP. Cancer Cell, 25(6), 822-830. doi:10.1016/j.ccr. 2014.04.017.

94. Chen, X., Wu, Q., Tan, L., Porter, D., Jager, M. J., Emery, C., et al. (2014). Combined PKC and MEK inhibition in uveal melanoma with GNAQ and GNA11 mutations. Oncogene, 33(39), 4724 4734. doi:10.1038/onc.2013.418.

95. Wu, X., Li, J., Zhu, M., Fletcher, J. A., \& Hodi, F. S. (2012). Protein kinase $\mathrm{C}$ inhibitor AEB071 targets ocular melanoma harboring GNAQ mutations via effects on the PKC/Erk1/2 and PKC/ NF-kappaB pathways. Molecular Cancer Therapeutics, 11(9), 1905-1914. doi:10.1158/1535-7163.MCT-12-0121.

96. Ambrosini, G., Sawle, A. D., Musi, E., \& Schwartz, G. K. (2015). BRD4-targeted therapy induces Myc-independent cytotoxicity in
Gnaq/11-mutatant uveal melanoma cells. Oncotarget, 6(32), 33397-33409. doi:10.18632/oncotarget.5179.

97. Musi, E., Ambrosini, G., de Stanchina, E., \& Schwartz, G. K. (2014). The phosphoinositide 3-kinase alpha selective inhibitor BYL719 enhances the effect of the protein kinase C inhibitor AEB071 in GNAQ/GNA11-mutant uveal melanoma cells. Molecular Cancer Therapeutics, 13(5), 1044-1053. doi:10. 1158/1535-7163.MCT-13-0550.

98. Surriga, O., Rajasekhar, V. K., Ambrosini, G., Dogan, Y., Huang, R., \& Schwartz, G. K. (2013). Crizotinib, a c-Met inhibitor, prevents metastasis in a metastatic uveal melanoma model. Molecular Cancer Therapeutics, 12(12), 2817-2826. doi:10.1158/15357163.MCT-13-0499.

99. Ho, A. L., Musi, E., Ambrosini, G., Nair, J. S., Deraje Vasudeva, S., de Stanchina, E., et al. (2012). Impact of combined mTOR and MEK inhibition in uveal melanoma is driven by tumor genotype. PloS One, 7(7), e40439. doi:10.1371/journal.pone.0040439.

100. Bi, M. C., Hose, N., Xu, C. L., Zhang, C., Sassoon, J., \& Song, E. (2016). Nonlethal levels of zeaxanthin inhibit cell migration, invasion, and secretion of MMP-2 via NF-kappaB pathway in cultured human uveal melanoma cells. Journal of Ophthalmology, 2016, 8734309. doi:10.1155/2016/8734309.

101. All-Ericsson, C., Girnita, L., Muller-Brunotte, A., Brodin, B., Seregard, S., Ostman, A., et al. (2004). c-Kit-dependent growth of uveal melanoma cells: a potential therapeutic target? Investigative Ophthalmology \& Visual Science, 45(7), 2075-2082.

102. Ma, D., \& Niederkorn, J. Y. (1998). Role of epidermal growth factor receptor in the metastasis of intraocular melanomas. Investigative Ophthalmology \& Visual Science, 39(7), 1067-1075.

103. Huang, X., Wang, L., Zhang, H., Wang, H., Zhao, X., Qian, G., et al. (2012). Therapeutic efficacy by targeting correction of Notch1-induced aberrants in uveal tumors. PloS One, 7(8), e44301. doi:10.1371/journal.pone.0044301.

104. Huang, X., Jia, R., Zhao, X., Liu, B., Wang, H., Wang, J., et al. (2012). Recombinant oncolytic adenovirus H101 combined with siBCL2: cytotoxic effect on uveal melanoma cell lines. The British Journal of Ophthalmology, 96(10), 1331-1338. doi:10.1136/ bjophthalmol-2011-301470.

105. Lefevre, G., Babchia, N., Calipel, A., Mouriaux, F., Faussat, A. M., Mrzyk, S., et al. (2009). Activation of the FGF2/FGFR1 autocrine loop for cell proliferation and survival in uveal melanoma cells. Investigative Ophthalmology \& Visual Science, 50(3), 10471057. doi:10.1167/iovs.08-2378.

106. Calipel, A., Landreville, S., De La Fouchardiere, A., Mascarelli, F., Rivoire, M., Penel, N., et al. (2014). Mechanisms of resistance to imatinib mesylate in KIT-positive metastatic uveal melanoma. Clinical \& Experimental Metastasis, 31(5), 553-564. doi:10. 1007/s10585-014-9649-2.

107. Hu, K., Babapoor-Farrokhran, S., Rodrigues, M., Deshpande, M., Puchner, B., Kashiwabuchi, F., et al. (2016). Hypoxia-inducible factor 1 upregulation of both VEGF and ANGPTL4 is required to promote the angiogenic phenotype in uveal melanoma. Oncotarget, 7(7), 7816-7828. doi:10.18632/oncotarget.6868.

108. Yang, H., Jager, M. J., \& Grossniklaus, H. E. (2010). Bevacizumab suppression of establishment of micrometastases in experimental ocular melanoma. Investigative Ophthalmology \& Visual Science, 51(6), 2835-2842. doi:10.1167/iovs.09-4755.

109. Mangiameli, D. P., Blansfield, J. A., Kachala, S., Lorang, D., Schafer, P. H., Muller, G. W., et al. (2007). Combination therapy targeting the tumor microenvironment is effective in a model of human ocular melanoma. Journal of Translational Medicine, 5, 38. doi:10.1186/1479-5876-5-38.

110. Abdel-Rahman, M. H., Boru, G., Massengill, J., Salem, M. M., \& Davidorf, F. H. (2010). MET oncogene inhibition as a potential target of therapy for uveal melanomas. Investigative 
Ophthalmology \& Visual Science, 51(7), 3333-3339. doi:10.1167/ iovs.09-4801.

111. Sun, L., Bian, G., Meng, Z., Dang, G., Shi, D., \& Mi, S. (2015). MiR-144 inhibits uveal melanoma cell proliferation and invasion by regulating c-Met expression. PloS One, 10(5), e0124428. doi: 10.1371/journal.pone.0124428.

112. Yan, D., Dong, X. D., Chen, X., Yao, S., Wang, L., Wang, J., et al. (2012). Role of microRNA-182 in posterior uveal melanoma: regulation of tumor development through MITF, BCL2 and cyclin D2. PloS One, 7(7), e40967. doi:10.1371/journal.pone.0040967.

113. Yan, D., Zhou, X., Chen, X., Hu, D. N., Dong, X. D., Wang, J., et al. (2009). MicroRNA-34a inhibits uveal melanoma cell proliferation and migration through downregulation of c-Met. Investigative Ophthalmology \& Visual Science, 50(4), 15591565. doi:10.1167/iovs.08-2681.

114. Chattopadhyay, C., Grimm, E. A., \& Woodman, S. E. (2014). Simultaneous inhibition of the HGF/MET and Erk1/2 pathways affect uveal melanoma cell growth and migration. PloS One, 9(2), e83957. doi:10.1371/journal.pone.0083957.

115. Landreville, S., Agapova, O. A., Matatall, K. A., Kneass, Z. T., Onken, M. D., Lee, R. S., et al. (2012). Histone deacetylase inhibitors induce growth arrest and differentiation in uveal melanoma. [Research support, N.I.H., extramural]. Clinical Cancer Research, 18(2), 408-416. doi:10.1158/1078-0432.CCR-11-0946.

116. von Euw, E., Atefi, M., Attar, N., Chu, C., Zachariah, S., Burgess, B. L., et al. (2012). Antitumor effects of the investigational selective MEK inhibitor TAK733 against cutaneous and uveal melanoma cell lines. Molecular Cancer, 11, 22. doi:10.1186/1476-4598-11-22.

117. Chen, X., Wang, J., Shen, H., Lu, J., Li, C., Hu, D., et al. (2011). Epigenetics, microRNAs, and carcinogenesis: functional role of microRNA-137 in uveal melanoma. Investigative Ophthalmology \& Visual Science. doi:10.1167/iovs.10-5272.

118. Hu, S., Luo, Q., Cun, B., Hu, D., Ge, S., Fan, X., et al. (2012). The pharmacological NF-kappaB inhibitor BAY11-7082 induces cell apoptosis and inhibits the migration of human uveal melanoma cells. International Journal of Molecular Sciences, 13(12), 15653-15667. doi:10.3390/ijms131215653.

119. Sabe, H., Hashimoto, S., Morishige, M., Hashimoto, A., \& Ogawa, E. (2008). The EGFR-GEP100-Arf6 pathway in breast cancer: full invasiveness is not from the inside. Cell Adhesion \& Migration, 2(2), 71-73.

120. Hashimoto, A., Hashimoto, S., Ando, R., Noda, K., Ogawa, E., Kotani, H., et al. (2011). GEP100-Arf6-AMAP1-cortactin pathway frequently used in cancer invasion is activated by VEGFR2 to promote angiogenesis. PloS One, 6(8), e23359. doi:10.1371/ journal.pone.0023359.

121. Grossmann, A. H., Yoo, J. H., Clancy, J., Sorensen, L. K., Sedgwick, A., Tong, Z., et al. (2013). The small GTPase ARF6 stimulates beta-catenin transcriptional activity during WNT5Amediated melanoma invasion and metastasis. Science Signaling, 6(265), ra14. doi:10.1126/scisignal.2003398.

122. Sumiyoshi, M., Masuda, N., Tanuma, N., Ogoh, H., Imai, E., Otsuka, M., et al. (2015). Mice doubly-deficient in the Arf GAPs SMAP1 and SMAP2 exhibit embryonic lethality. FEBS Letters, 589(19 Pt B), 2754-2762. doi:10.1016/j.febslet.2015.07.050.

123. Hamadeh, F., Medina, C. A., Singh, A. D., Reynolds, J. P., \& Biscotti, C. V. (2016). Uveal melanoma: an analysis of cellular features and comparison to monosomy 3 status. Diagnostic Cytopathology, 44(5), 377-383. doi:10.1002/dc.23450.

124. McLean, I. W., Foster, W. D., Zimmerman, L. E., \& Gamel, J. W. (1983). Modifications of Callender's classification of uveal melanoma at the Armed Forces Institute of Pathology. American Journal of Ophthalmology, 96(4), 502-509.
125. Gamel, J. W., McCurdy, J. B., \& McLean, I. W. (1992). A comparison of prognostic covariates for uveal melanoma. Investigative Ophthalmology \& Visual Science, 33(6), 1919-1922.

126. Griewank, K. G., van de Nes, J., Schilling, B., Moll, I., Sucker, A., Kakavand, H., et al. (2014). Genetic and clinico-pathologic analysis of metastatic uveal melanoma. Modern Pathology, 27(2), 175-183. doi:10.1038/modpathol.2013.138.

127. Kalirai, H., Dodson, A., Faqir, S., Damato, B. E., \& Coupland, S. E. (2014). Lack of BAP1 protein expression in uveal melanoma is associated with increased metastatic risk and has utility in routine prognostic testing. British Journal of Cancer, 111(7), 1373-1380. doi:10.1038/bjc.2014.417.

128. Koopmans, A. E., Verdijk, R. M., Brouwer, R. W., van den Bosch, T. P., van den Berg, M. M., Vaarwater, J., et al. (2014). Clinical significance of immunohistochemistry for detection of BAP1 mutations in uveal melanoma. Modern Pathology, 27(10), 13211330. doi:10.1038/modpathol.2014.43.

129. van Essen, T. H., van Pelt, S. I., Versluis, M., Bronkhorst, I. H., van Duinen, S. G., Marinkovic, M., et al. (2014). Prognostic parameters in uveal melanoma and their association with BAP1 expression. The British Journal of Ophthalmology. doi:10.1136/ bjophthalmol-2014-305047.

130. van de Nes, J. A., Nelles, J., Kreis, S., Metz, C. H., Hager, T., Lohmann, D. R., et al. (2016). Comparing the prognostic value of BAP1 mutation pattern, chromosome 3 status, and BAP1 immunohistochemistry in uveal melanoma. The American Journal of Surgical Pathology, 40(6), 796-805. doi:10.1097/PAS. 0000000000000645.

131. Horsman, D. E., Sroka, H., Rootman, J., \& White, V. A. (1990). Monosomy 3 and isochromosome $8 \mathrm{q}$ in a uveal melanoma. Cancer Genetics and Cytogenetics, 45(2), 249-253.

132. Prescher, G., Bornfeld, N., \& Becher, R. (1990). Nonrandom chromosomal abnormalities in primary uveal melanoma. Journal of the National Cancer Institute, 82(22), 1765-1769.

133. Prescher, G., Bornfeld, N., Hirche, H., Horsthemke, B., Jockel, K. H., \& Becher, R. (1996). Prognostic implications of monosomy 3 in uveal melanoma. Lancet, 347(9010), 1222-1225.

134. Sisley, K., Rennie, I. G., Parsons, M. A., Jacques, R., Hammond, D. W., Bell, S. M., et al. (1997). Abnormalities of chromosomes 3 and 8 in posterior uveal melanoma correlate with prognosis. Genes, Chromosomes \& Cancer, 19(1), 22-28. doi:10.1002/ (SICI) 1098-2264(199705)19:1<22::AID-GCC4>3.0.CO;2-2.

135. Singh, A. D., Tubbs, R., Biscotti, C., Schoenfield, L., \& Trizzoi, P. (2009). Chromosomal 3 and 8 status within hepatic metastasis of uveal melanoma. Archives of Pathology \& Laboratory Medicine, 133(8), 1223-1227.

136. Tschentscher, F., Prescher, G., Zeschnigk, M., Horsthemke, B., \& Lohmann, D. R. (2000). Identification of chromosomes 3, 6, and 8 aberrations in uveal melanoma by microsatellite analysis in comparison to comparative genomic hybridization. Cancer Genetics and Cytogenetics, 122(1), 13-17.

137. Aalto, Y., Eriksson, L., Seregard, S., Larsson, O., \& Knuutila, S. (2001). Concomitant loss of chromosome 3 and whole arm losses and gains of chromosome 1,6 , or 8 in metastasizing primary uveal melanoma. Investigative Ophthalmology \& Visual Science, 42(2), 313-317.

138. Damato, B., Duke, C., Coupland, S. E., Hiscott, P., Smith, P. A., Campbell, I., et al. (2007). Cytogenetics of uveal melanoma: a 7year clinical experience. Ophthalmology, 114(10), 1925-1931. doi:10.1016/j.ophtha.2007.06.012.

139. Damato, B., Dopierala, J. A., \& Coupland, S. E. (2010). Genotypic profiling of 452 choroidal melanomas with multiplex ligationdependent probe amplification. Clinical Cancer Research, 16(24), 6083-6092. doi:10.1158/1078-0432.CCR-10-2076.

140. Shields, C. L., Ganguly, A., Bianciotto, C. G., Turaka, K., Tavallali, A., \& Shields, J. A. (2011). Prognosis of uveal 
melanoma in 500 cases using genetic testing of fine-needle aspiration biopsy specimens. Ophthalmology, 118(2), 396-401. doi: 10.1016/j.ophtha.2010.05.023.

141. Thomas, S., Putter, C., Weber, S., Bornfeld, N., Lohmann, D. R., $\&$ Zeschnigk, M. (2012). Prognostic significance of chromosome 3 alterations determined by microsatellite analysis in uveal melanoma: a long-term follow-up study. British Journal of Cancer, 106(6), 1171-1176. doi:10.1038/bjc.2012.54.

142. van den Bosch, T., van Beek, J. G., Vaarwater, J., Verdijk, R. M., Naus, N. C., Paridaens, D., et al. (2012). Higher percentage of FISH-determined monosomy 3 and $8 \mathrm{q}$ amplification in uveal melanoma cells relate to poor patient prognosis. Investigative Ophthalmology \& Visual Science, 53(6), 2668-2674. doi:10. 1167/iovs.11-8697.

143. Ewens, K. G., Kanetsky, P. A., Richards-Yutz, J., Al-Dahmash, S., De Luca, M. C., Bianciotto, C. G., et al. (2013). Genomic profile of 320 uveal melanoma cases: chromosome $8 \mathrm{p}$-loss and metastatic outcome. Investigative Ophthalmology \& Visual Science, 54(8), 5721-5729. doi:10.1167/iovs.13-12195.

144. Damato, B., \& Coupland, S. E. (2009). A reappraisal of the significance of largest basal diameter of posterior uveal melanoma. Eye (London, England), 23(12), 2152-2160 quiz 2161-2152. doi: 10.1038/eye.2009.235-cme.

145. Shields, C. L., Furuta, M., Thangappan, A., Nagori, S., Mashayekhi, A., Lally, D. R., et al. (2009). Metastasis of uveal melanoma millimeter-by-millimeter in 8033 consecutive eyes. Archives of Ophthalmology, 127(8), 989-998. doi:10.1001/ archophthalmol.2009.208.

146. Caines, R., Eleuteri, A., Kalirai, H., Fisher, A. C., Heimann, H., Damato, B. E., et al. (2015). Cluster analysis of multiplex ligationdependent probe amplification data in choroidal melanoma. Molecular Vision, 21, 1-11.

147. Versluis, M., de Lange, M. J., van Pelt, S. I., Ruivenkamp, C. A., Kroes, W. G., Cao, J., et al. (2015). Digital PCR validates 8q dosage as prognostic tool in uveal melanoma. PloS One, 10(3), e0116371. doi:10.1371/journal.pone.0116371.

148. Harbour, J. W., Onken, M. D., Roberson, E. D., Duan, S., Cao, L., Worley, L. A., et al. (2010). Frequent mutation of BAP1 in metastasizing uveal melanomas. Science, 330(6009), 1410-1413. doi: 10.1126/science.1194472.

149. Tschentscher, F., Prescher, G., Horsman, D. E., White, V. A., Rieder, H., Anastassiou, G., et al. (2001). Partial deletions of the long and short arm of chromosome 3 point to two tumor suppressor genes in uveal melanoma. Cancer Research, 61(8), 3439-3442.

150. Parrella, P., Fazio, V. M., Gallo, A. P., Sidransky, D., \& Merbs, S. L. (2003). Fine mapping of chromosome 3 in uveal melanoma: identification of a minimal region of deletion on chromosomal arm 3p25.1-p25.2. Cancer Research, 63(23), 8507-8510.

151. Trolet, J., Hupe, P., Huon, I., Lebigot, I., Decraene, C., Delattre, O., et al. (2009). Genomic profiling and identification of high-risk uveal melanoma by array CGH analysis of primary tumors and liver metastases. Investigative Ophthalmology \& Visual Science, 50(6), 2572-2580. doi:10.1167/iovs.08-2296.

152. White, V. A., McNeil, B. K., Thiberville, L., \& Horsman, D. E. (1996). Acquired homozygosity (isodisomy) of chromosome 3 during clonal evolution of a uveal melanoma: association with morphologic heterogeneity. Genes, Chromosomes \& Cancer, 15(2), 138-143. doi:10.1002/(SICI)1098-2264(199602)15: $2<138::$ AID-GCC10>3.0.CO;2-J.

153. Onken, M. D., Worley, L. A., Person, E., Char, D. H., Bowcock, A. M., \& Harbour, J. W. (2007). Loss of heterozygosity of chromosome 3 detected with single nucleotide polymorphisms is superior to monosomy 3 for predicting metastasis in uveal melanoma. Clinical Cancer Research, 13(10), 2923-2927. doi:10.1158/ 1078-0432.CCR-06-2383.
154. Paraoan, L., Gray, D., Hiscott, P., Ebrahimi, B., Damato, B., \& Grierson, I. (2006). Expression of p53-induced apoptosis effector PERP in primary uveal melanomas: downregulation is associated with aggressive type. Experimental Eye Research, 83(4), 911919. doi:10.1016/j.exer.2006.04.016.

155. Awais, R., Spiller, D. G., White, M. R., \& Paraoan, L. (2016). p63 is required beside $\mathrm{p} 53$ for PERP-mediated apoptosis in uveal melanoma. British Journal of Cancer. doi:10.1038/bjc.2016.269.

156. Lake, S. L., Damato, B. E., Kalirai, H., Dodson, A. R., Taktak, A. F., Lloyd, B. H., et al. (2013). Single nucleotide polymorphism array analysis of uveal melanomas reveals that amplification of CNKSR3 is correlated with improved patient survival. The American Journal of Pathology, 182(3), 678-687. doi:10.1016/j. ajpath.2012.11.036.

157. Johansson, P., Aoude, L. G., Wadt, K., Glasson, W. J., Warrier, S. K., Hewitt, A. W., et al. (2016). Deep sequencing of uveal melanoma identifies a recurrent mutation in PLCB4. Oncotarget, 7(4), 4624-4631. doi:10.18632/oncotarget.6614.

158. Onken, M. D., Worley, L. A., Long, M. D., Duan, S., Council, M. L., Bowcock, A. M., et al. (2008). Oncogenic mutations in GNAQ occur early in uveal melanoma. Investigative Ophthalmology \& Visual Science, 49(12), 5230-5234. doi:10.1167/jovs.08-2145.

159. Bauer, J., Kilic, E., Vaarwater, J., Bastian, B. C., Garbe, C., \& de Klein, A. (2009). Oncogenic GNAQ mutations are not correlated with disease-free survival in uveal melanoma. British Journal of Cancer, 101(5), 813-815. doi:10.1038/sj.bjc.6605226.

160. Daniels, A. B., Lee, J. E., MacConaill, L. E., Palescandolo, E., Van Hummelen, P., Adams, S. M., et al. (2012). High throughput mass spectrometry-based mutation profiling of primary uveal melanoma. [Research support, N.I.H., extramural research support, nonU.S. Gov't]. Investigative Ophthalmology \& Visual Science, 53(11), 6991-6996. doi:10.1167/iovs.12-10427.

161. Furney, S. J., Pedersen, M., Gentien, D., Dumont, A. G., Rapinat, A., Desjardins, L., et al. (2013). SF3B1 mutations are associated with alternative splicing in uveal melanoma. Cancer Discovery, 3(10), 1122-1129. doi:10.1158/2159-8290.cd-13-0330.

162. Koopmans, A. E., Vaarwater, J., Paridaens, D., Naus, N. C., Kilic, E., de Klein, A., et al. (2013). Patient survival in uveal melanoma is not affected by oncogenic mutations in GNAQ and GNA11. British Journal of Cancer, 109(2), 493-496. doi:10.1038/bjc. 2013.299.

163. Ewens, K. G., Kanetsky, P. A., Richards-Yutz, J., Purrazzella, J., Shields, C. L., Ganguly, T., et al. (2014). Chromosome 3 status combined with BAP1 and EIF1AX mutation profiles are associated with metastasis in uveal melanoma. Investigative Ophthalmology \& Visual Science, 55(8), 5160-5167. doi:10. 1167/iovs.14-14550.

164. de Lange, M. J., Razzaq, L., Versluis, M., Verlinde, S., Dogrusoz, M., Bohringer, S., et al. (2015). Distribution of GNAQ and GNA11 mutation signatures in uveal melanoma points to a light dependent mutation mechanism. PloS One, 10(9), e0138002. doi: 10.1371/journal.pone.0138002.

165. Alsafadi, S., Houy, A., Battistella, A., Popova, T., Wassef, M., Henry, E., et al. (2016). Cancer-associated SF3B1 mutations affect alternative splicing by promoting alternative branchpoint usage. Nature Communications, 7, 10615. doi:10.1038/ncomms10615.

166. Decatur, C. L., Ong, E., Garg, N., Anbunathan, H., Bowcock, A. M., Field, M. G., et al. (2016). Driver mutations in uveal melanoma: associations with gene expression profile and patient outcomes. JAMA Ophthalmol, 134(7), 728-733. doi:10.1001/ jamaophthalmol.2016.0903.

167. Yavuzyigitoglu, S., Koopmans, A. E., Verdijk, R. M., Vaarwater, J., Eussen, B., van Bodegom, A., et al. (2016). Uveal melanomas with SF3B1 mutations: a distinct subclass associated with lateonset metastases. Ophthalmology, 123(5), 1118-1128. doi:10. 1016/j.ophtha.2016.01.023. 
168. Yavuzyigitoglu, S., Mensink, H. W., Smit, K. N., Vaarwater, J., Verdijk, R. M., Beverloo, B., et al. (2016). Metastatic disease in polyploid uveal melanoma patients is associated with BAP1 mutations. Investigative Ophthalmology \& Visual Science, 57(4), 2232-2239. doi:10.1167/iovs.15-18608.

169. Moore, A. R., Ceraudo, E., Sher, J. J., Guan, Y., Shoushtari, A. N., Chang, M. T., et al. (2016). Recurrent activating mutations of Gprotein-coupled receptor CYSLTR2 in uveal melanoma. Nature Genetics, 48(6), 675-680. doi:10.1038/ng.3549.

170. Xu, X., Wei, W. B., Li, B., Gao, F., Zhang, Z., \& Jonas, J. B. (2014). Oncogenic GNAQ and GNA11 mutations in uveal melanoma in Chinese. PloS One, 9(10), e109699. doi:10.1371/journal. pone.0109699.

171. Populo, H., Vinagre, J., Lopes, J. M., \& Soares, P. (2011). Analysis of GNAQ mutations, proliferation and MAPK pathway activation in uveal melanomas. The British Journal of Ophthalmology, 95(5), 715-719. doi:10.1136/bjo.2009.174417.

172. Dratviman-Storobinsky, O., Cohen, Y., Frenkel, S., Pe'er, J., \& Goldenberg-Cohen, N. (2010). Lack of oncogenic GNAQ mutations in melanocytic lesions of the conjunctiva as compared to uveal melanoma. Investigative Ophthalmology \& Visual Science, 51(12), 6180-6182. doi:10.1167/iovs.10-5677.

173. Henriquez, F., Janssen, C., Kemp, E. G., \& Roberts, F. (2007). The T1799A BRAF mutation is present in iris melanoma. Investigative Ophthalmology \& Visual Science, 48(11), 4897-4900. doi:10. 1167/iovs.07-0440.

174. Janssen, C. S., Sibbett, R., Henriquez, F. L., McKay, I. C., Kemp, E. G., \& Roberts, F. (2008). The T1799A point mutation is present in posterior uveal melanoma. British Journal of Cancer, 99(10), 1673-1677. doi:10.1038/sj.bjc.6604731.

175. Markby, D. W., Onrust, R., \& Bourne, H. R. (1993). Separate GTP binding and GTPase activating domains of a G alpha subunit. Science, 262(5141), 1895-1901. doi:10. 1126/science.8266082.

176. Gerami, P., Pouryazdanparast, P., Vemula, S., \& Bastian, B. C. (2010). Molecular analysis of a case of nevus of ota showing progressive evolution to melanoma with intermediate stages resembling cellular blue nevus. The American Journal of Dermatopathology, 32(3), 301-305. doi:10.1097/DAD. 0b013e3181b96db7.

177. Kusters-Vandevelde, H. V., Klaasen, A., Kusters, B., Groenen, P. J., van Engen-van Grunsven, I. A., van Dijk, M. R., et al. (2010). Activating mutations of the GNAQ gene: a frequent event in primary melanocytic neoplasms of the central nervous system. Acta Neuropathologica, 119(3), 317-323. doi:10.1007/s00401-009-0611-3.

178. Shirley, M. D., Tang, H., Gallione, C. J., Baugher, J. D., Frelin, L. P., Cohen, B., et al. (2013). Sturge-Weber syndrome and port-wine stains caused by somatic mutation in GNAQ. The New England Journal of Medicine, 368(21), 1971-1979. doi:10.1056/ NEJMoa1213507.

179. Hawkes, J. E., Campbell, J., Garvin, D., Cannon-Albright, L., Cassidy, P., \& Leachman, S. A. (2013). Lack of GNAQ and GNA11 germ-line mutations in familial melanoma pedigrees with uveal melanoma or blue nevi. Frontiers in Oncology, 3, 160. doi: 10.3389/fonc. 2013.00160 .

180. Giulietti, M., Vivenzio, V., Piva, F., Principato, G., Bellantuono, C., \& Nardi, B. (2014). How much do we know about the coupling of G-proteins to serotonin receptors? Molecular Brain, 7, 49. doi: 10.1186/s13041-014-0049-y.

181. Lobikin, M., Lobo, D., Blackiston, D. J., Martyniuk, C. J., Tkachenko, E., \& Levin, M. (2015). Serotonergic regulation of melanocyte conversion: a bioelectrically regulated network for stochastic all-or-none hyperpigmentation. Science Signaling, 8(397), ra99. doi:10.1126/scisignal.aac6609.
182. Tschentscher, F., Husing, J., Holter, T., Kruse, E., Dresen, I. G., Jockel, K. H., et al. (2003). Tumor classification based on gene expression profiling shows that uveal melanomas with and without monosomy 3 represent two distinct entities. Cancer Research, 63(10), 2578-2584.

183. Onken, M. D., Worley, L. A., Ehlers, J. P., \& Harbour, J. W. (2004). Gene expression profiling in uveal melanoma reveals two molecular classes and predicts metastatic death. Cancer Research, 64(20), 7205-7209. doi:10.1158/0008-5472.CAN-04-1750.

184. Ivey, K., Tyson, B., Ukidwe, P., McFadden, D. G., Levi, G., Olson, E. N., et al. (2003). Galphaq and Galpha11 proteins mediate endothelin-1 signaling in neural crest-derived pharyngeal arch mesenchyme. Developmental Biology, 255(2), 230-237. doi:10. 1016/S0012-1606(02)00097-0.

185. Deo, M., Huang, J. L., \& Van Raamsdonk, C. D. (2013). Genetic interactions between neurofibromin and endothelin receptor B in mice. PloS One, 8(3), e59931. doi:10.1371/journal.pone.0059931.

186. Zuidervaart, W., van der Velden, P. A., Hurks, M. H., van Nieuwpoort, F. A., Out-Luiting, C. J., Singh, A. D., et al. (2003). Gene expression profiling identifies tumour markers potentially playing a role in uveal melanoma development. British Journal of Cancer, 89(10), 1914-1919. doi:10.1038/ sj.bjc. 6601374 .

187. Smith, S. L., Damato, B. E., Scholes, A. G., Nunn, J., Field, J. K., \& Heighway, J. (2002). Decreased endothelin receptor B expression in large primary uveal melanomas is associated with early clinical metastasis and short survival. British Journal of Cancer, 87(11), 1308-1313. doi:10.1038/sj.bjc.6600620.

188. Urtatiz, O., \& Van Raamsdonk, C. D. (2016). Gnaq and Gna11 in the endothelin signaling pathway and melanoma. Frontiers in Genetics, 7, 59. doi:10.3389/fgene.2016.00059.

189. O'Hayre, M., Degese, M. S., \& Gutkind, J. S. (2014). Novel insights into $\mathrm{G}$ protein and $\mathrm{G}$ protein-coupled receptor signaling in cancer. Current Opinion in Cell Biology, 27C, 126-135. doi:10. 1016/j.ceb.2014.01.005.

190. Feng, X., Degese, M. S., Iglesias-Bartolome, R., Vaque, J. P., Molinolo, A. A., Rodrigues, M., et al. (2014). Hippoindependent activation of YAP by the GNAQ uveal melanoma oncogene through a trio-regulated rho GTPase signaling circuitry. Cancer Cell, 25(6), 831-845. doi:10.1016/j.ccr.2014.04.016.

191. Moroishi, T., Hansen, C. G., \& Guan, K.-L. (2015). The emerging roles of YAP and TAZ in cancer. [Progress]. Nature Reviews. Cancer, 15(2), 73-79. doi:10.1038/nrc3876.

192. Lin, L., Sabnis, A. J., Chan, E., Olivas, V., Cade, L., Pazarentzos, E., et al. (2015). The Hippo effector YAP promotes resistance to RAF- and MEK-targeted cancer therapies. Nature Genetics, 47(3), 250-256. doi:10.1038/ng.3218.

193. Sorrentino, G., Ruggeri, N., Specchia, V., Cordenonsi, M., Mano, M., Dupont, S., et al. (2014). Metabolic control of YAP and TAZ by the mevalonate pathway. Nature Cell Biology, 16(4), 357-366. doi:10.1038/ncb2936.

194. Jensen, D. E., Proctor, M., Marquis, S. T., Gardner, H. P., Ha, S. I., Chodosh, L. A., et al. (1998). BAP1: a novel ubiquitin hydrolase which binds to the BRCA1 RING finger and enhances BRCA1mediated cell growth suppression. Oncogene, 16(9), 1097-1112.

195. Abdel-Rahman, M. H., Pilarski, R., Cebulla, C. M., Massengill, J. B., Christopher, B. N., Boru, G., et al. (2011). Germline BAP1 mutation predisposes to uveal melanoma, lung adenocarcinoma, meningioma, and other cancers. Journal of Medical Genetics, 48(12), 856-859. doi:10.1136/jmedgenet-2011-100156.

196. Wiesner, T., Obenauf, A. C., Murali, R., Fried, I., Griewank, K. G., Ulz, P., et al. (2011). Germline mutations in BAP1 predispose to melanocytic tumors. Nature Genetics, 43(10), 1018-1021. doi:10. 1038/ng. 910

197. Testa, J. R., Cheung, M., Pei, J., Below, J. E., Tan, Y., Sementino, E., et al. (2011). Germline BAP1 mutations predispose to 
malignant mesothelioma. Nature Genetics, 43(10), 1022-1025. doi:10.1038/ng.912.

198. Njauw, C. N., Kim, I., Piris, A., Gabree, M., Taylor, M., Lane, A. M., et al. (2012). Germline BAP1 inactivation is preferentially associated with metastatic ocular melanoma and cutaneousocular melanoma families. PloS One, 7(4), e35295. doi:10.1371/ journal.pone.0035295.

199. Carbone, M., Ferris, L. K., Baumann, F., Napolitano, A., Lum, C. A., Flores, E. G., et al. (2012). BAP1 cancer syndrome: malignant mesothelioma, uveal and cutaneous melanoma, and MBAITs. Journal of Translational Medicine, 10, 179. doi:10.1186/14795876-10-179.

200. Carbone, M., Yang, H., Pass, H. I., Krausz, T., Testa, J. R., \& Gaudino, G. (2013). BAP1 and cancer. Nature Reviews. Cancer, 13(3), 153-159.

201. Maerker, D. A., Zeschnigk, M., Nelles, J., Lohmann, D. R., Worm, K., Bosserhoff, A. K., et al. (2014). BAP1 germline mutation in two first grade family members with uveal melanoma. The British Journal of Ophthalmology, 98(2), 224-227. doi:10.1136/ bjophthalmol-2013-303814.

202. Cebulla, C. M., Binkley, E. M., Pilarski, R., Massengill, J. B., Rai, K., Liebner, D. A., et al. (2015). Analysis of BAP1 germline gene mutation in young uveal melanoma patients. Ophthalmic Genetics, 36(2), 126-131. doi:10.3109/13816810.2015.1010734.

203. Nishikawa, H., Wu, W., Koike, A., Kojima, R., Gomi, H., Fukuda, M., et al. (2009). BRCA1-associated protein 1 interferes with BRCA1/BARD1 RING heterodimer activity. Cancer Research, 69(1), 111-119. doi:10.1158/0008-5472.CAN-08-3355.

204. Ventii, K. H., Devi, N. S., Friedrich, K. L., Chernova, T. A., Tighiouart, M., Van Meir, E. G., et al. (2008). BRCA1-associated protein-1 is a tumor suppressor that requires deubiquitinating activity and nuclear localization. Cancer Research, 68(17), 6953-6962. doi:10.1158/0008-5472.CAN-08-0365.

205. Eletr, Z. M., \& Wilkinson, K. D. (2011). An emerging model for BAP1's role in regulating cell cycle progression. Cell Biochemistry and Biophysics, 60(1-2), 3-11. doi:10.1007/ s12013-011-9184-6.

206. Scheuermann, J. C., de Ayala Alonso, A. G., Oktaba, K., LyHartig, N., McGinty, R. K., Fraterman, S., et al. (2010). Histone H2A deubiquitinase activity of the polycomb repressive complex PR-DUB. Nature, 465(7295), 243-247. doi:10.1038/ nature08966.

207. Yu, H., Mashtalir, N., Daou, S., Hammond-Martel, I., Ross, J., Sui, G., et al. (2010). The ubiquitin carboxyl hydrolase BAP1 forms a ternary complex with YY1 and HCF-1 and is a critical regulator of gene expression. Molecular and Cellular Biology, 30(21), 50715085. doi:10.1128/MCB.00396-10.

208. Pan, H., Jia, R., Zhang, L., Xu, S., Wu, Q., Song, X., et al. (2015). BAP1 regulates cell cycle progression through E2F1 target genes and mediates transcriptional silencing via $\mathrm{H} 2 \mathrm{~A}$ monoubiquitination in uveal melanoma cells. The International Journal of Biochemistry \& Cell Biology, 60, 176-184. doi:10. 1016/j.biocel.2015.01.001.

209. Matatall, K. A., Agapova, O. A., Onken, M. D., Worley, L. A., Bowcock, A. M., \& Harbour, J. W. (2013). BAP1 deficiency causes loss of melanocytic cell identity in uveal melanoma. BMC Cancer, 13, 371. doi:10.1186/1471-2407-13-371.

210. Schilling, B., Bielefeld, N., Sucker, A., Hillen, U., Zimmer, L., Schadendorf, D., et al. (2013). Lack of SF3B1 R625 mutations in cutaneous melanoma. [Research support, non-U.S. Gov't]. Diagnostic Pathology, 8, 87. doi:10.1186/1746-1596-8-87.

211. Kong, Y., Krauthammer, M., \& Halaban, R. (2014). Rare SF3B1 R625 mutations in cutaneous melanoma. Melanoma Research, 24(4), 332-334. doi:10.1097/CMR.0000000000000071.

212. DeBoever, C., Ghia, E. M., Shepard, P. J., Rassenti, L., Barrett, C. L., Jepsen, K., et al. (2015). Transcriptome sequencing reveals potential mechanism of cryptic $3^{\prime}$ splice site selection in SF3B1mutated cancers. PLoS Computational Biology, 11(3), e1004105. doi:10.1371/journal.pcbi.1004105.

213. Darman, R. B., Seiler, M., Agrawal, A. A., Lim, K. H., Peng, S., Aird, D., et al. (2015). Cancer-associated SF3B1 hotspot mutations induce cryptic $3^{\prime}$ splice site selection through use of a different branch point. Cell Reports, 13(5), 1033-1045. doi:10.1016/j. celrep.2015.09.053.

214. Van Beek, J. G. M., Koopmans, A. E., Vaarwater, J., Verdijk, R. M., de Klein, A., Naus, N. C., et al. (2015). Metastatic disease in uveal melanoma: Importance of a genetic profile? Melanoma Research, 25(5), 447-449. doi:10.1097/cmr.0000000000000176.

215. Field, M. G., Decatur, C. L., Kurtenbach, S., Gezgin, G., van der Velden, P. A., Jager, M. J., et al. (2016). PRAME as an independent biomarker for metastasis in uveal melanoma. Clinical Cancer Research, 22(5), 1234-1242. doi:10.1158/1078-0432.CCR-15-2071.

216. Epping, M. T., Wang, L., Edel, M. J., Carlee, L., Hernandez, M., \& Bernards, R. (2005). The human tumor antigen PRAME is a dominant repressor of retinoic acid receptor signaling. Cell, 122(6), 835-847. doi:10.1016/j.cell.2005.07.003.

217. Field, M. G., Durante, M. A., Decatur, C. L., Tarlan, B., Oelschlager, K. M., Stone, J. F., et al. (2016). Epigenetic reprogramming and aberrant expression of PRAME are associated with increased metastatic risk in class 1 and class 2 uveal melanomas. Oncotarget, 7(37), 59209-59219. doi:10.18632/ oncotarget.10962.

218. Agrawal, N., Akbani, R., Aksoy, B. A., Ally, A., Arachchi, H., Asa Sylvia, L., et al. (2014). Integrated genomic characterization of papillary thyroid carcinoma. Cell, 159(3), 676-690. doi:10. 1016/j.cell.2014.09.050.

219. Kunstman, J. W., Juhlin, C. C., Goh, G., Brown, T. C., Stenman, A., Healy, J. M., et al. (2015). Characterization of the mutational landscape of anaplastic thyroid cancer via whole-exome sequencing. Human Molecular Genetics, 24(8), 2318-2329. doi:10.1093/ hmg/ddu 749 .

220. Hunter, S. M., Anglesio, M. S., Ryland, G. L., Sharma, R., Chiew, Y. E., Rowley, S. M., et al. (2015). Molecular profiling of low grade serous ovarian tumours identifies novel candidate driver genes. Oncotarget, 6(35), 37663-37677. doi:10.18632/ oncotarget.5438.

221. van Gils, W., Lodder, E. M., Mensink, H. W., Kilic, E., Naus, N. C., Bruggenwirth, H. T., et al. (2008). Gene expression profiling in uveal melanoma: two regions on $3 p$ related to prognosis. Investigative Ophthalmology \& Visual Science, 49(10), 4254-4262.

222. Laurent, C., Valet, F., Planque, N., Silveri, L., Maacha, S., Anezo, O., et al. (2011). High PTP4A3 phosphatase expression correlates with metastatic risk in uveal melanoma patients. [Research support, non-U.S. Gov't]. Cancer Research, 71(3), 666-674. doi:10. 1158/0008-5472.CAN-10-0605.

223. Amaro, A., Parodi, F., Diedrich, K., Angelini, G., Gotz, C., Viaggi, S., et al. (2016). Analysis of the expression and single-nucleotide variant frequencies of the butyrophilin-like 2 gene in patients with uveal melanoma. JAMA Ophthalmol. doi:10.1001/ jamaophthalmol.2016.2691.

224. Onken, M. D., Ehlers, J. P., Worley, L. A., Makita, J., Yokota, Y., \& Harbour, J. W. (2006). Functional gene expression analysis uncovers phenotypic switch in aggressive uveal melanomas. Cancer Research, 66(9), 4602-4609. doi:10.1158/0008-5472. CAN-05-4196.

225. Onken, M. D., Worley, L. A., Davila, R. M., Char, D. H., \& Harbour, J. W. (2006). Prognostic testing in uveal melanoma by transcriptomic profiling of fine needle biopsy specimens. The Journal of Molecular Diagnostics, 8(5), 567-573.

226. Onken, M. D., Worley, L. A., Tuscan, M. D., \& Harbour, J. W. (2010). An accurate, clinically feasible multi-gene expression 
assay for predicting metastasis in uveal melanoma. The Journal of Molecular Diagnostics, 12(4), 461-468. doi:10.2353/jmoldx. 2006.060077

227. Onken, M. D., Worley, L. A., Char, D. H., Augsburger, J. J., Correa, Z. M., Nudleman, E., et al. (2012). Collaborative Ocular Oncology Group report number 1: prospective validation of a multi-gene prognostic assay in uveal melanoma. [Comparative study multicenter study research support, N.I.H., extramural research support, non-U.S. Gov't validation studies]. Ophthalmology, 119(8), 1596-1603. doi:10. 1016/j.ophtha.2012.02.017.

228. Harbour, J. W., \& Chen, R. (2013). The DecisionDx-UM gene expression profile test provides risk stratification and individualized patient care in uveal melanoma. PLoS Currents, 5. doi:10. 1371/currents.eogt.af8ba80fc 776c8f1ce8f5dc485d4a618.

229. Harbour, J. W. (2014). A prognostic test to predict the risk of metastasis in uveal melanoma based on a 15-gene expression profile. Methods in Molecular Biology, 1102, 427-440. doi:10.1007/ 978-1-62703-727-3 22.

230. Sorlie, T., Perou, C. M., Tibshirani, R., Aas, T., Geisler, S., Johnsen, H., et al. (2001). Gene expression patterns of breast carcinomas distinguish tumor subclasses with clinical implications. [Research support, non-U.S. Gov't; research support, U.S. Gov't, P.H.S.]. Proceedings of the National Academy of Sciences of the United States of America, 98(19), 10869-10874. doi:10. 1073/pnas.191367098.

231. Gruvberger, S., Ringner, M., Chen, Y., Panavally, S., Saal, L. H., Borg, A., et al. (2001). Estrogen receptor status in breast cancer is associated with remarkably distinct gene expression patterns. [Research support, non-U.S. Gov't]. Cancer Research, 61(16), 5979-5984

232. Pfeffer, U., Romeo, F., Noonan, D. M., \& Albini, A. (2009). Prediction of breast cancer metastasis by genomic profiling: where do we stand? Clinical \& Experimental Metastasis, 26(6), 547558. doi:10.1007/s10585-009-9254-y.

233. Li, Z., Yu, X., Shen, J., \& Jiang, Y. (2015). MicroRNA dysregulation in uveal melanoma: a new player enters the game. Oncotarget, 6(7), 4562-4568. doi:10.18632/oncotarget.2923.

234. Worley, L. A., Long, M. D., Onken, M. D., \& Harbour, J. W. (2008). Micro-RNAs associated with metastasis in uveal melanoma identified by multiplexed microarray profiling. Melanoma Research, 18(3), 184-190. doi:10.1097/CMR.0b013e3282feeac6.

235. Knudson, A. G. (1971). Mutation and cancer: statistical study of retinoblastoma. Proceedings of the National Academy of Sciences, 68(4), 820-823.

236. Moolgavkar, S. H., \& Knudson, A. G. (1981). Mutation and cancer: a model for human carcinogenesis. Journal of the National Cancer Institute, 66(6), 1037-1052. doi:10.1093/jnci/66.6.1037.

237. Vogelstein, B., \& Kinzler, K. W. (1993). The multistep nature of cancer. Trends in Genetics, 9(4), 138-141.

238. Hanahan, D., \& Weinberg, R. A. (2000). The hallmarks of cancer. Cell, 100(1), 57-70. doi:10.1016/S0092-8674(00)81683-9.

239. Hanahan, D., \& Weinberg, R. A. (2011). Hallmarks of cancer: the next generation. Cell, 144(5), 646-674. doi:10.1016/j.cell.2011. 02.013 .

240. Coupland, S. E., Lake, S. L., Zeschnigk, M., \& Damato, B. E. (2013). Molecular pathology of uveal melanoma. Eye (London, England), 27(2), 230-242. doi:10.1038/eye.2012.255.

241. Ehlers, J. P., Worley, L., Onken, M. D., \& Harbour, J. W. (2005). DDEF1 is located in an amplified region of chromosome $8 \mathrm{q}$ and is overexpressed in uveal melanoma. Clinical Cancer Research, 11(10), 3609-3613. doi:10.1158/1078-0432.CCR-04-1941.

242. Furman, C., Short, S. M., Subramanian, R. R., Zetter, B. R., \& Roberts, T. M. (2002). DEF-1/ASAP1 is a GTPase-activating protein (GAP) for ARF1 that enhances cell motility through a GAP- dependent mechanism. The Journal of Biological Chemistry, 277(10), 7962-7969. doi:10.1074/jbc.M109149200.

243. Sabe, H., Hashimoto, S., Morishige, M., Ogawa, E., Hashimoto, A., Nam, J. M., et al. (2009). The EGFRGEP100-Arf6-AMAP1 signaling pathway specific to breast cancer invasion and metastasis. Traffic, 10(8), 982-993. doi: 10.1111/j.1600-0854.2009.00917.x.

244. White, V. A., Chambers, J. D., Courtright, P. D., Chang, W. Y., \& Horsman, D. E. (1998). Correlation of cytogenetic abnormalities with the outcome of patients with uveal melanoma. Cancer, 83(2), 354-359. doi:10.1002/(SICI) 1097-0142(19980715)83:2<354:: AID-CNCR20>3.0.CO;2-R

245. Naus, N. C., Verhoeven, A. C., van Drunen, E., Slater, R., Mooy, C. M., Paridaens, D. A., et al. (2002). Detection of genetic prognostic markers in uveal melanoma biopsies using fluorescence in situ hybridization. Clinical Cancer Research, 8(2), 534-539.

246. Beby, F., Des Portes, V., Till, M., Mottolese, C., \& Denis, P. (2012). Chromosome 6p25 deletion syndrome: report of a case with optic disc coloboma and review of published ophthalmic findings. Ophthalmic Genetics, 33(4), 240-248. doi:10.3109/ 13816810.2012 .675396$.

247. Arnett, H. A., \& Viney, J. L. (2014). Immune modulation by butyrophilins. Nature Reviews. Immunology, 14(8), 559-569. doi:10.1038/nri3715.

248. Maat, W., Haasnoot, G. W., Claas, F. H., Schalij-Delfos, N. E., Schreuder, G. M., \& Jager, M. J. (2006). HLA class I and II genotype in uveal melanoma: relation to occurrence and prognosis. Investigative Ophthalmology \& Visual Science, 47(1), 3-6. doi:10.1167/iovs.05-1122.

249. Krishnakumar, S., Abhyankar, D., Lakshmi, S. A., Shanmugam, M. P., Pushparaj, V., \& Biswas, J. (2003). HLA class II antigen expression in uveal melanoma: correlation with clinicopathological features. Experimental Eye Research, 77(2), 175-180.

250. Maat, W., van der Slik, A. R., Verhoeven, D. H., Alizadeh, B. Z., Ly, L. V., Verduijn, W., et al. (2009). Evidence for natural killer cell-mediated protection from metastasis formation in uveal melanoma patients. Investigative Ophthalmology \& Visual Science, 50(6), 2888-2895. doi:10.1167/iovs.08-2733.

251. Crusz, S. M., \& Balkwill, F. R. (2015). Inflammation and cancer: advances and new agents. Nature Reviews. Clinical Oncology, 12(10), 584-596. doi:10.1038/nrclinonc.2015.105.

252. Mantovani, A., \& Allavena, P. (2015). The interaction of anticancer therapies with tumor-associated macrophages. The Journal of Experimental Medicine, 212(4), 435-445. doi:10.1084/jem. 20150295.

253. Bonavita, E., Galdiero, M. R., Jaillon, S., \& Mantovani, A. (2015). Phagocytes as corrupted policemen in cancer-related inflammation. Advances in Cancer Research, 128, 141-171. doi:10.1016/ bs.acr.2015.04.013.

254. Noy, R., \& Pollard, J. W. (2014). Tumor-associated macrophages: from mechanisms to therapy. Immunity, 41(1), 49-61. doi:10. 1016/j.immuni.2014.06.010.

255. Sica, A., \& Mantovani, A. (2012). Macrophage plasticity and polarization: in vivo veritas. The Journal of Clinical Investigation, 122(3), 787-795. doi:10.1172/JCI59643.

256. Murray, P. J., Allen, J. E., Biswas, S. K., Fisher, E. A., Gilroy, D. W., Goerdt, S., et al. (2014). Macrophage activation and polarization: nomenclature and experimental guidelines. Immunity, 41(1), 14-20. doi:10.1016/j.immuni.2014.06.008.

257. Bronkhorst, I. H., \& Jager, M. J. (2013). Inflammation in uveal melanoma. Eye (London, England), 27(2), 217-223. doi:10.1038/ eye.2012.253.

258. Makitie, T., Summanen, P., Tarkkanen, A., \& Kivela, T. (2001). Tumor-infiltrating macrophages (CD68(+) cells) and prognosis in malignant uveal melanoma. Investigative Ophthalmology \& Visual Science, 42(7), 1414-1421. 
259. Maat, W., Ly, L. V., Jordanova, E. S., de Wolff-Rouendaal, D., Schalij-Delfos, N. E., \& Jager, M. J. (2008). Monosomy of chromosome 3 and an inflammatory phenotype occur together in uveal melanoma. Investigative Ophthalmology \& Visual Science, 49(2), 505-510. doi:10.1167/jovs.07-0786.

260. Bronkhorst, I. H., Ly, L. V., Jordanova, E. S., Vrolijk, J., Versluis, M., Luyten, G. P., et al. (2011). Detection of M2-macrophages in uveal melanoma and relation with survival. Investigative Ophthalmology \& Visual Science, 52(2), 643-650. doi:10.1167/ iovs. 10-5979.

261. Oliva, M., Rullan, A. J., \& Piulats, J. M. (2016). Uveal melanoma as a target for immune-therapy. Ann Transl Med, 4(9), 172. doi:10. 21037/atm.2016.05.04

262. Napolitano, A., Pellegrini, L., Dey, A., Larson, D., Tanji, M., Flores, E. G., et al. (2016). Minimal asbestos exposure in germline BAP1 heterozygous mice is associated with deregulated inflammatory response and increased risk of mesothelioma. Oncogene, 35(15), 1996-2002. doi:10.1038/onc.2015.243.

263. Toivonen, P., Makitie, T., Kujala, E., \& Kivela, T. (2004). Microcirculation and tumor-infiltrating macrophages in choroidal and ciliary body melanoma and corresponding metastases. Investigative Ophthalmology \& Visual Science, 45(1), 1-6.

264. Ly, L. V., Baghat, A., Versluis, M., Jordanova, E. S., Luyten, G. P., van Rooijen, N., et al. (2010). In aged mice, outgrowth of intraocular melanoma depends on proangiogenic M2-type macrophages. Journal of Immunology, 185(6), 3481-3488. doi:10. 4049/jimmunol.0903479.

265. Stei, M. M., Loeffler, K. U., Holz, F. G., \& Herwig, M. C. (2016). Animal models of uveal melanoma: methods, applicability, and limitations. BioMed Research International, 2016, 4521807. doi: 10.1155/2016/4521807.

266. Tham, M., Khoo, K., Yeo, K. P., Kato, M., Prevost-Blondel, A., Angeli, V., et al. (2015). Macrophage depletion reduces postsurgical tumor recurrence and metastatic growth in a spontaneous murine model of melanoma. Oncotarget, 6(26), 22857-22868. doi:10.18632/oncotarget.3127.

267. Clarijs, R., Schalkwijk, L., Ruiter, D. J., \& de Waal, R. M. (2003). EMAP-II expression is associated with macrophage accumulation in primary uveal melanoma. Investigative Ophthalmology \& Visual Science, 44(5), 1801-1806.

268. Nagarkatti-Gude, N., Bronkhorst, I. H., van Duinen, S. G., Luyten, G. P., \& Jager, M. J. (2012). Cytokines and chemokines in the vitreous fluid of eyes with uveal melanoma. Investigative Ophthalmology \& Visual Science, 53(11), 6748-6755. doi:10. 1167/iovs.12-10123.

269. Jehs, T., Faber, C., Juel, H. B., Bronkhorst, I. H., Jager, M. J., \& Nissen, M. H. (2014). Inflammation-induced chemokine expression in uveal melanoma cell lines stimulates monocyte chemotaxis. Investigative Ophthalmology \& Visual Science, 55(8), 51695175. doi:10.1167/iovs.14-14394.

270. Lattanzio, L., Tonissi, F., Torta, I., Gianello, L., Russi, E., Milano, G., et al. (2013). Role of IL-8 induced angiogenesis in uveal melanoma. Investigational New Drugs, 31(5), 1107-1114. doi:10. 1007/s10637-013-0005-1.

271. Messmer, E., Bornfeld, N., Foerster, M., Schilling, H., \& Wessing, A. (1992). Histopathologic findings in eyes treated with a ruthenium plaque for uveal melanoma. Graefe's Archive for Clinical and Experimental Ophthalmology, 230(4), 391-396.

272. Toivonen, P., \& Kivela, T. (2012). Infiltrating macrophages in extratumoural tissues after brachytherapy of uveal melanoma. Acta Ophthalmologica, 90(4), 341-349. doi:10.1111/j.17553768.2010.01985.x.

273. Young, L. H., \& Gragoudas, E. S. (1994). Macular uveal melanoma treated with proton beam irradiation. 10-year follow-up observation with histopathologic correlation. Retina, 14(1), 43-46.
274. Dennaoui, J., Bronkhorst, I. H., Ly, L. V., de Wolff-Rouendaal, D., Keunen, J. E., Schalij-Delfos, N. E., et al. (2011). Changes in immunological markers and influx of macrophages following trans-scleral thermotherapy of uveal melanoma. Acta Ophthalmologica, 89(3), 268-273. doi:10.1111/j.1755-3768. 2010.02076.x.

275. Chen, R. W., \& Harbour, J. W. (2014). Rapid regression of a subset of class 1 uveal melanomas after iodine- 125 plaque radiotherapy suggests an inflammatory mechanism. Graefe's Archive for Clinical and Experimental Ophthalmology, 252(12), 20212022. doi:10.1007/s00417-014-2793-1.

276. Topalian, S. L., Drake, C. G., \& Pardoll, D. M. (2015). Immune checkpoint blockade: a common denominator approach to cancer therapy. Cancer Cell, 27(4), 450-461. doi:10.1016/j.ccell.2015. 03.001.

277. Mlecnik, B., Bindea, G., Angell, H. K., Maby, P., Angelova, M., Tougeron, D., et al. (2016). Integrative analyses of colorectal cancer show immunoscore is a stronger predictor of patient survival than microsatellite instability. Immunity, 44(3), 698-711. doi:10. 1016/j.immuni.2016.02.025.

278. Donnem, T., Kilvaer, T. K., Andersen, S., Richardsen, E., Paulsen, E. E., Hald, S. M., et al. (2016). Strategies for clinical implementation of TNM-Immunoscore in resected nonsmall-cell lung cancer. Annals of Oncology, 27(2), 225-232. doi:10.1093/annonc/ mdv560.

279. Gabrielson, A., Wu, Y., Wang, H., Jiang, J., Kallakury, B., Gatalica, Z., et al. (2016). Intratumoral CD3 and CD8 T-cell densities associated with relapse-free survival in HCC. Cancer Immunology Research, 4(5), 419-430. doi:10.1158/2326-6066. CIR-15-0110.

280. Dunn, G. P., Old, L. J., \& Schreiber, R. D. (2004). The immunobiology of cancer immunosurveillance and immunoediting. Immunity, 21(2), 137-148. doi:10.1016/j. immuni.2004.07.017.

281. Okazaki, T., \& Honjo, T. (2006). The PD-1-PD-L pathway in immunological tolerance. Trends in Immunology, 27(4), 195201. doi:10.1016/j.it.2006.02.001.

282. Topalian, S. L., Sznol, M., McDermott, D. F., Kluger, H. M., Carvajal, R. D., Sharfman, W. H., et al. (2014). Survival, durable tumor remission, and long-term safety in patients with advanced melanoma receiving nivolumab. Journal of Clinical Oncology, 32(10), 1020-1030. doi:10.1200/JCO.2013.53.0105.

283. Weber, J. S., D'Angelo, S. P., Minor, D., Hodi, F. S., Gutzmer, R., Neyns, B., et al. (2015). Nivolumab versus chemotherapy in patients with advanced melanoma who progressed after anti-CTLA4 treatment (CheckMate 037): a randomised, controlled, open-label, phase 3 trial. The Lancet Oncology, 16(4), 375-384. doi:10. 1016/S1470-2045(15)70076-8.

284. Schumacher, T. N., \& Schreiber, R. D. (2015). Neoantigens in cancer immunotherapy. Science, 348(6230), 69-74. doi:10.1126/ science.aaa4971.

285. Taube, J. M., Klein, A., Brahmer, J. R., Xu, H., Pan, X., Kim, J. H., et al. (2014). Association of PD-1, PD-1 ligands, and other features of the tumor immune microenvironment with response to anti-PD-1 therapy. Clinical Cancer Research, 20(19), 5064 5074. doi:10.1158/1078-0432.CCR-13-3271.

286. Daud, A. I., Loo, K., Pauli, M. L., Sanchez-Rodriguez, R., Sandoval, P. M., Taravati, K., et al. (2016). Tumor immune profiling predicts response to anti-PD-1 therapy in human melanoma. The Journal of Clinical Investigation, 126(9), 3447-3452. doi:10. 1172/JCI87324.

287. Walker, L. S., \& Sansom, D. M. (2011). The emerging role of CTLA4 as a cell-extrinsic regulator of T cell responses. Nature Reviews. Immunology, 11(12), 852-863. doi:10.1038/nri3108.

288. Hodi, F. S., O'Day, S. J., McDermott, D. F., Weber, R. W., Sosman, J. A., Haanen, J. B., et al. (2010). Improved survival with 
ipilimumab in patients with metastatic melanoma. The New England Journal of Medicine, 363(8), 711-723. doi:10.1056/ NEJMoa1003466.

289. Niederkorn, J. Y. (2012). Ocular immune privilege and ocular melanoma: parallel universes or immunological plagiarism? Frontiers in Immunology, 3(148), 1-10. doi:10.3389/fimmu. 2012.00148.

290. Bronkhorst, I. H., Vu, T. H., Jordanova, E. S., Luyten, G. P., Burg, S. H., \& Jager, M. J. (2012). Different subsets of tumor-infiltrating lymphocytes correlate with macrophage influx and monosomy 3 in uveal melanoma. Investigative Ophthalmology \& Visual Science, 53(9), 5370-5378. doi:10.1167/iovs.11-9280.

291. Luke, J. J., Triozzi, P. L., McKenna, K. C., Van Meir, E. G., Gershenwald, J. E., Bastian, B. C., et al. (2015). Biology of advanced uveal melanoma and next steps for clinical therapeutics. Pigment Cell \& Melanoma Research, 28(2), 135-147. doi:10. 1111/pcmr.12304.

292. Taylor, A. W. (2016). Ocular immune privilege and transplantation. Frontiers in Immunology, 7, 37. doi:10.3389/fimmu.2016. 00037.

293. Stein-Streilein, J., \& Streilein, J. W. (2002). Anterior chamber associated immune deviation (ACAID): regulation, biological relevance, and implications for therapy. International Reviews of Immunology, 21(2-3), 123-152.

294. Lin, H. H., Faunce, D. E., Stacey, M., Terajewicz, A., Nakamura, T., Zhang-Hoover, J., et al. (2005). The macrophage F4/80 receptor is required for the induction of antigen-specific efferent regulatory T cells in peripheral tolerance. The Journal of Experimental Medicine, 201(10), 1615-1625. doi:10.1084/jem.20042307.

295. Wilbanks, G. A., \& Streilein, J. W. (1992). Fluids from immune privileged sites endow macrophages with the capacity to induce antigen-specific immune deviation via a mechanism involving transforming growth factor-beta. European Journal of Immunology, 22(4), 1031-1036. doi:10.1002/eji.1830220423.

296. Ryu, Y. H., \& Kim, J. C. (2007). Expression of indoleamine 2,3dioxygenase in human corneal cells as a local immunosuppressive factor. Investigative Ophthalmology \& Visual Science, 48(9), 4148-4152. doi:10.1167/iovs.05-1336.

297. Platten, M., Wick, W., \& Van den Eynde, B. J. (2012). Tryptophan catabolism in cancer: beyond IDO and tryptophan depletion. Cancer Research, 72(21), 5435-5440. doi:10.1158/0008-5472. CAN-12-0569.

298. Repp, A. C., Mayhew, E. S., Apte, S., \& Niederkorn, J. Y. (2000). Human uveal melanoma cells produce macrophage migrationinhibitory factor to prevent lysis by NK cells. Journal of Immunology, 165(2), 710-715.

299. Hurks, H. M., Valter, M. M., Wilson, L., Hilgert, I., van den Elsen, P. J., \& Jager, M. J. (2001). Uveal melanoma: no expression of HLA-G. Investigative Ophthalmology \& Visual Science, 42(13), 3081-3084.

300. Moretta, L., Pietra, G., Vacca, P., Pende, D., Moretta, F., Bertaina, A., et al. (2016). Human NK cells: from surface receptors to clinical applications. Immunology Letters, 178, 15-19. doi:10.1016/j. imlet.2016.05.007.

301. Vetter, C. S., Lieb, W., Brocker, E. B., \& Becker, J. C. (2004). Loss of nonclassical MHC molecules MIC-A/B expression during progression of uveal melanoma. British Journal of Cancer, 91(8), 1495-1499. doi:10.1038/sj.bjc.6602123.

302. de la Cruz Jr., P. O., Specht, C. S., \& McLean, I. W. (1990). Lymphocytic infiltration in uveal malignant melanoma. Cancer, 65(1), 112-115. doi:10.1002/1097-0142(19900101)65:1<112:: AID-CNCR2820650123>3.0.CO;2-X.

303. Whelchel, J. C., Farah, S. E., McLean, I. W., \& Burnier, M. N. (1993). Immunohistochemistry of infiltrating lymphocytes in uveal malignant melanoma. Investigative Ophthalmology \& Visual Science, 34(8), 2603-2606.
304. de Waard-Siebinga, I., Hilders, C. G., Hansen, B. E., van Delft, J. L., \& Jager, M. J. (1996). HLA expression and tumor-infiltrating immune cells in uveal melanoma. Graefe's Archive for Clinical and Experimental Ophthalmology, 234(1), 34-42.

305. Bronkhorst, I. H., \& Jager, M. J. (2012). Uveal melanoma: the inflammatory microenvironment. Journal of Innate Immunity, 4(5-6), 454-462. doi:10.1159/000334576.

306. Lagouros, E., Salomao, D., Thorland, E., Hodge, D. O., Vile, R., \& Pulido, J. S. (2009). Infiltrative T regulatory cells in enucleated uveal melanomas. Transactions of the American Ophthalmological Society, 107, 223-228.

307. Mougiakakos, D., Johansson, C. C., Trocme, E., All-Ericsson, C., Economou, M. A., Larsson, O., et al. (2010). Intratumoral forkhead box P3-positive regulatory $\mathrm{T}$ cells predict poor survival in cyclooxygenase-2-positive uveal melanoma. Cancer, 116(9), 2224-2233. doi:10.1002/cncr.24999.

308. Ma, J., Usui, Y., Kezuka, T., Okunuki, Y., Zhang, L., An, X., et al. (2012). Costimulatory molecule expression on human uveal melanoma cells: functional analysis of CD40 and B7-H1. Experimental Eye Research, 96(1), 98-106. doi:10.1016/j.exer. 2011.12.014.

309. Jia, R., Jiao, Z., Xu, X., Wang, J., Zhou, Y., Song, X., et al. (2011). Functional significance of B7-H1 expressed by human uveal melanoma cells. Molecular Medicine Reports, 4(1), 163-167. doi:10. 3892/mmr.2010.397.

310. Yang, W., Chen, P. W., Li, H., Alizadeh, H., \& Niederkorn, J. Y. (2008). PD-L1: PD-1 interaction contributes to the functional suppression of T-cell responses to human uveal melanoma cells in vitro. Investigative Ophthalmology \& Visual Science, 49(6), 2518-2525. doi:10.1167/iovs.07-1606.

311. Chen, P. W., Mellon, J. K., Mayhew, E., Wang, S., He, Y. G., Hogan, N., et al. (2007). Uveal melanoma expression of indoleamine 2,3-deoxygenase: establishment of an immune privileged environment by tryptophan depletion. Experimental Eye Research, 85(5), 617-625. doi:10.1016/j.exer.2007.07.014.

312. Krauthammer, M., Kong, Y., Ha, B. H., Evans, P., Bacchiocchi, A., McCusker, J. P., et al. (2012). Exome sequencing identifies recurrent somatic RAC1 mutations in melanoma. Nature Genetics, 44(9), 1006-1014. doi:10.1038/ng.2359.

313. Larkin, J., Hodi, F. S., \& Wolchok, J. D. (2015). Combined nivolumab and ipilimumab or monotherapy in untreated melanoma. The New England Journal of Medicine, 373(13), 1270-1271. doi:10.1056/NEJMc1509660.

314. Bol, K. F., Mensink, H. W., Aarntzen, E. H., Schreibelt, G., Keunen, J. E., Coulie, P. G., et al. (2014). Long overall survival after dendritic cell vaccination in metastatic uveal melanoma patients. American Journal of Ophthalmology, 158(5), 939-947. doi:10.1016/j.ajo.2014.07.014.

315. Rothermel, L. D., Sabesan, A. C., Stephens, D. J., Chandran, S. S., Paria, B. C., Srivastava, A. K., et al. (2016). Identification of an immunogenic subset of metastatic uveal melanoma. Clinical Cancer Research, 22(9), 2237-2249. doi:10.1158/1078-0432. CCR-15-2294.

316. Olofsson, R., Cahlin, C., All-Ericsson, C., Hashimi, F., Mattsson, J., Rizell, M., et al. (2014). Isolated hepatic perfusion for ocular melanoma metastasis: registry data suggests a survival benefit. Annals of Surgical Oncology, 21(2), 466-472. doi:10.1245/ s10434-013-3304-z.

317. Eskelin, S., Pyrhonen, S., Summanen, P., Prause, J. U., \& Kivela, T. (1999). Screening for metastatic malignant melanoma of the uvea revisited. Cancer, 85(5), 1151-1159.

318. Mouriaux, F., Diorio, C., Bergeron, D., Berchi, C., \& Rousseau, A. (2012). Liver function testing is not helpful for early diagnosis of metastatic uveal melanoma. Ophthalmology, 119(8), 15901595. doi:10.1016/j.ophtha.2012.01.045. 
319. Choudhary, M. M., Gupta, A., Bena, J., Emch, T., \& Singh, A. D. (2016). Hepatic ultrasonography for surveillance in patients with uveal melanoma. JAMA Ophthalmol, 134(2), 174-180. doi:10. 1001/jamaophthalmol.2015.4810.

320. Missotten, G. S., Tang, N. E., Korse, C. M., Hurks, H. M., de Wolff-Rouendaal, D., Keunen, J. E., et al. (2003). Prognostic value of S-100-beta serum concentration in patients with uveal melanoma. Archives of Ophthalmology, 121(8), 1117-1119. doi:10. 1001/archopht.121.8.1117.

321. Schaller, U. C., Bosserhoff, A. K., Neubauer, A. S., Buettner, R., Kampik, A., \& Mueller, A. J. (2002). Melanoma inhibitory activity: a novel serum marker for uveal melanoma. Melanoma Research, 12(6), 593-599. doi:10.1097/01.cmr.0000043146. 28051.b8

322. Reiniger, I. W., Schaller, U. C., Haritoglou, C., Hein, R., Bosserhoff, A. K., Kampik, A., et al. (2005). "Melanoma inhibitory activity" (MIA): a promising serological tumour marker in metastatic uveal melanoma. Graefe's Archive for Clinical and Experimental Ophthalmology, 243(11), 1161-1166. doi:10. 1007/s00417-005-1171-4.

323. Missotten, G. S., Korse, C. M., van Dehn, C., Linders, T. C., Keunen, J. E., Jager, M. J., et al. (2007). S-100B protein and melanoma inhibitory activity protein in uveal melanoma screening. A comparison with liver function tests. Tumour Biology, 28(2), 63-69. doi:10.1159/000099151.

324. Barak, V., Frenkel, S., Kalickman, I., Maniotis, A. J., Folberg, R., $\&$ Pe'er, J. (2007). Serum markers to detect metastatic uveal melanoma. Anticancer Research, 27(4A), 1897-1900.

325. Barak, V., Frenkel, S., Valyi-Nagy, K., Leach, L., Apushkin, M. A., Lin, A. Y., et al. (2007). Using the direct-injection model of early uveal melanoma hepatic metastasis to identify TPS as a potentially useful serum biomarker. Investigative Ophthalmology \& Visual Science, 48(10), 4399-4402. doi:10.1167/iovs.07-0552.

326. Frenkel, S., Zloto, O., Pe'er, J., \& Barak, V. (2013). Insulin-like growth factor-1 as a predictive biomarker for metastatic uveal melanoma in humans. Investigative Ophthalmology \& Visual Science, 54(1), 490-493. doi:10.1167/iovs.12-10228.

327. Suesskind, D., Schatz, A., Schnichels, S., Coupland, S. E., Lake, S. L., Wissinger, B., et al. (2012). GDF-15: a novel serum marker for metastases in uveal melanoma patients. Graefe's Archive for Clinical and Experimental Ophthalmology, 250(6), 887-895. doi: 10.1007/s00417-011-1786-6.

328. Chen, L. L., Tian, J. J., Su, L., Jing, Y., Zhang, S. C., Zhang, H. X., et al. (2015). DJ-1: a promising marker in metastatic uveal melanoma. Journal of Cancer Research and Clinical Oncology, 141(2), 315-321. doi:10.1007/s00432-014-1804-2.

329. Barak, V., Pe'er, J., Kalickman, I., \& Frenkel, S. (2011). VEGF as a biomarker for metastatic uveal melanoma in humans. Current Eye Research, 36(4), 386-390. doi:10.3109/02713683.2010.534573.

330. Barisione, G., Fabbi, M., Gino, A., Queirolo, P., Orgiano, L., Spano, L., et al. (2015). Potential role of soluble c-Met as a new candidate biomarker of metastatic uveal melanoma. JAMA Ophthalmol, 133(9), 1013-1021. doi:10.1001/jamaophthalmol. 2015.1766.

331. Hofman, P., \& Popper, H. H. (2016). Pathologists and liquid biopsies: to be or not to be? Virchows Archiv. doi:10.1007/s00428016-2004-z.

332. Tura, A., Luke, J., Merz, H., Reinsberg, M., Luke, M., Jager, M. J., et al. (2014). Identification of circulating melanoma cells in uveal melanoma patients by dual-marker immunoenrichment. Investigative Ophthalmology \& Visual Science, 55(7), 43954404. doi:10.1167/iovs.14-14512.

333. Mazzini, C., Pinzani, P., Salvianti, F., Scatena, C., Paglierani, M., Ucci, F., et al. (2014). Circulating tumor cells detection and counting in uveal melanomas by a filtration-based method. Cancers (Basel), 6(1), 323-332. doi:10.3390/cancers6010323.
334. Charitoudis, G., Schuster, R., Joussen, A. M., Keilholz, U., \& Bechrakis, N. E. (2016). Detection of tumour cells in the bloodstream of patients with uveal melanoma: influence of surgical manipulation on the dissemination of tumour cells in the bloodstream. The British Journal of Ophthalmology, 100(4), 468-472. doi:10.1136/bjophthalmol-2015-306955.

335. Ulmer, A., Beutel, J., Susskind, D., Hilgers, R. D., Ziemssen, F., Luke, M., et al. (2008). Visualization of circulating melanoma cells in peripheral blood of patients with primary uveal melanoma. Clinical Cancer Research, 14(14), 4469-4474. doi:10.1158/10780432.CCR-08-0012.

336. Suesskind, D., Ulmer, A., Schiebel, U., Fierlbeck, G., Spitzer, B., Spitzer, M. S., et al. (2011). Circulating melanoma cells in peripheral blood of patients with uveal melanoma before and after different therapies and association with prognostic parameters: a pilot study. Acta Ophthalmologica, 89(1), 17-24. doi:10.1111/j.17553768.2009.01617.x

337. Bande, M. F., Santiago, M., Muinelo-Romay, L., Blanco, M. J., Mera, P., Capeans, C., et al. (2015). Detection of circulating melanoma cells in choroidal melanocytic lesions. BMC Research Notes, 8, 452. doi:10.1186/s13104-015-1420-5.

338. Tura, A., Merz, H., Reinsberg, M., Luke, M., Jager, M. J., Grisanti, S., et al. (2016). Analysis of monosomy-3 in immunomagnetically-isolated circulating melanoma cells in uveal melanoma patients. Pigment Cell \& Melanoma Research, 29(5), 583-589. doi:10.1111/pcmr.12507.

339. Schuster, R., Bechrakis, N. E., Stroux, A., Busse, A., Schmittel, A., Scheibenbogen, C., et al. (2007). Circulating tumor cells as prognostic factor for distant metastases and survival in patients with primary uveal melanoma. Clinical Cancer Research, 13(4), 1171-1178. doi:10.1158/1078-0432.CCR-06-2329.

340. Schuster, R., Bechrakis, N. E., Stroux, A., Busse, A., Schmittel, A., Thiel, E., et al. (2011). Prognostic relevance of circulating tumor cells in metastatic uveal melanoma. Oncology, $80(1-2)$, 57-62. doi:10.1159/000328283.

341. Bettegowda, C., Sausen, M., Leary, R. J., Kinde, I., Wang, Y., Agrawal, N., et al. (2014). Detection of circulating tumor DNA in early- and late-stage human malignancies. Science Translational Medicine, 6(224), 224ra224. doi:10.1126/ scitranslmed.3007094.

342. Stroun, M., Lyautey, J., Lederrey, C., Mulcahy, H. E., \& Anker, P. (2001). Alu repeat sequences are present in increased proportions compared to a unique gene in plasma/serum DNA: evidence for a preferential release from viable cells? Annals of the New York Academy of Sciences, 945, 258-264. doi:10.1111/j.1749-6632. 2001.tb03894.x.

343. Metz, C. H., Scheulen, M., Bornfeld, N., Lohmann, D., \& Zeschnigk, M. (2013). Ultradeep sequencing detects GNAQ and GNA11 mutations in cell-free DNA from plasma of patients with uveal melanoma. Cancer Medicine, 2(2), 208215. doi:10.1002/cam4.61.

344. Diaz Jr., L. A., \& Bardelli, A. (2014). Liquid biopsies: Genotyping circulating tumor DNA. Journal of Clinical Oncology, 32(6), 579586. doi:10.1200/JCO.2012.45.2011.

345. Bidard, F. C., Madic, J., Mariani, P., Piperno-Neumann, S., Rampanou, A., Servois, V., et al. (2014). Detection rate and prognostic value of circulating tumor cells and circulating tumor DNA in metastatic uveal melanoma. International Journal of Cancer, 134(5), 1207-1213. doi:10.1002/ijc.28436.

346. Shivapurkar, N., Weiner, L. M., Marshall, J. L., Madhavan, S., Deslattes Mays, A., Juhl, H., et al. (2014). Recurrence of early stage colon cancer predicted by expression pattern of circulating microRNAs. PloS One, 9(1), e84686. doi:10.1371/journal.pone. 0084686.

347. Subramanian, A., Gupta, V., Sarkar, S., Maity, G., Banerjee, S., Ghosh, A., et al. (2016). Exosomes in carcinogenesis: molecular 
palkis carry signals for the regulation of cancer progression and metastasis. J Cell Commun Signal. doi:10.1007/s12079-0160338-6.

348. Ragusa, M., Barbagallo, C., Statello, L., Caltabiano, R., Russo, A., Puzzo, L., et al. (2015). miRNA profiling in vitreous humor, vitreal exosomes and serum from uveal melanoma patients: pathological and diagnostic implications. Cancer Biology \& Therapy, 16(9), 1387-1396. doi:10.1080/15384047.2015.1046021.

349. Achberger, S., Aldrich, W., Tubbs, R., Crabb, J. W., Singh, A. D., \& Triozzi, P. L. (2014). Circulating immune cell and microRNA in patients with uveal melanoma developing metastatic disease. Molecular Immunology, 58(2), 182-186. doi:10.1016/j.molimm. 2013.11.018

350. Eldh, M., Olofsson Bagge, R., Lasser, C., Svanvik, J., Sjostrand, M., Mattsson, J., et al. (2014). MicroRNA in exosomes isolated directly from the liver circulation in patients with metastatic uveal melanoma. BMC Cancer, 14, 962. doi:10.1186/1471-2407-14-962.

351. Malho, P., Dunn, K., Donaldson, D., Dubielzig, R. R., Birand, Z., \& Starkey, M. (2013). Investigation of prognostic indicators for human uveal melanoma as biomarkers of canine uveal melanoma metastasis. The Journal of Small Animal Practice, 54(11), 584 593. doi:10.1111/jsap.12141.

352. Galan, A., Martin-Suarez, E. M., Molleda, J. M., Raya, A., Gomez-Laguna, J., \& Martin De Las Mulas, J. (2009). Presumed primary uveal melanoma with brain extension in a dog. The Journal of Small Animal Practice, 50(6), 306-310. doi:10.1111/j.1748-5827.2009.00721.x.

353. Niederkorn, J. Y., Shadduck, J. A., Albert, D., \& Essex, M. (1981). Serum antibodies against feline oncornavirus-associated cell membrane antigen in cats bearing virally induced uveal melanomas. Investigative Ophthalmology \& Visual Science, 20(5), 598-605.

354. Planellas, M., Pastor, J., Torres, M. D., Pena, T., \& Leiva, M. (2010). Unusual presentation of a metastatic uveal melanoma in a cat. Veterinary Ophthalmology, 13(6), 391-394. doi:10.1111/j. 1463-5224.2010.00839.x.

355. Dithmar, S., Albert, D. M., \& Grossniklaus, H. E. (2000). Animal models of uveal melanoma. Melanoma Research, 10(3), 195-211.

356. Schuh, J. C. (1989). Congenital intraocular melanoma in a calf. Journal of Comparative Pathology, 101(1), 113-116.

357. Fidler, I. J., \& Nicolson, G. L. (1976). Organ selectivity for implantation survival and growth of B16 melanoma variant tumor lines. Journal of the National Cancer Institute, 57(5), 1199-1202.

358. Grossniklaus, H. E., Barron, B. C., \& Wilson, M. W. (1995). Murine model of anterior and posterior ocular melanoma. Current Eye Research, 14(5), 399-404.

359. Diaz, C. E., Rusciano, D., Dithmar, S., \& Grossniklaus, H. E. (1999). B16LS9 melanoma cells spread to the liver from the murine ocular posterior compartment (PC). Current Eye Research, $18(2), 125-129$.

360. Yang, W., Li, H., Mayhew, E., Mellon, J., Chen, P. W., \& Niederkorn, J. Y. (2011). NKT cell exacerbation of liver metastases arising from melanomas transplanted into either the eyes or spleens of mice. Investigative Ophthalmology \& Visual Science, 52(6), 3094-3102. doi:10.1167/iovs.10-7067.

361. Yang, H., Brackett, C. M., Morales-Tirado, V. M., Li, Z., Zhang, Q., Wilson, M. W., et al. (2016). The Toll-like receptor 5 agonist entolimod suppresses hepatic metastases in a murine model of ocular melanoma via an NK cell-dependent mechanism. Oncotarget, 7(3), 2936-2950. doi:10.18632/oncotarget.6500.

362. de Lange, J., Ly, L. V., Lodder, K., Verlaan-de Vries, M., Teunisse, A. F., Jager, M. J., et al. (2012). Synergistic growth inhibition based on small-molecule p53 activation as treatment for intraocular melanoma. Oncogene, 31(9), 1105-1116. doi:10.1038/onc. 2011.309.

363. Mueller, A. J., Maniotis, A. J., Freeman, W. R., Bartsch, D. U., Schaller, U. C., Bergeron-Lynn, G., et al. (2002). An orthotopic model for human uveal melanoma in SCID mice. Microvascular Research, 64(2), 207-213.

364. Braun, R. D., Abbas, A., Bukhari, S. O., \& Wilson 3rd, W. (2002). Hemodynamic parameters in blood vessels in choroidal melanoma xenografts and rat choroid. Investigative Ophthalmology \& Visual Science, 43(9), 3045-3052.

365. Liu, L. H., \& Ni, C. (1983). Rabbit model of uveal Greene melanoma: morphologic studies of metastatic lesions. Graefe's Archive for Clinical and Experimental Ophthalmology, 220(4), 179-183.

366. van der Ent, W., Burrello, C., Teunisse, A. F., Ksander, B. R., van der Velden, P. A., Jager, M. J., et al. (2014). Modeling of human uveal melanoma in zebrafish xenograft embryos. Investigative Ophthalmology \& Visual Science, 55(10), 6612-6622. doi:10. 1167/iovs.14-15202.

367. Ma, D., Luyten, G. P., Luider, T. M., Jager, M. J., \& Niederkorn, J. Y. (1996). Association between NM23-H1 gene expression and metastasis of human uveal melanoma in an animal model. Investigative Ophthalmology \& Visual Science, 37(11), 2293-2301.

368. Yang, H., Fang, G., Huang, X., Yu, J., Hsieh, C. L., \& Grossniklaus, H. E. (2008). In-vivo xenograft murine human uveal melanoma model develops hepatic micrometastases. Melanoma Research, 18(2), 95-103. doi:10.1097/CMR. 0b013e3282f628df.

369. Kelland, L. R. (2004). Of mice and men: values and liabilities of the athymic nude mouse model in anticancer drug development. European Journal of Cancer, 40(6), 827-836. doi:10.1016/j.ejca. 2003.11.028.

370. Kuzu, O. F., Nguyen, F. D., Noory, M. A., \& Sharma, A. (2015). Current state of animal (mouse) modeling in melanoma research. Cancer Growth Metastasis, 8(Suppl 1), 81-94. doi:10.4137/ CGM.S21214.

371. Braun, R. D., \& Vistisen, K. S. (2012). Modeling human choroidal melanoma xenograft growth in immunocompromised rodents to assess treatment efficacy. Investigative Ophthalmology \& Visual Science, 53(6), 2693-2701. doi:10.1167/iovs.11-9265.

372. Notting, I. C., Buijs, J. T., Que, I., Mintardjo, R. E., van der Horst, G., Karperien, M., et al. (2005). Whole-body bioluminescent imaging of human uveal melanoma in a new mouse model of local tumor growth and metastasis. Investigative Ophthalmology \& Visual Science, 46(5), 1581-1587. doi:10.1167/iovs.04-0245.

373. Folberg, R., Leach, L., Valyi-Nagy, K., Lin, A. Y., Apushkin, M. A., Ai, Z., et al. (2007). Modeling the behavior of uveal melanoma in the liver. Investigative Ophthalmology \& Visual Science, 48(7), 2967-2974. doi:10.1167/iovs.06-1522.

374. Kuruppu, D., Christophi, C., Bertram, J. F., \& O’Brien, P. E. (1996). Characterization of an animal model of hepatic metastasis. Journal of Gastroenterology and Hepatology, 11(1), 26-32. doi: 10.1111/j.1440-1746.1996.tb00006.x.

375. Lafreniere, R., \& Rosenberg, S. A. (1986). A novel approach to the generation and identification of experimental hepatic metastases in a murine model. Journal of the National Cancer Institute, 76(2), 309-322.

376. Gangemi, R., Amaro, A., Gino, A., Barisione, G., Fabbi, M., Pfeffer, U., et al. (2014). ADAM10 correlates with uveal melanoma metastasis and promotes in vitro invasion. Pigment Cell \& Melanoma Research, 27(6), 1138-1148. doi:10.1111/pcmr.12306.

377. Li, H., Alizadeh, H., \& Niederkorn, J. Y. (2008). Differential expression of chemokine receptors on uveal melanoma cells and their metastases. Investigative Ophthalmology \& Visual Science, 49(2), 636-643. doi:10.1167/iovs.07-1035.

378. Li, H., Yang, W., Chen, P. W., Alizadeh, H., \& Niederkorn, J. Y. (2009). Inhibition of chemokine receptor expression on uveal melanomas by CXCR4 siRNA and its effect on uveal melanoma liver metastases. Investigative Ophthalmology \& Visual Science, 50(12), 5522-5528. doi:10.1167/iovs.09-3804. 
379. Ozaki, S., Vuyyuru, R., Kageyama, K., Terai, M., Ohara, M., Cheng, H., et al. (2016). Establishment and characterization of orthotopic mouse models for human uveal melanoma hepatic colonization. The American Journal of Pathology, 186(1), 43-56. doi:10.1016/j.ajpath.2015.09.011.

380. Heegaard, S., Spang-Thomsen, M., \& Prause, J. U. (2003). Establishment and characterization of human uveal malignant melanoma xenografts in nude mice. Melanoma Research, 13(3), 247-251. doi:10.1097/01.cmr.0000056239.78713.c8.

381. Nemati, F., Sastre-Garau, X., Laurent, C., Couturier, J., Mariani, P., Desjardins, L., et al. (2010). Establishment and characterization of a panel of human uveal melanoma xenografts derived from primary and/or metastatic tumors. Clinical Cancer Research, 16(8), 2352-2362. doi:10.1158/1078-0432.CCR-09-3066.

382. Laurent, C., Gentien, D., Piperno-Neumann, S., Nemati, F., Nicolas, A., Tesson, B., et al. (2013). Patient-derived xenografts recapitulate molecular features of human uveal melanomas. Molecular Oncology, 7(3), 625-636. doi:10.1016/j.molonc. 2013.02.004

383. Nemati, F., de Montrion, C., Lang, G., Kraus-Berthier, L., Carita, G., Sastre-Garau, X., et al. (2014). Targeting Bcl-2/Bcl-XL induces antitumor activity in uveal melanoma patient-derived xenografts. PloS One, 9(1), e80836. doi:10.1371/journal.pone. 0080836.

384. Carita, G., Frisch-Dit-Leitz, E., Dahmani, A., Raymondie, C., Cassoux, N., Piperno-Neumann, S., et al. (2016). Dual inhibition of protein kinase C and p53-MDM2 or PKC and mTORC1 are novel efficient therapeutic approaches for uveal melanoma. Oncotarget, 33542-33556. doi:10.18632/oncotarget.9552.

385. Mueller, A. J., Folberg, R., Freeman, W. R., Bartsch, D. U., Bergeron-Lynn, G., Mehaffey, M. G., et al. (1999). Evaluation of the human choroidal melanoma rabbit model for studying microcirculation patterns with confocal ICG and histology. Experimental Eye Research, 68(6), 671-678. doi:10.1006/exer.1998.0650.

386. Blanco, G., Saornil, A. M., Domingo, E., Diebold, Y., Lopez, R., Rabano, G., et al. (2000). Uveal melanoma model with metastasis in rabbits: effects of different doses of cyclosporine A. Current Eye Research, 21(3), 740-747.

387. Lopez-Velasco, R., Morilla-Grasa, A., Saornil-Alvarez, M. A., Ordonez, J. L., Blanco, G., Rabano, G., et al. (2005). Efficacy of five human melanocytic cell lines in experimental rabbit choroidal melanoma. Melanoma Research, 15(1), 29-37.

388. Luyten, G. P., Mooy, C. M., De Jong, P. T., Hoogeveen, A. T., \& Luider, T. M. (1993). A chicken embryo model to study the growth of human uveal melanoma. Biochemical and Biophysical Research Communications, 192(1), 22-29.

389. Kalirai, H., Shahidipour, H., Coupland, S. E., \& Luyten, G. (2015). Use of the chick embryo model in uveal melanoma. Ocul Oncol Pathol, 1(3), 133-140. doi:10.1159/000370151.

390. van der Ent, W., Burrello, C., de Lange, M. J., van der Velden, P. A., Jochemsen, A. G., Jager, M. J., et al. (2015). Embryonic zebrafish: different phenotypes after injection of human uveal melanoma cells. Ocul Oncol Pathol, 1(3), 170-181. doi:10.1159/ 000370159 .
391. Walrath, J. C., Hawes, J. J., Van Dyke, T., \& Reilly, K. M. (2010). Genetically engineered mouse models in cancer research. Advances in Cancer Research, 106, 113-164. doi:10.1016/ S0065-230X(10)06004-5.

392. Iwamoto, T., Takahashi, M., Ito, M., Hamatani, K., Ohbayashi, M., Wajjwalku, W., et al. (1991). Aberrant melanogenesis and melanocytic tumour development in transgenic mice that carry a metallothionein/ret fusion gene. The EMBO Journal, 10(11), 3167-3175.

393. Cheng, Y., Zhang, G., \& Li, G. (2013). Targeting MAPK pathway in melanoma therapy. Cancer Metastasis Reviews, 32(3-4), 567584. doi:10.1007/s10555-013-9433-9.

394. Lengagne, R., Graff-Dubois, S., Garcette, M., Renia, L., Kato, M., Guillet, J. G., et al. (2008). Distinct role for CD8 $\mathrm{T}$ cells toward cutaneous tumors and visceral metastases. Journal of Immunology, 180(1), 130-137. doi:10.4049/ jimmunol.180.1.130.

395. Dabbeche-Bouricha, E., Araujo, L. M., Kato, M., PrevostBlondel, A., \& Garchon, H. J. (2016). Rapid dissemination of RET-transgene-driven melanoma in the presence of non-obese diabetic alleles: critical roles of dectin- 1 and nitric-oxide synthase type 2. Oncoimmunology, 5(5), e1100793. doi:10.1080/ 2162402X.2015.1100793.

396. Chin, L., Pomerantz, J., Polsky, D., Jacobson, M., Cohen, C., Cordon-Cardo, C., et al. (1997). Cooperative effects of INK4a and ras in melanoma susceptibility in vivo. Genes \& Development, 11(21), 2822-2834.

397. Tolleson, W. H., Doss, J. C., Latendresse, J., Warbritton, A. R., Melchior Jr., W. B., Chin, L., et al. (2005). Spontaneous uveal amelanotic melanoma in transgenic Tyr-RAS+ Ink4a/Arf-/- mice. Archives of Ophthalmology, 123(8), 1088-1094. doi:10.1001/ archopht.123.8.1088.

398. Pollock, P. M., Cohen-Solal, K., Sood, R., Namkoong, J., Martino, J. J., Koganti, A., et al. (2003). Melanoma mouse model implicates metabotropic glutamate signaling in melanocytic neoplasia. Nature Genetics, 34(1), 108-112. doi:10.1038/ng1148.

399. Schiffner, S., Braunger, B. M., de Jel, M. M., Coupland, S. E., Tamm, E. R., \& Bosserhoff, A. K. (2014). Tg(Grm1) transgenic mice: a murine model that mimics spontaneous uveal melanoma in humans? Experimental Eye Research, 127C, 59-68. doi:10.1016/ j.exer.2014.07.009.

400. Huang, J. L., Urtatiz, O., \& Van Raamsdonk, C. D. (2015). Oncogenic G protein GNAQ induces uveal melanoma and intravasation in mice. Cancer Research, 75(16), 3384-3397. doi:10.1158/0008-5472.CAN-14-3229.

401. Mouti, M. A., Dee, C., Coupland, S. E., \& Hurlstone, A. F. (2016). Minimal contribution of ERK1/2-MAPK signalling towards the maintenance of oncogenic GNAQQ209P-driven uveal melanomas in zebrafish. Oncotarget, 7(56), 39654-39670. doi:10. 18632/oncotarget.9207.

402. Patel, B. R., \& Tall, G. G. (2016). Ric-8A gene deletion or phorbol ester suppresses tumorigenesis in a mouse model of GNAQ(Q209L)-driven melanoma. Oncogenesis, 5(6), e236. doi: 10.1038/oncsis.2016.45. 